\title{
PROTECTIVE EFFECTS OF MILK PHOSPHOLIPIDS AGAINST UV-INDUCED DNA DAMAGE IN HUMAN SKIN CELLS
}

\author{
A Thesis \\ presented to \\ the Faculty of California Polytechnic State University, \\ San Luis Obispo
}

\author{
In Partial Fulfillment \\ of the Requirements for the Degree \\ Master of Science in Biomedical Engineering
}

by

Lan-Anh Ngoc Nguyen

December 2014 
(C) 2014

Lan-Anh Ngoc Nguyen

ALL RIGHTS RESERVED 


\section{COMMITTEE MEMBERSHIP}

TITLE:

Protective Effects Of Milk Phospholipids Against UV-induced DNA Damage In Human Skin Cells

AUTHOR: $\quad$ Lan-Anh Ngoc Nguyen

DATE SUBMITTED: December 2014

COMMITTEE CHAIR: Lily Hsu Laiho, Ph.D

Associate Professor of Biomedical Engineering Department

COMMITTEE MEMBER: Rafael Jimenez-Flores, Ph.D

Professor of Dairy Science Department

COMMITTEE MEMBER: $\quad$ Kristen Cardinal, Ph.D

Associate Professor of Biomedical Engineering Department 


\begin{abstract}
Protective Effects of Milk Phospholipids against UV-induced DNA Damage in Human Skin Cells

Lan-Anh Ngoc Nguyen
\end{abstract}

Skin cancer is the most common type of cancer in the US. The American Academy of Dermatology estimated that more than 3.5 million new cases of skin cancer are diagnosed in the US each year and 1 in 5 Americans will likely to develop skin cancer in their life time. Most cases of skin cancer are caused by exposure to ultraviolet (UV) radiation from the sun. Some of the most common sunscreen ingredients are unstable and can form harmful radicals upon exposure to UV radiation. There is a strong clinical need for a more stable and effective sunscreen ingredient such as bovine milk phospholipids (MP). Phospholipids were shown to have beneficial health effects such as regulation of the inflammatory reactions, protective effects against colon cancer, and reducing cardiovascular risk factors. Previous histology and MTT tissue viability research studies suggested that MP act upon skin cells in a protective manner against UV radiation.

This thesis aims to further investigate the protective effects of bovine milk phospholipids by evaluating the expression of a UV-induced DNA damage marker, cyclin-dependent kinase inhibitor, p21WAF1/CIP1. Western blots were used to quantify p21 expression in human keratinocytes in four categories of samples: No-UV, UV, UV+MP, MP and in HeLa (p21 positive control). In the No-UV samples, cells were not irradiated by UV light. However, in the UV samples, keratinocytes were exposed to a UV dosage of $10 \mathrm{~mJ} / \mathrm{cm} 2$. In the UV+MP samples, keratinocytes were first treated with $1 \% \mathrm{MP}$ solution (w/v) in their culture media for 24 hours 
then exposed to a UV dosage of $10 \mathrm{~mJ} / \mathrm{cm} 2$. In MP, keratinocytes were treated with $1 \% \mathrm{MP}$ solution in their culture media for 24 hours. Total cell proteins were extracted 24 hours post-UV irradiation. The same amount of protein from each sample (determined by BCA assay) was loaded into a 4-12\% Bis-Tris SDS-PAGE gel, run under denaturing, non-reducing conditions then blotted and treated with antibodies for the quantitative detection of p21 proteins. Finally, intensities of p21 protein bands were analyzed by using ImageJ software.

Under non-reducing conditions, three p21 proteins covalently bonded with each other showed up as $63 \mathrm{KDa}$ molecules on the PVDF membrane. The UV, and HeLa samples showed a 2.28 fold, and 1.23 fold increase in p21 expression, respectively, compared with the No-UV samples control. The MP samples showed a 0.948 fold decrease in p21 compared with the NoUV samples, and the UV+MP samples showed only a 1.13 fold increase in $\mathrm{p} 21$. When comparing with the UV sample, the UV+MP sample has 50.4\% less p21 expression. Less p21 expression in the UV+MP sample compare with the UV sample suggested that less DNA damage occurred in the sample that was treated with milk phospholipids. This result strongly suggests that $1 \%$ bovine milk phospholipids can protect skin cells from UV induced DNA damage.

Keywords: Keratinocytes, milk phospholipids, p21, UV-induced DNA damage, skin cancer 


\section{ACKNOWLEDGMENTS}

I would like to express my deepest gratitude to Dr. Lily Laiho, my thesis advisor and mentor for always being supportive and giving me many helpful suggestions for my thesis project. I couldn't have done this project without your continuous support and trust in me! Thank you for your positive encouragement and your cheerful smiles whenever I encountered technical challenges with my project. Thank you so much for reading my manuscript and providing many insightful comments in the revision of my manuscript and my PowerPoint presentation! I also really appreciate all your advices about career and job search!

Moreover, I would like to thank Dr. Rafael Jimenez-Flores for being a caring thesis advisor. Thank you for always being there for me and guiding me to overcome many technical challenges throughout my project. You are a great model for me as being a very passionate, dedicated and persistent scientist. Thank you for letting me use your labs and equipments to conduct experiments in my project! I also thank Andrea Laubscher for providing all the technical advice and training and milk phospholipids. You always helped me with a smile and a cheerful attitude!

I also like to express my gratitude for Dr. Kristen Cardinal for being a wonderful thesis committee member, for your thought-provoking questions and for everything that I learn in your class.

I would also like to acknowledge my fellow labmates Carl Dargitz, Kathleen De Guzman, Erin Fong for helping me with cell cultures for my experiences, for sharing your ideas, encouragement and support throughout my project!

Finally, I would like to thank my family for all your love and continuous support my whole life. Thank you my mom Thu Nguyen and my dad Hung Nguyen for showing me great examples of hard working, focus and discipline to be successful in life! Thank you for pushing me really hard, believing in me and helping me whenever I need your help! Thank you my brothers, Minh and Khoa Nguyen for always being there for me and helping me overcome any obstacles in life! You are my best brothers and my best friends! Thank you Anna for your encouragement and support with this thesis project! 


\section{TABLE OF CONTENTS}

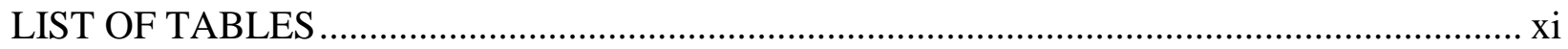

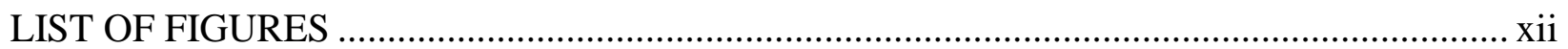

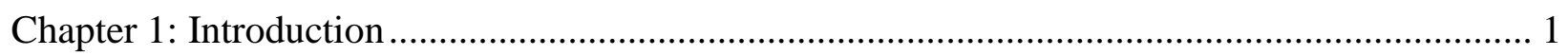

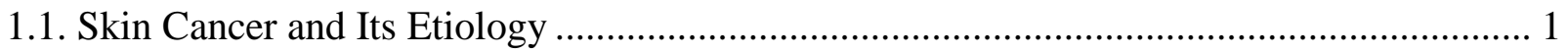

1.2. The Current Problem with Sunscreen Ingredients ............................................... 1

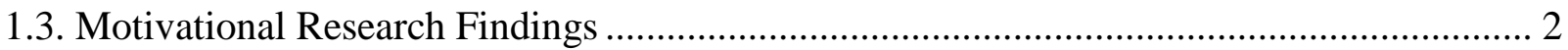

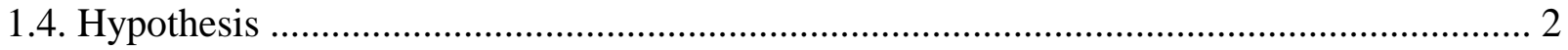

1.5. Bovine Milk Phospholipids and p21 Background ......................................................... 2

1.6. Goals and the Road Map of This Project ................................................................ 3

Chapter 2: Background ….................................................................................................... 5

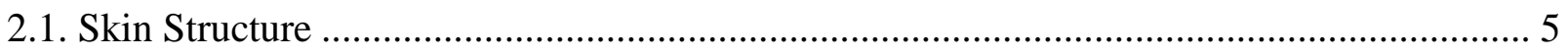

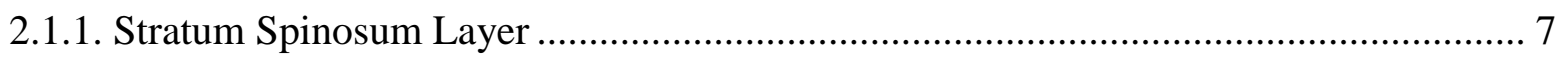

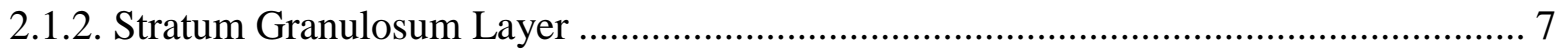

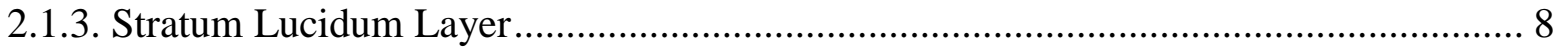

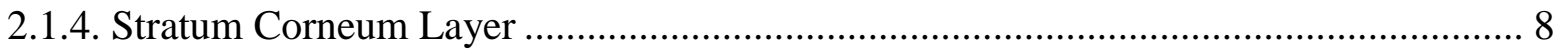

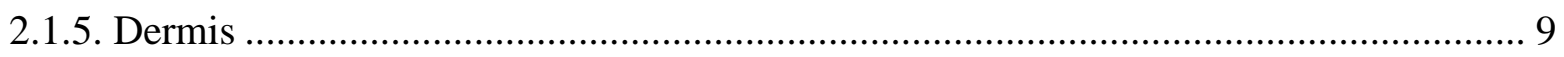

2.2. Functions of the Skin ......................................................................................... 12

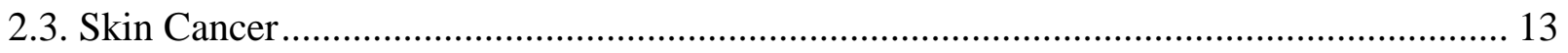

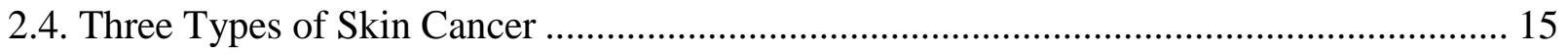

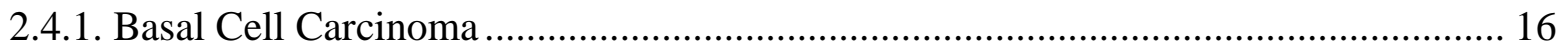

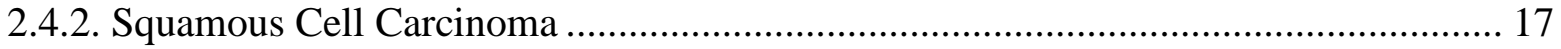

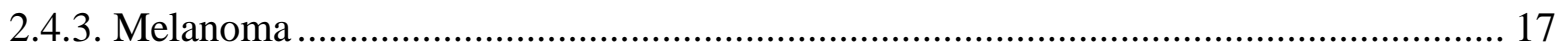

2.5. Five ABCDEs Warning Signs of Melanoma .......................................................... 18 


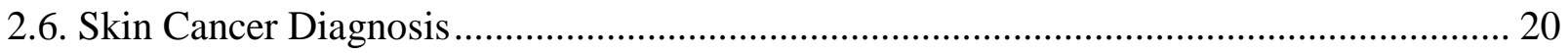

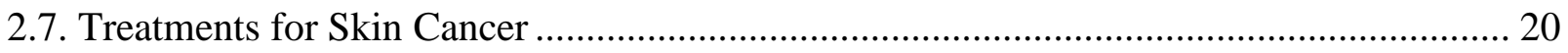

2.8. Skin Cancer Pathology ……………………………………………………………….. 23

2.8.1. Cellular Changes after Exposing to Acute UV ........................................................ 24

2.8.2. Cellular Changes after Exposing to Chronic UV ..................................................... 31

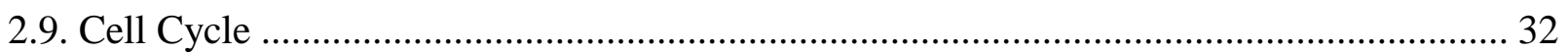

2.10. Protein p21 and Its Cellular Functions …………………………………………....... 33

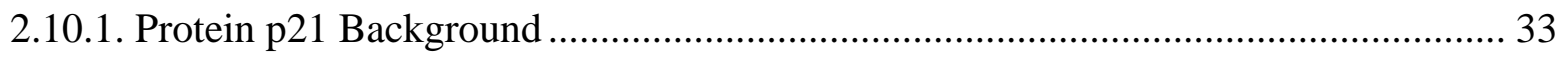

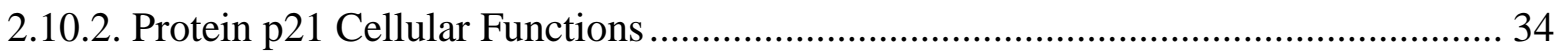

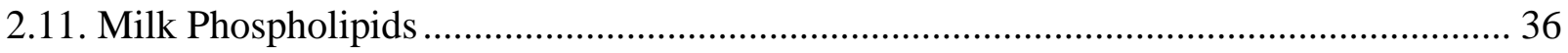

2.12. Health Benefits of Bovine Milk Phospholipids ................................................................. 40

2.12.1. Reduced Risks of Type 2 Diabetes and Heart Disease.............................................. 40

2.12.2. Protective Effects against Gastrointestinal Infections and Febrile Episodes ............ 41

2.12.3. Protective Effects against Chronic Stress and Improving Working Memory ........... 41

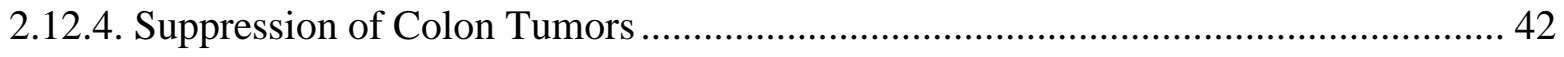

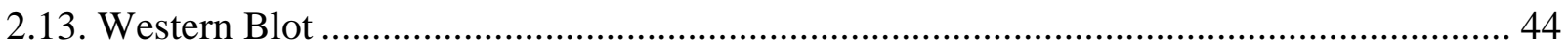

2.13.1. Protein Extraction from Cells ..................................................................................... 44

2.13.2. Proteins are separated by sizes using SDS-PAGE gel electrophoresis ..................... 45

2.13.3. Primary and Secondary Antibodies are Added to the Membrane ............................. 47

2.13.4. A Substrate is Added and Produce Signals on the Membrane ................................. 48

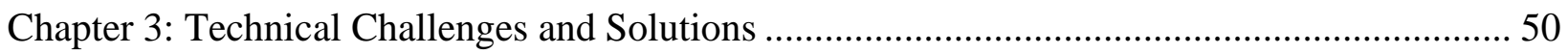

3.1. First Challenge - Developing a Protocol to induce p21 Expression in ................................. 50

Keratinocytes Using UV Light ........................................................................................... 50

3.2. Second Challenge - Determining Minimum Amount of Keratinocytes Needed ................. 51 


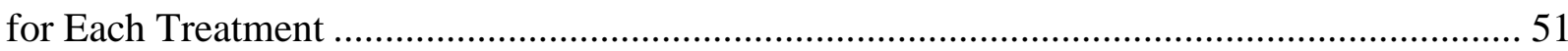

3.3. Third Challenge - Developing a Working Western Blot Protocol to Show ....................... 52

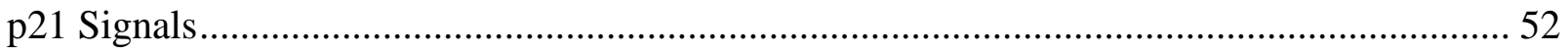

3.3.1. First Experiment Parameter: Transferring Time ………………………………....... 53

3.3.2. Second Experiment Parameter: Primary and Secondary Antibody Concentration ..... 59

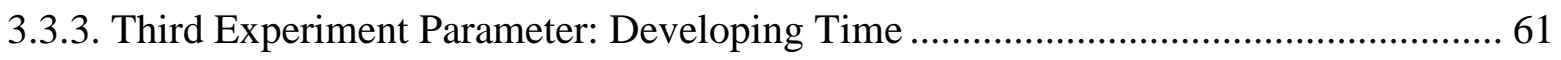

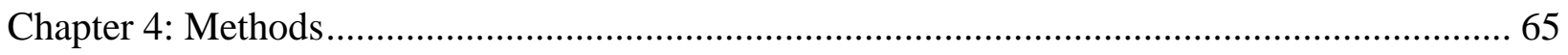

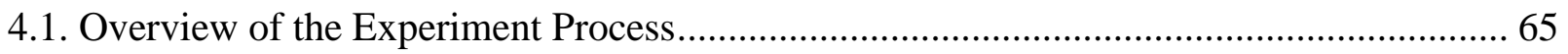

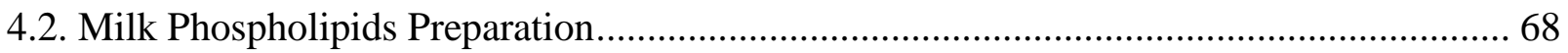

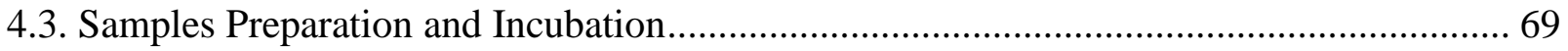

4.4. Total Cells Protein Extraction Using SDS Lysis Buffer..................................................... 70

4.5. Quantification of Total Cell Protein Concentration Using BCA Assay ............................. 71

4.6. Sodium Dodecyl Sulfate Polyacrylamide (SDS-PAGE) Gel Electrophoresis..................... 74

4.7. Protein Transferring from the Gel to the PVDF Membrane ............................................... 77

4.8. Western Immunoblotting Detection Procedure …………………....................................... 79

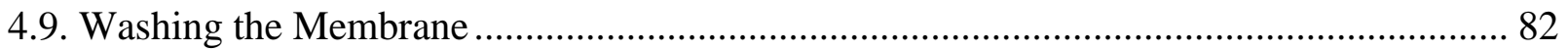

4.10. Chromogenic Detection to Detect p21 Signals ……………............................................ 82

4.11. Visualization of p21 Signals on the PVDF Membrane................................................. 82

4.12. Analysis of p21 Protein Bands Using ImageJ Software ................................................... 83

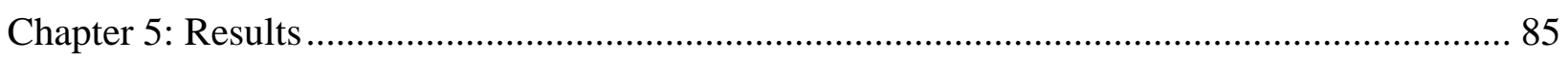

5.1. Molecular Weight of p21 Bands on Western Blot Membrane .......................................... 85

5.2. Analysis of the Intensity of p21 Protein Bands ............................................................... 88

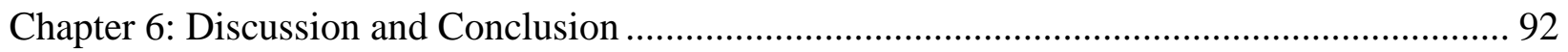

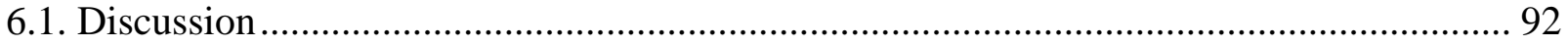




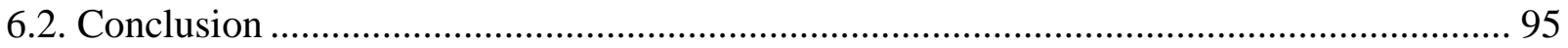

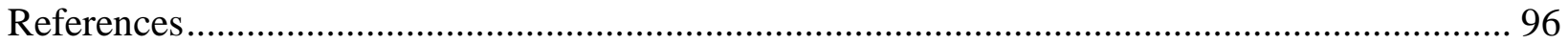

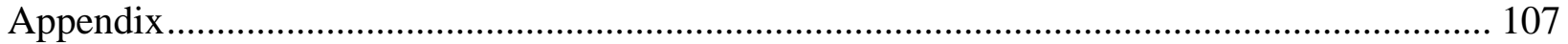




\section{LIST OF TABLES}

Table 4.1: Protein Standard Samples in the BCA Assay .....................................................72

Table 4.2: Summary of Different Samples Loaded in the Gels ............................................. 75

Table 4.3: NuPAGE ${ }^{\circledR}$ Novex Bis-Tris Mini Gel Sample Preparation Guide ...............................75

Table 5.1: The Log MW of Proteins and Their Respective Migration Distance (mm).......... 86

Table 5.2: Analysis of p21 Protein Levels in Different Samples Using ImageJ Software UV-Ultraviolet Light Radiation, MP-Milk Phospholipids, HeLa-Human Epithelial Carcinoma Cell Line 


\section{LIST OF FIGURES}

Figure 2.1: UVA and UVB Wavelengths Can Penetrate Skin and Cause Damage.....................14

Figure 2.2: A Cut-away View of Skin ............................................................................ 14

Figure 2.3: The Relevance of 3 Types of Skin Cancer ....................................................... 16

Figure 2.4: Basal Cell Carcinomas Morphology .............................................................. 17

Figure 2.5: Squamous Cell Carcinomas Morphology............................................................17

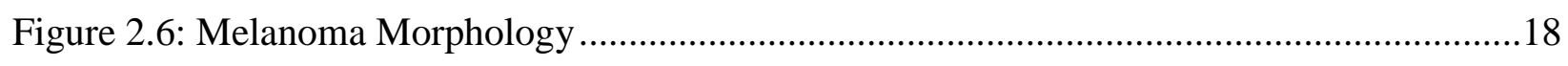

Figure 2.7: The Assymetry Sign of Melanoma.............................................................. 18

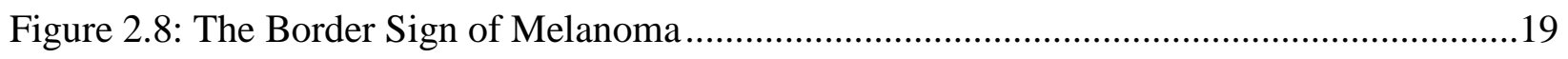

Figure 2.9: The Color Sign of Melanoma ........................................................................... 19

Figure 2.10: The Diameter Sign of Melanoma ............................................................... 19

Figure 2.11: The Evolving Sign of Melanoma ...............................................................20

Figure 2.12: The Outline of Mohs Micrographic Surgery .....................................................22

Figure 2.13: Progression of Human Squamous Cell Carcinoma ........................................... 24

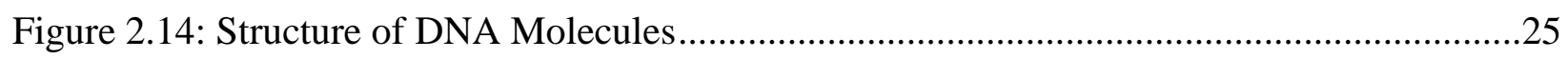

Figure 2.15: UVB Induces Pyrimidine Dimmers and Stops Movement of DNA/RNA

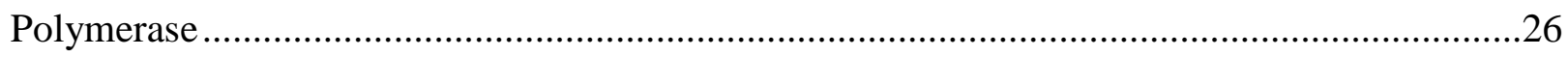

Figure 2.16: Nucleotide Excision Repair (NER) Mechanism ............................................. 27

Figure 2.17: UVB induced Mutations $\mathrm{C} \rightarrow \mathrm{T}$ and $\mathrm{CC} \rightarrow \mathrm{TT}$ at Pyrimidine Dimmers .............. 28

Figure 2.18: p53 Initiates Different Cellular Pathways to Response to UV-induced DNA

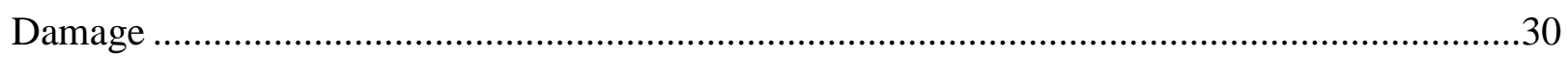

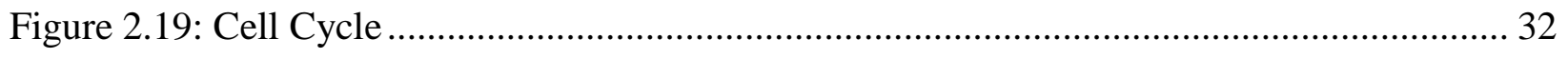

Figure 2.20: The Structure and Composition of Milk Fat Globule Membrane ...........................36 
Figure 2.21: Structure of the Milk Fat Globule Membrane

Figure 2.22: The Molecular Structures of Important Glycerophospholipids in the

Milk Fat Globule Membrane 39

Figure 2.23: The Molecular Structures of Sphingomyelin and Its Components .40

Figure 2.24: Protein Extraction Process. .45

Figure 2.25: Proteins Denaturation Process by SDS and Heat Treatment 46

Figure 2.26: Proteins are Separated by Sizes Using SDS-PAGE Gel Electrophoresis .47

Figure 2.27: The Process of Detecting the Target Proteins on the Membrane

Figure 3.1: The Transferring Process of Proteins from Gel to PVDF Membrane Using

Invitrogen iBlot Dry Blotting System 53

Figure 3.2: Proteins were Transferred from Gel to PVDF Membrane in 2, 3,4, and 5 Minutes...55

Figure 3.3: Proteins were Transferred from Gel to PVDF Membrane in 3.5, 4, 4.5, 5

and 5.5 Minutes .56

Figure 3.4: Proteins were Transferred from Gel to PVDF Membrane in 3.5 Minutes

and p21 Signals were Detected 57

Figure 3.5: Proteins were Transferred from Gel to PVDF Membrane in 4.5 Minutes and p21 Signals were Detected. .58

Figure 3.6: Antibody Titration on Dot Blot Membrane. 60

Figure 3.7: PVDF Membrane was Developed in 15 Minutes 62

Figure 3.8: PVDF Membrane was Developed in 30 Minutes .63

Figure 3.9: PVDF Membrane was Developed in 60 Minutes .64

Figure 4.1: Overview of Western Blot Assay .... 67

Figure 4.2: Milk Phospholipids Powder .68 
Figure 4.3: Four 6-Well Plates Containing Human Keratinocytes Under Different

Figure 4.4: Four Centrifuge Tubes Containing Extracted Proteins in the Supernatant

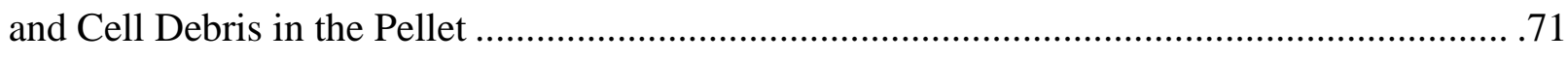

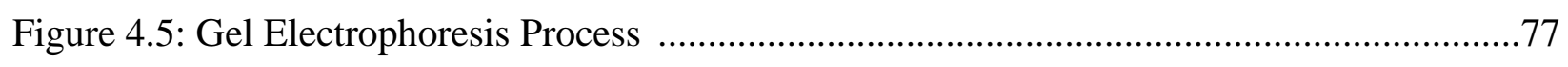

Figure 4.6: Invitrogen iBlot Gel Transfer Device............................................................

Figure 4.7: The Process of Protein Transferring from a Gel to a PVDF Membrane ................. 79

Figure 5.1: The Standard Curve of Log MW vs. Migration Distance (mm) .............................87

Figure 5.2: ImageJ Analysis of the Intensity of p21 Protein Bands ........................................8

Figure 5.3: Western Blot Membrane Shows p21 Protein Levels in Different Samples .............. 90 


\section{Chapter 1: Introduction}

\subsection{Skin Cancer and Its Etiology}

Skin cancer is the most common type of cancer in the US. According to the American Academy of Dermatology, more than 3.5 million new cases of skin cancer are diagnosed in the US each year (Rogers 2010). It is also estimated that 1 in 5 Americans will likely to develop skin cancer in their life time (RS. 2010). By 2015, 1 in 50 Americans will develop melanoma, the most serious form of skin cancer that can spread to other parts of the body (Rigel DS 2010). Melanoma attributes for about $75 \%$ of skin cancer deaths and is estimated to cause about 9,480 American deaths in 2013. Studies about cancer incidence across different races showed that Caucasians have five times higher in risks of developing melanoma than Hispanics and African Americans (Society 2013). In the US, the cost for melanoma treatment was $\$ 2.36$ billion in 2010 and for non-melanoma treatment was \$1.5 billion in 2004 (Bickers DR 2006, A. 2007).

Skin cancer is mostly caused by exposure to ultraviolet (UV) rays. About $86 \%$ of melanoma and $90 \%$ of nonmelanoma skin cancers are caused by exposure to UV radiation (Koh HK 1996, Parkin DM 2011). Over the last decade, many topical sunscreen products have been developed to reduce the effect of UV radiation on skin. Sunscreen products contain ingredients that can absorb, reflect or scatter UV rays. Therefore, they can decrease the effect of UV radiation on the skin and prevent skin cancer.

\subsection{The Current Problem with Sunscreen Ingredients}

Butylmethoxydibenzoylmethane (BMDM) and Octyle methoxycinnamate (OMC) are the most widely used UVA and UVB filters in sunscreen products (Tarras-Wahlberg, Stenhagen et al. 1999, Chatelain and Gabard 2001). However, they are not very stable when exposed to 
sunlight. BMDM often decomposes under sunlight irradiation. Its photofragmentation also leads to the formation of free radicals that are harmful to the skin (Tarras-Wahlberg, Stenhagen et al. 1999, Chatelain and Gabard 2001). There is a strong clinical need for a more stable, and effective sunscreen ingredients. Bovine milk phospholipids, naturally derived from milk, are very promising sunscreen ingredients.

\subsection{Motivational Research Findings}

Russel et al., 2010 \& Achay et al., 2011 found that bovine milk phospholipids (BMP) act upon skin cells in a protective manner against the effect of UV radiation. Milk phospholipids incubation also induced an increase in epidermal thickening in human skin tissue equivalents, which enhanced the protective barrier of the skin against UV radiation (Russell, Laubscher et al. 2010, Achay 2011)

Hurato-Ono et al., 2012 showed that dietary sphingomyelin (SM) concentrate, an important phospholipid of BMC can improve epidermal functions in mice model by increasing the epidermal hydration, ceramide content and decreasing transepidermal water loss (HarutaOno, Setoguchi et al. 2012)

\subsection{Hypothesis}

Bovine milk phospholipids can reduce UV-induced DNA damage in skin cells, which protect and prevent skin cells from not developing into malignant tumors in skin cancer.

\subsection{Bovine Milk Phospholipids and p21 Background}

Phospholipids are found mostly in the milk fat globule membrane. Phospholipids were shown to have beneficial health effects such as regulation of the inflammatory reactions, 
protective effects against gastrointestinal infections and colon cancer, and reducing cardiovascular risk factors.

Protein $\mathrm{p} 21^{\mathrm{Cip} 1 / \mathrm{Waf} 1}$ is a biomarker for DNA damage. P21 stops the cell cycle to repair DNA damage before replication or induces apoptosis if the DNA damage is too extensive to repair.

\subsection{Goals and the Road Map of This Project}

The goal of this project is to investigate whether or not bovine milk phospholipids can protect skin cells from DNA damage induced by ultraviolet radiation by studying the expression of $\mathrm{p} 21^{\mathrm{Cip} 1 / \mathrm{Waf} 1}$, a biomarker for DNA damage. The Western Blot assay was used to detect and quantify the expression of protein p21 in 4 treatment groups: a control group with no milk phospholipid and UV treatment (No UV), a group exposed to UV alone (UV), a group treated with milk phospholipids then UV (MP+UV) and a group treated with milk phospholipids alone (MP). The expression level of p21 corresponds to the amount of DNA damage. It was expected that if the bovine milk phospholipids could protect skin cells from DNA damage caused by UV radiation, the MP+UV group would have less p21 expression than the UV group.

There were three main technical challenges to accomplish the goal of this thesis project.

The first challenge was to develop a protocol to successfully induce p21 expression in keratinocyte cells using UV light. The second challenge was to determine the minimum amount of cells needed for each treatment so that there were sufficient extracted proteins for the Western blot assay. Finally, the third challenge was to develop a working Western blot protocol to show clear signals of p21 from each treatment on the PDF membrane so that researchers can 
evaluate the effects of milk phospholipid in protecting skin cells from UV induced DNA damage. 


\section{Chapter 2: Background}

\subsection{Skin Structure}

Skin is the largest organ in the body that accounts for about $16 \%$ of the body weight (GJ and BH 2009). The skin thickness is usually 1-2 mm; however, it varies throughout the body depending on the location and the function (C 1998). The skin can be $0.5 \mathrm{~mm}$ thick at the eyelid or 3-4 $\mathrm{mm}$ thick at the soles of the feet (C 1998). The skin consists of thick outer layers, a network of sweat glands that is sensitive to temperature changes, cells that are sensitive to touch, pain, pressure, itching, temperature and a layer of fatty tissue under the skin surface (C 1998).

The skin structure is usually divided into 3 main regions from top to bottom: the epidermis, the dermis, and the subcutaneous tissue.

The epidermis is composed of many layers of stratified keratinised squamous epithelium near the surface of the skin (GJ and BH 2009). It is avascular (without blood vessels), therefore all oxygenation, metabolite provisions and removal of metabolic waste products activities of cells in the epidermis depends on the blood vessels of the dermis (GJ and BH 2009). The epidermis consists of four main types of cells: keratinocytes (90\%), melanocytes (8\%), Langerhans cell and Merkel cells (2\%) (GJ and BH 2009). The keratinocytes function as a barrier against environmental damage such as pathogens, heat, UV radiation and water loss (GJ and $\mathrm{BH} 2009)$. The melanocytes involve in the production of the skin pigment, melanin (GJ and BH 2009). Langerhans cells are responsible for immune response and Merkel cells are involved in the sensation of touch (GJ and BH 2009). The epidermis consists of 5 main layers from bottom to top: the stratum basale (stratum germinativum), stratum spinosum, stratum granulosum, stratum lucidum, and stratum corneum (S. and R. 2005). Normally, cells mature and 
divide in the bottom layer stratum basale then move up to the top layer stratum corneum, where they are shed (GJ and BH 2009).

The stratum basale consists of keratinocytes, melanocytes and Merkel cells that are capable of dividing (GJ and BH 2009). After mitosis, keratinocytes formed 2 daughter cells (GJ and BH 2009). However, only 1 cell stays in the stratum basale, the other cell will move up through other layers to the top surface of the epidermis (GJ and BH 2009). It usually takes 28 days for keratinocytes to move up and reach the top layer in an epidermis of $0.1 \mathrm{~mm}$ thickness (GJ and BH 2009). The stratum basale is the nearest layer to the dermis and receives nutrients from the blood supply of the dermis through diffusion (GJ and BH 2009). However, as keratinocytes divide and move up away from the stratum basale, they receive less nutrition and start to die on their way up to the top surface of the epidermis (GJ and BH 2009). These keratinocytes cells also become more keratinised by accumulating more keratin, a fibrous protein that protects the skin from heat, chemicals and microorganisms (GJ and BH 2009). The body usually maintains a balance between the formation of new keratinocytes in the stratum basale and the shedding of dead keratinocytes in the stratum corneum (GJ and BH 2009).

On average, one in every six cells in the stratum basale is melanocyte cell (C and JS 2007). Melanocytes produce melanin, a pigment that involves in the protection of the skin from the effects of ultraviolet (UV) radiation (C and JS 2007). The melanocytes have long projections that contain melanin granules (C and JS 2007). These projections extend and transfer melanin granules among keratinocytes (C and JS 2007). Inside keratinocytes, these melanin granules accumulate and form a covering around the nucleus to protect keratinocytes from UV radiation damage (C and JS 2007). The amount of melanin in epidermal cells affects the skin color (C and JS 2007). The more melanin is present in keratinocytes, the darker the skin is (C and JS 2007). 
Besides keratinocytes, melanocytes, the stratum basale also contains Merkel cells $(\mathrm{C}$ and JS 2007). These Merkel cells connect with a Merkel disc, a sensory neuron, to detect the sensation of touch (C and JS 2007).

\subsubsection{Stratum Spinosum Layer}

The stratum spinosum layer is 5 to 12 cells thick and contains mainly keratinocytes and Langerhans cells (Patton 2012). After each round of mitosis, one keratinocyte cell produces two new keratinocytes in the stratum basale (Patton 2012). However, only one daughter keratinocyte stays in the stratum basale, the other new keratinocyte moves up to the stratum spinosum layer (GJ and BH 2009). When keratinocyte cells move into the stratum spinosum layer, they lose the ability to divide and also become rounder and spikier in shape (Patton 2012). Keratinocyte cells are also connected with each other via demosomes, thorn-like projection intracellular bridges. This arrangement gives the skin its tensile strength and flexibility (Haruta-Ono, Setoguchi et al. 2012).

Besides keratinocytes, the stratum spinosum layer also contains Langerhans cells, which are specialized dendritic cells of the immune system (C and JS 2007). Langerhans cells are also found in the dermis, lymph nodes and thymus (C and JS 2007). The red bone marrow produces Langerhans cells, then these cells move up to the stratum spinosum layer ( $F$ and R 2002). Langerhans cells attract and phagocytose microbes then present their antigens to T lymphocytes and activate lymphocytes to attack the microorganisms (F and R 2002).

\subsubsection{Stratum Granulosum Layer}

As keratinocytes move up to the stratum granulosum layer, they become longer and flatten horizontally (GJ and BH 2009). The stratum granulosum layer is three to five layers of 
flattened keratinocytes thick (GJ and BH 2009). This layer consists of dead keratinocytes, proteins keratohyalin, and Odland's bodies (F and R 2002). When reach this layer, keratinocytes often go through apoptosis, a programmed cell death, in which the nucleus breaks up and the cells die (GJ and BH 2009). After that, the cells become keratinised and mainly compose of a tough protein called keratin ( $\mathrm{F}$ and $\mathrm{R}$ 2002). The stratum granulosum also contains keratohyalin, a protein that can convert tonofilaments into keratin (GJ and BH 2009). Odland's bodies are also found in this layer (GJ and BH 2009). These are lamellar granules that produce lipid and help connect individual keratinocyte together (GJ and BH 2009).

\subsubsection{Stratum Lucidum Layer}

The stratum lucidum layer is only found in thick skin areas such as the palms of the hands and soles of the feet (GJ and BH 2009). The statum lucidum often consists of three to five layers of clear, dead, and flattened keratinocytes with thick plasma membranes (GJ and BH 2009).

\subsubsection{Stratum Corneum Layer}

The stratum corneum is the top skin layer and consists of 25-30 layers of dead and flattened keratinocytes (GJ and BH 2009). These keratinocyte cells contain protein keratin that can protect underlying skin layers from heat, microorganisms and chemicals (GJ and BH 2009). The intracellular lipid from the lamellar granules in the stratum granulosum plays an important role in keeping the cells together and preventing the cells from drying out (GJ and BH 2009). As keratinocyte cells move through the stratum corneum, they start to dissociate from each other and are shed singly or in clumps (GJ and BH 2009). Since keratinocyte cells in the stratum corneum are exposed to external environment, they are lost on a continuous basic and are 
replaced with new cells moving up from the stratum basale, the deepest skin layer (GJ and BH 2009). A hard callus, an abnormal thickening of the stratum corneum, is usually formed when an area of the skin is constantly exposed to friction (GJ and BH 2009).

\subsubsection{Dermis}

The dermis is below the epidermis and above the subcutaneous layer. It provides nutrients and serves as a physical support to the epidermis ( $F$ and $R$ 2002). The dermis contains lymph vessels, nerve endings, hair follicles and different glands. The dermis is connected to the epidermis via rete ridges ( $\mathrm{F}$ and $\mathrm{R} 2002$ ). These rete ridges allow the exchange of nutrients between the dermis and epidermis ( $\mathrm{F}$ and $\mathrm{R} 2002$ ). If for some reasons, the dermis and epidermis layers become separated as a result of shearing force, fluid will accumulate between two layers and form blister (C and JS 2007).

The dermis contains two layers: the reticular and papillary layers (F and R 2002). The papillary layer contains nerves and capillaries that supply nutrients to the whole dermis ( $\mathrm{F}$ and $\mathrm{R}$ 2002). The reticular layer contains strong connective tissue made up of elastin and collagen fibers (F and R 2002).

\section{Collagen and Elastin Fibers}

Collagen proteins in connective tissue fibers account for $70 \%$ of the dry weight of the dermis (F and R 2002). With a high tensile strength, collagen fibers prevent tearing when the skin is stretched (F and $\mathrm{R} 2002)$.

Elastin fibers are found interwoven among collagen fibers (GJ and BH 2009). With elastic properties, elastin fibers allow the skin to return to its normal position after stretching (GJ 
and $\mathrm{BH} 2009$ ). As people age, the number of elastin fibers reduces, elastin fibers start to lose their elasticity, thicken into bundles and result in wrinkled appearance skin (GJ and BH 2009).

\section{Eccrine Glands}

Eccrine glands are simple, coiled glands that are mostly distributed in the skin of the

forehead, palms of the hands and soles of the feet (GJ and BH 2009). Sweat from the eccrine glands is composed of water, sodium, chlorine ions, urea, uric acid, ammonia, amino acids, glucose and lactic acid (GJ and BH 2009). There is an average of $600 \mathrm{~mL}$ of sweat produced by the eccrine glands daily (GJ and BH 2009).

\section{Apocrine Glands}

Apocrine glands are activated by sex hormones during puberty ( $\mathrm{F}$ and $\mathrm{R} 2002)$. The apocrine glands are coiled, tubular glands and are mainly distributed in the axillae, groin, areolae of the breasts and bearded regions of the face in adult male (GJ and BH 2009). The apocrine glands produce milky, yellowish sweat (GJ and BH 2009). This sweat has no smell but when it meets with the bacteria on the surface of the skin, the bacteria break down components of the sweat and produce body odor (GJ and BH 2009).

\section{Sebaceous Glands}

A sebaceous gland has a sac-like secretory unit and an obvious lumen. Most sebaceous glands are connected to hair follicles (F and R 2002). Sebaceous glands produce sebum, an oily substance composed of triglycerides, cholesterol, proteins and organic salts (F and R 2002). Sebum protects hair surface from becoming drying and brittle (F and R 2002). Sebum also has antifungal and antibacterial properties ( $\mathrm{F}$ and $\mathrm{R} 2002$ ). 


\section{Ceruminous Glands}

Ceruminous glands are found in the external ears (GJ and BH 2009). Ceruminous glands produce waxy secretion that can combine with secreted substance from the sebaceous glands to form a yellowish substance called cerumen (GJ and BH 2009). Cerumen and the hair in the external auditory canal prevent the entrance of foreign bodies and insects into the ear (GJ and BH 2009).

\section{Blood Vessels}

There are two main blood networks: the deep plexus and the superficial plexus (F and $\mathrm{R}$ 2002). The deep plexus is found at the boundary of the dermis and the subcutaneous fat layer (F and R 2002). This network supplies blood for tissues in the dermis and subcutaneous layer. The superficial plexus is found at the uppermost layer of the dermis and provides blood for the dermis and epidermis tissues ( $\mathrm{F}$ and $\mathrm{R} 2002)$.

\section{Hair}

Each hair is made up of dead, keratinized epidermal cells connected together with extracellular proteins (GJ and BH 2009). The shaft of hair is the part that grows above the surface of the skin, the root of the hair is the segment that is below the skin surface and anchored to the dermis or subcutaneous layer (GJ and $\mathrm{BH} 2009$ ). The root of the hair is surrounded by a hair follicle (GJ and BH 2009). The dermis that encircles the hair follicle is called the dermal root sheath (GJ and BH 2009). The base of each hair follicle and its dermal root sheath is collectively called the bulb (GJ and BH 2009). The bulb contains hair matrix cells, which come from the stratum basale layer where cell division occurs (GJ and BH 2009). Hair matrix cells contribute to the growth of existing hairs (GJ and BH 2009). 
Each hair follicle normally goes through three stages of the growth cycle: growth, regression and resting (GJ and BH 2009). The cells of the hair matrix divide during the growth stage and new cells are added at the base of the hair follicle (GJ and BH 2009). In the growth stage, as hair gets longer, it becomes keratinised and dies (GJ and BH 2009). Hair remains in the growth stage for two to six years (GJ and BH 2009). In the regression stage, the hair stops dividing and remains in this stage for two to three weeks (GJ and BH 2009). Then the hair enters resting stage and remains in this phase for about three months (GJ and BH 2009). On average, an adult loses about 70-100 hairs per day (GJ and BH 2009).

\subsection{Functions of the Skin}

The skin has four main functions: sensation, thermoregulation, protection and synthesis of vitamin D (E, A et al. 2009). Since the skin has about one million nerve fibers, it is able to sense cold, heat, pain, touch and pressure (E, A et al. 2009). The skin also contains many receptors that can sense temperature and transmit impulses back to the hypothalamus in the forebrain (E, A et al. 2009). The hypothalamus then sends signals back to receptors in the skin to regulate temperature (E, A et al. 2009). The skin has many thermoregulatory mechanisms such as insulation, sweating and control of blood flow (E, A et al. 2009). Moreover, the skin also serves as the body's physical barrier and prevents harmful microorganisms to colonize and enter the body ( $\mathrm{F}$ and $\mathrm{R}$ 2002). It also prevents fluid loss and protects the internal organs from drying out ( $F$ and $R$ 2002). In addition, the skin also synthesizes Vitamin D from cholesterol when the skin is exposed to UV light from the sun (GJ and BH 2009). Vitamin D plays a critical role in controlling the amount of calcium and phosphorus that the body absorbs via the small intestine and bone (GJ and BH 2009). Calcium and phosphorus are important in bone formation (GJ and 
BH 2009). Vitamin D deficiency can lead to bone softening diseases known as rickets in children and osteomalacia in adults (GJ and BH 2009).

\subsection{Skin Cancer}

Skin cancer is the uncontrolled growth of abnormal skin cells. Skin cancer is mostly caused by exposure to ultraviolet radiation (UV) from the sun or tanning beds. UV radiation causes DNA damage in skin cells and triggers mutations or genetic defects that eventually lead skin cells to multiply rapidly, out of control and form malignant tumors.

Most skin cancer cases are caused by UV radiation from sunshine (Vladislava $\mathrm{O}$.

Melnikova 2004). The sun emits three types of UV light: UVA (320-400 nm), UVB (280-320 $\mathrm{nm}$ ), and UVC (200-280 nm) (Vladislava O. Melnikova 2004). However, the UVC is blocked by the ozone layer and cannot reach the earth's surface. Therefore, only UVA and UVB can penetrate our skin and cause harm. With a short wavelength 280-320 nm, UVB can only penetrates the epidermis, the most superficial layer of our skin, and increase the risks of skin cancer (Vladislava O. Melnikova 2004). With a longer wavelength 320-400 nm, UVA can penetrate deeper into the skin and cause aging, and wrinkling of skin (Vladislava O. Melnikova 2004). 


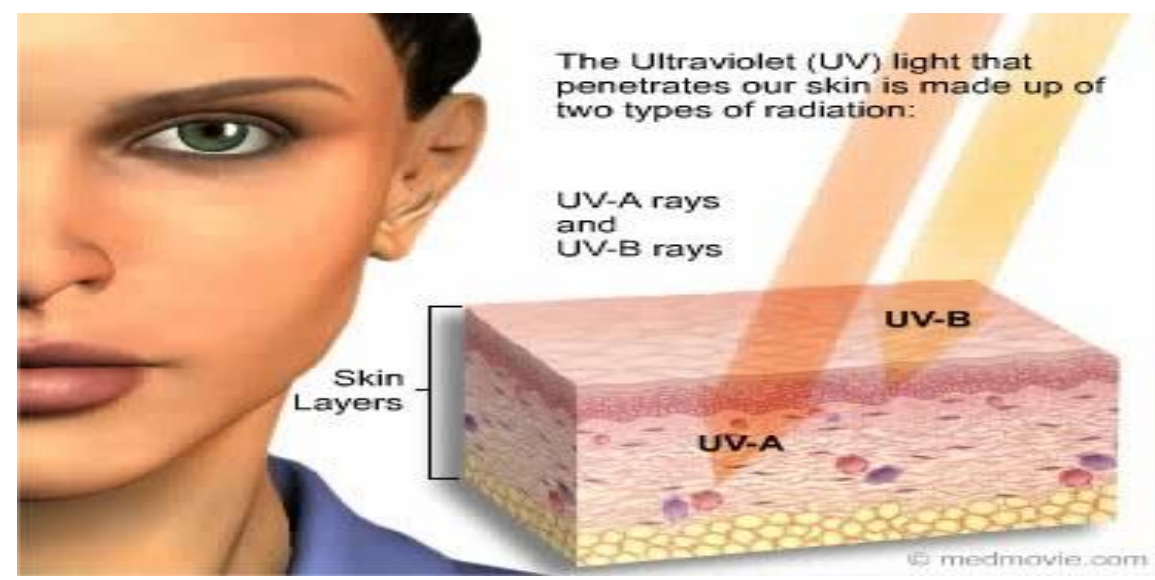

Figure 2.1: UVA and UVB Wavelengths Can Penetrate Skin and Cause Damage (Administration 2014)

Skin cancer is usually classified into 3 different types: basal cell carcinoma, squamous cell carcinoma, and melanoma. They are different because they arise from 3 different types of cells that found in the epidermis, the outermost layer of skin (Foundation 2013).

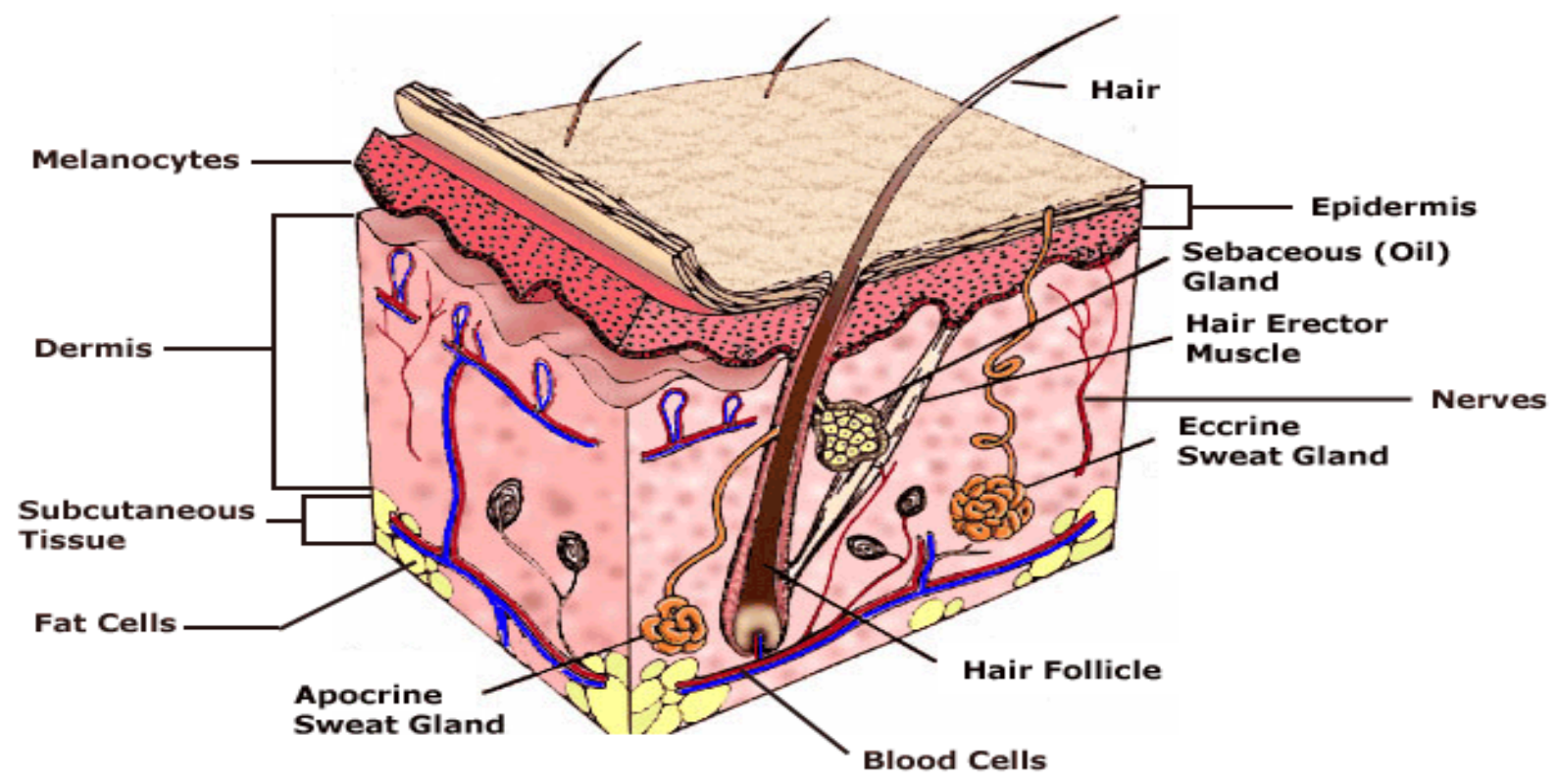

Figure 2.2: A Cut-away View of Skin (Association 2013) 
The skin is made up of 3 layers: epidermis, dermis, and fat layer (Foundation 2013). Epidermis is the outer layer of the skin (Foundation 2013). Dermis is the middle layer of the skin. It contains nerves, blood vessels, sweat glands, hair follicles, and oil producing cells to prevent the skin from drying out (Foundation 2013). The fat layer is the deepest layer of the skin (Foundation 2013). It is mostly made up of fat cells (Foundation 2013).

Skin cancer usually begins in the epidermis (Foundation 2013). The epidermis is made up of 3 different types of cell that give names to 3 different types of skin cancer (Foundation 2013). Squamous cells are cells that form the outermost surface of the skin (Foundation 2013). These cells contain keratin, which is a tough, insoluble protein that makes the skin waterproof (Foundation 2013). Basal cells are cells at the base of the epidermis and serve as a reservoir for squamous cells lost from the skin (Foundation 2013). Melanocytes are cells within the epidermis. These cells produce pigment, a dark material that gives the skin its color (ehealthMD 2013, Foundation 2013).

\subsection{Three Types of Skin Cancer}

About $80 \%$ of skin cancer cases are basal cell carcinoma, a cancer that develops in the basal cells in the lowest layer of epidermis (Foundation 2013). Squamous cell carcinoma, a cancer that begins in the squamous cells in the upper layer of epidermis, accounts for $16 \%$ of skin cancer cases (Foundation 2013). About 4\% of diagnosed skin cancers are melanoma (Foundation 2013). Melanoma is a cancer that begins in melanocytes, cells within the epidermis that give skin its color (Foundation 2013). Although melanoma is the rarest form of skin cancer, it is the most lethal form because it can spread to lymph system and internal organs. Studies 
showed that in the US, on average, one person dies from melanoma every hour (Foundation 2013).

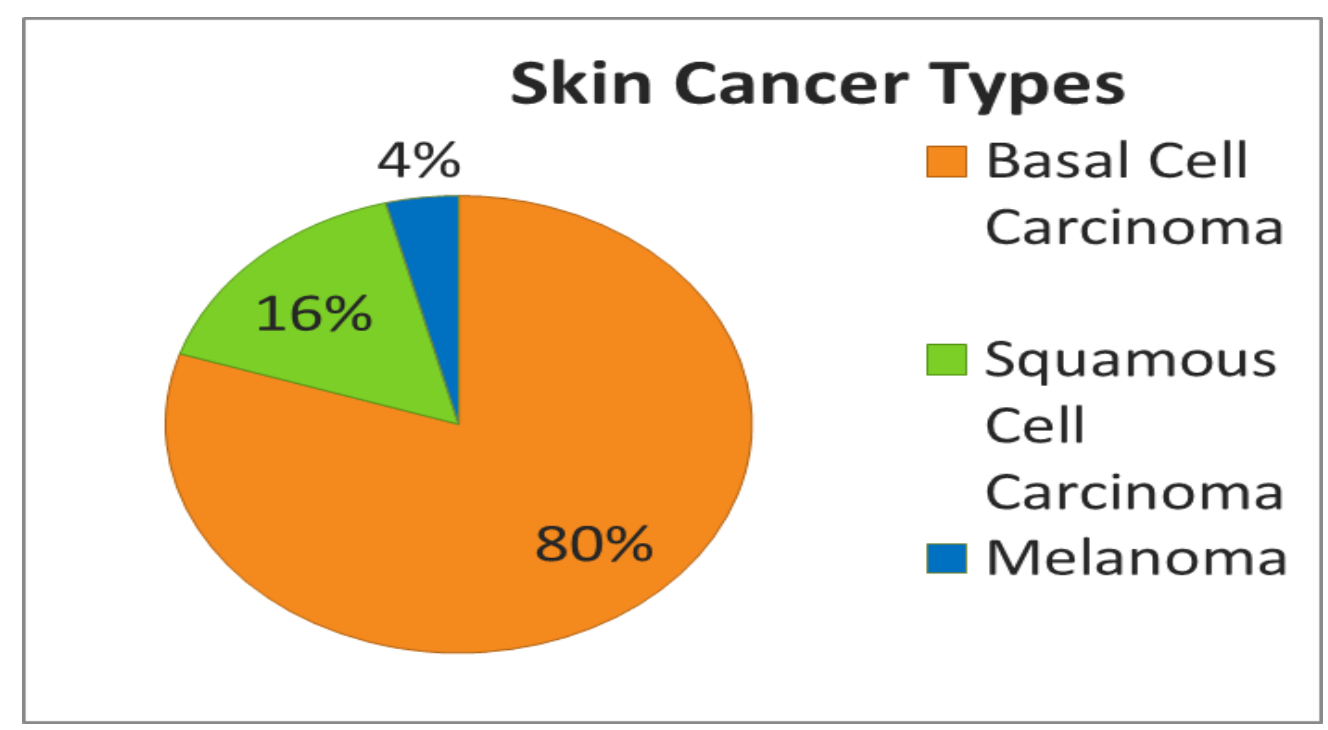

Figure 2.3: The Relevance of 3 Types of Skin Cancer

\subsubsection{Basal Cell Carcinoma}

Dermatologists examine the morphology of the skin to diagnose skin cancer. Basal cell carcinoma is the most common form of skin cancer. There are more than 2.8 million cases of BCC diagnosed in the US each year (Foundation 2013). Basal cell carcinoma (BCC) is caused by the uncontrolled growth of the skin's basal cells that located at the lowest layer of the skin (Foundation 2013). BCCs often look like open sores, red patches, pink growths, shiny bumps, or scars (Foundation 2013). BCCs usually do not spread beyond the original tumor site. 

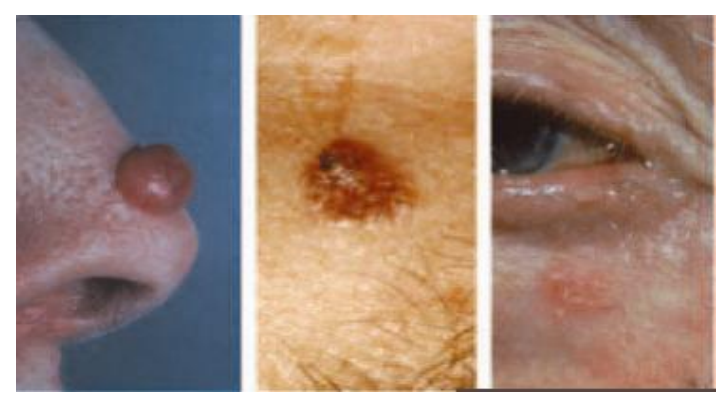

\section{Figure 2.4: Basal Cell Carcinomas Morphology (Foundation 2013)}

\subsubsection{Squamous Cell Carcinoma}

Squamous cell carcinoma (SCC) is caused by the uncontrolled growth of some abnormal squamous cells that make up the upper layer of the epidermis (Foundation 2013). SCCs look like

scaly red patches, open sores, or elevated growths with a central depression (Foundation 2013). More than 700,000 new cases of SCC are diagnosed in the US each year and SCC also causes 2500 deaths annually (Foundation 2013).
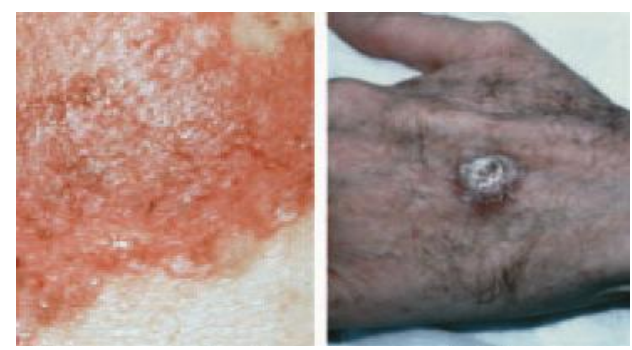

Figure 2.5: Squamous Cell Carcinomas Morphology (Foundation 2013)

\subsubsection{Melanoma}

The most dangerous form of skin cancer is melanoma. Melanoma is caused when unrepaired DNA damage to skin cells triggers mutations and causes cells to multiply rapidly and 
forms malignant tumors. These tumors often originate from melanocyte located at the bottom layer of the skin's epidermis (Foundation 2014). Melanocytes are cells that producing melanin, the pigment responsible for skin color (Foundation 2014). Melanoma often appears in an existing mole or a new mole that is changing shape and color (Foundation 2014). There are about 120,000 new cases of melanoma are diagnosed in the US each year (Foundation 2014). Melanoma also causes 8790 deaths in the US annually (Foundation 2014).
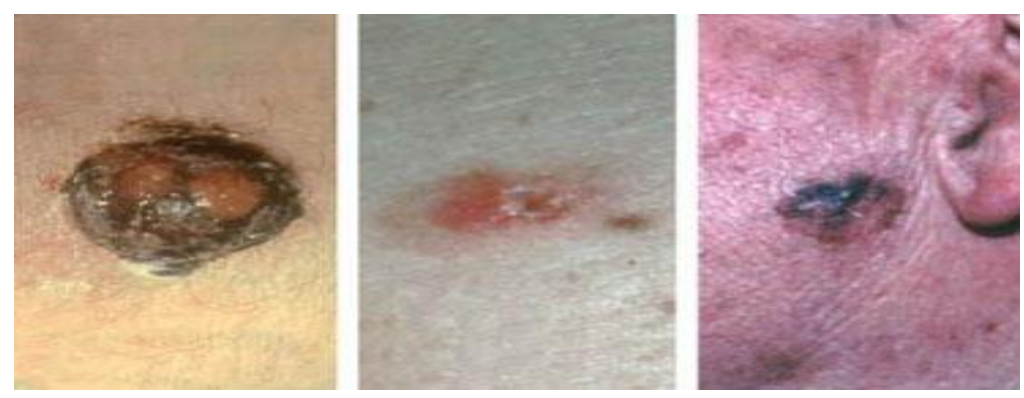

Figure 2.6: Melanoma Morphology (Foundation 2014)

\subsection{Five ABCDEs Warning Signs of Melanoma}

$$
\text { A - Asymmetry }
$$

The mole appears to be asymmetrical.

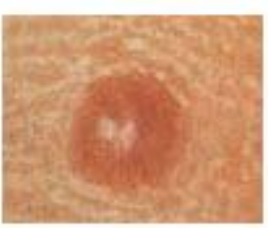

Symmetrical

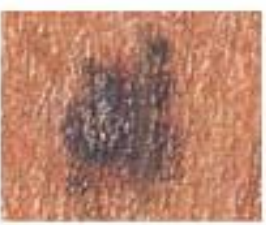

Asymmetrical

Figure 2.7: The Assymetry Sign of Melanoma. Image Source: (Foundation 2014) 
B - Border

The borders of melanoma often look uneven.

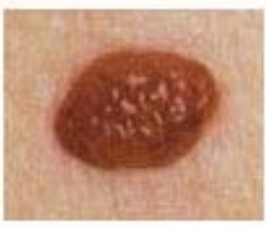

Borders are

even

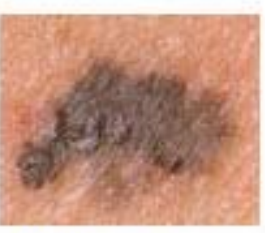

Borders are uneven

Figure 2.8: The Border Sign of Melanoma. Image Source: (Foundation 2014)

\section{C-Color}

A melanoma usually has a variety of color or shades.

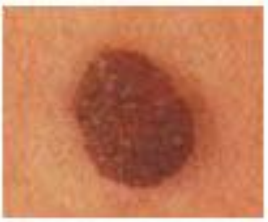

One Color

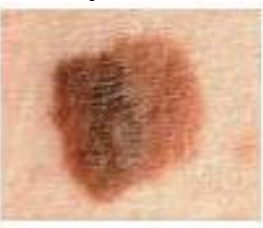

Multiple Colors

Figure 2.9: The Color Sign of Melanoma. Image Source: (Foundation 2014)

$$
\text { D - Diameter }
$$

Melanomas often are larger than the size of the eraser on your pencil ( $1 / 4$ inch or $6 \mathrm{~mm})$.

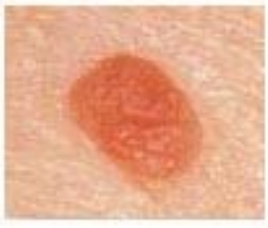

Smaller than

$1 / 4$ inch

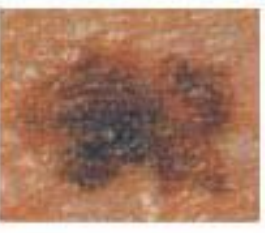

Larger than $1 / 4$ Inch

Figure 2.10: The Diameter Sign of Melanoma. (Foundation 2014) 


\section{E - Evolving}

Any changes in size, shaper, color of existing moles may be the signs of early melanoma.

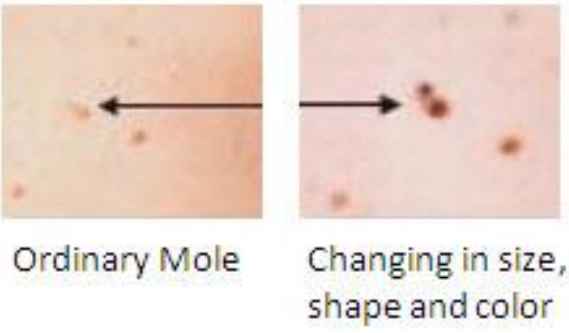

Figure 2.11: The Evolving Sign of Melanoma. Image Source: (Foundation 2014)

\subsection{Skin Cancer Diagnosis}

If you notice any changes on your skin in color, size, shape of the moles or the appearance of a tumor, you should see a dermatologist for a skin cancer screening. The dermatologist can either exam or do a biopsy to remove a portion of the suspicious area and send the tissue to a lab to be examined by a dermatopathologist. The lab results then show whether or not you have skin cancer and the type of skin cancer that you have.

\subsection{Treatments for Skin Cancer}

There are different treatment options available for skin cancer including freezing, scraping and burning, surgical removal, laser surgery and Mohs micrographic surgery.

\section{Mohs Micrographic Surgery}

Mohs micrographic surgery is accepted as the single most effective technique for removing basal cell carcinoma and squamous cell carcinoma with $98 \%$ success cure rate (Foundation 2014 ). Cancer cells can be present in the deeper tissues than the visible moles and 
can cause recurrence of skin cancer if these cancer cells are not completely removed (Foundation 2014 ). Mohs micrographic surgery was first described by Dr. Frederic Mohs in 1941 (Foundation 2014 ). This surgery involves surgeons remove skin tissue sequentially (layer by layer) then examine under the microscope immediately until the tissues are clear of cancer cells (Foundation 2014 ). Most patients usually clear of cancer cells after 2 or 3 layers of skin tissue removal (Foundation 2014 ). On average, Mohs surgery usually takes from 2 to 7 hours (Foundation 2014 ). The outline of Mohs surgery is shown as in Figure 2.12 (Foundation 2014 ) 


\section{Step 1}

The roots of a skin cancer may extend beyond the visible portion of the tumor. If these roots are not removed, the cancer will recur.

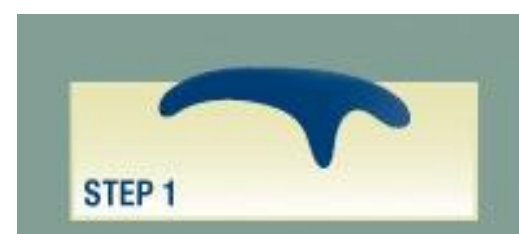

\section{Step 2}

The visible tumor is surgically removed.

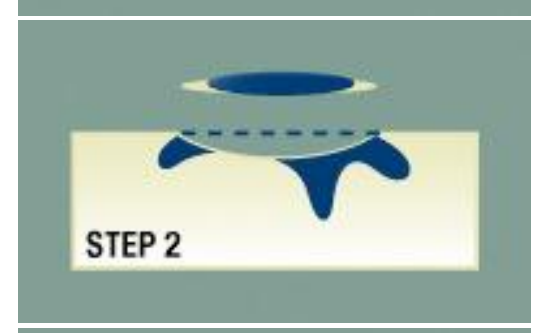

\section{Step 3}

A layer of skin is removed and divided into sections. The surgeon then color codes each of these sections with dyes and makes reference marks on the skin to show the source of these sections. A map of the surgical site is then drawn.

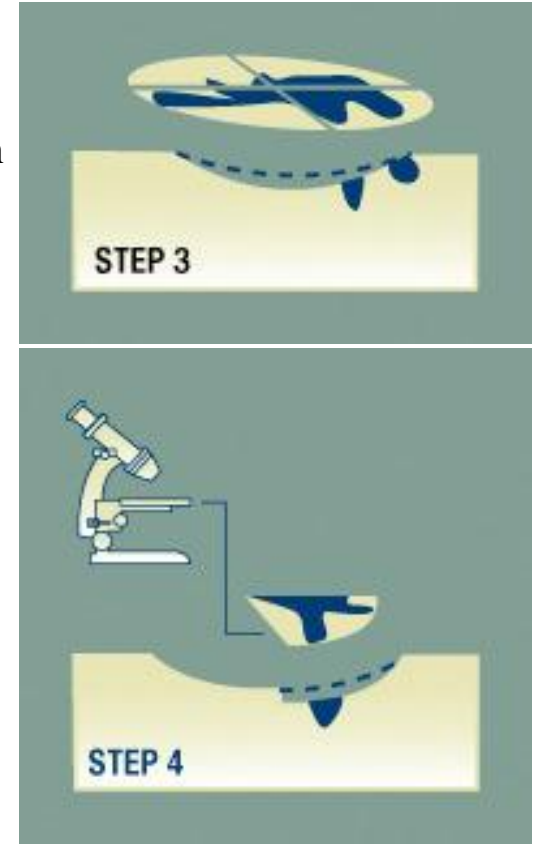

\section{Step 5}

If cancer cells are found under the microscope, the surgeon marks their location onto the "map" and returns to the patient to remove another layer of skin - but only from precisely where the cancer cells remain.

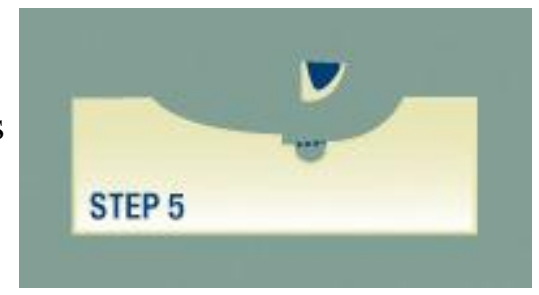

\section{Step 6}

The removal process stops when there is no longer any evidence of cancer remaining in the surgical site. Because Mohs surgey removes only tissue containing cancer, it ensures that the maximum amount of healthy tissue is kept intact.

Figure 2.12: The Outline of Mohs Micrographic Surgery. Image Source: (Surgery 2013) 


\subsection{Skin Cancer Pathology}

The transition process from a normal keratinocyte to a neoplastic cell is a very complicated process that involves both genetic and epigenetic factors (Melnikova and Ananthaswamy 2005). UV radiation causes DNA damage, inflammation, erythema, sunburn, immunosuppression, photoaging, gene mutation and eventually skin cancer (Melnikova and Ananthaswamy 2005). Upon exposure, UV radiation causes DNA damage and induces the over expression of $\mathrm{p} 53$, a tumor suppressor protein in keratinocytes. P53 proteins will initiate different cascade pathways to arrest the cell cycle, repair DNA, initiate the apoptosis process and activate cell survival and proliferation (Melnikova and Ananthaswamy 2005). Moreover, when keratinocytes are exposed to UV radiation chronically, the generation of DNA photoproducts and defects in DNA repair will cause the accumulation of mutations in p53 tumor suppressor gene, deregulation of Fas/FasL signaling and an increase in apoptosis resistance (Melnikova and Ananthaswamy 2005). These events will eventually lead to the clonal expansion of p53-mutated keratinocytes, activation of ras oncogenes and mutations in PATCH, INK4a/ARF tumor suppressor genes (Melnikova and Ananthaswamy 2005). These cellular events cause UV-induced skin tumors to eventually develop into squamous cell carcinomas (Melnikova and Ananthaswamy 2005). The progression from normal keratinocytes to squamous cell carcinoma is summarized in Figure 2.13 below. 


\section{Initiation and Progression of Human SCC}

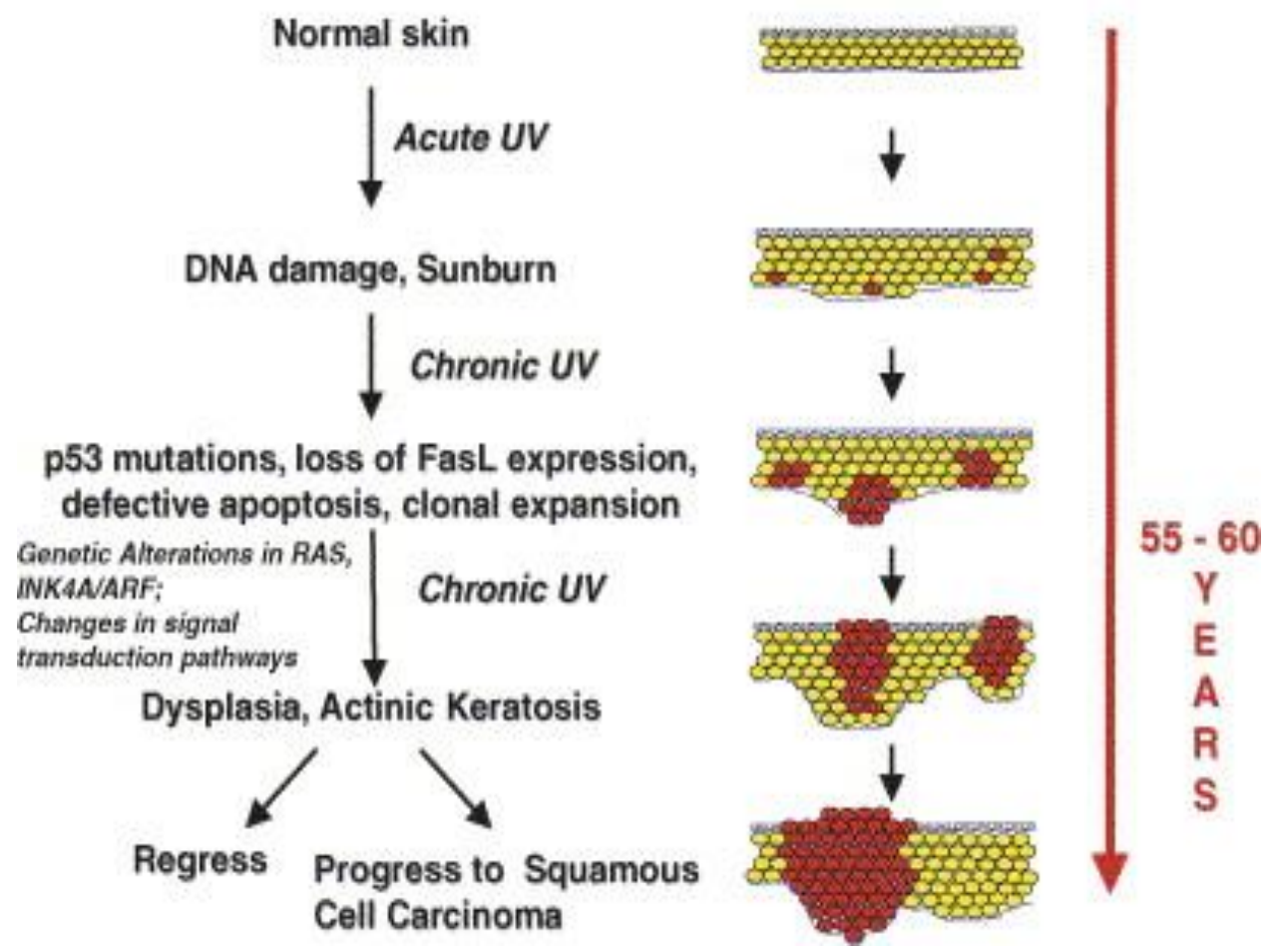

Figure 2.13: Progression of Human Squamous Cell Carcinoma (Melnikova and

Ananthaswamy 2005)

\subsubsection{Cellular Changes after Exposing to Acute UV DNA Damage}

DNA molecules are made up of polynucleotides. Each nucleotide contains a nitrogencontaining nucleobase - either Guanine (G), Adenine (A), Thymine (T) or Cytosine (C) as shown in Figure 2.14. Adenine (A) pairs with Thymine (T) and Guanine (G) pairs with Cytosine (C). 


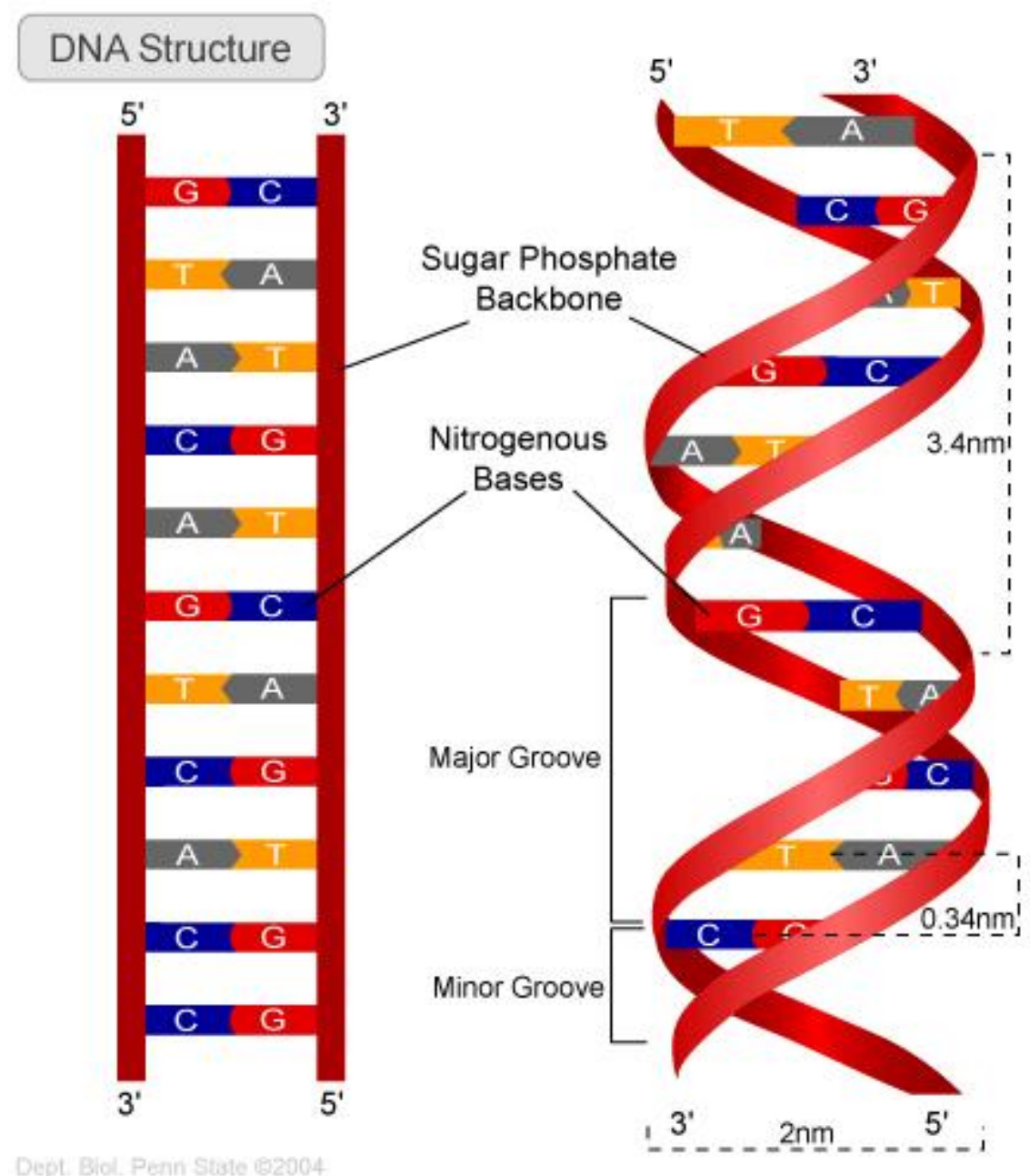

Figure 2.14: Structure of DNA Molecules

Pyrimidine bases include cytosine (C) and thymine (T). Upon exposure to UVB radiation, it will induce cyclobutane-type pyrimidine dimmers and pyrimidine (6-4) pyrimidone photoproducts in the DNA structure of skin cells (Brash 1988). The energy from UV light will cause two adjacent pyrimidine bases (cytosine: $\mathrm{C}$ and thymine: $\mathrm{T}$ ) to form covalent bonds and result in pyrimidine dimmers (C-C, C-T, T-C, T-T) (Brash 1988). A pyrimidine dimmer for example a thymine dimmer (T-T) will create a bend in DNA structure and stall the DNA/RNA polymerase as shown in Figure 2.15. 


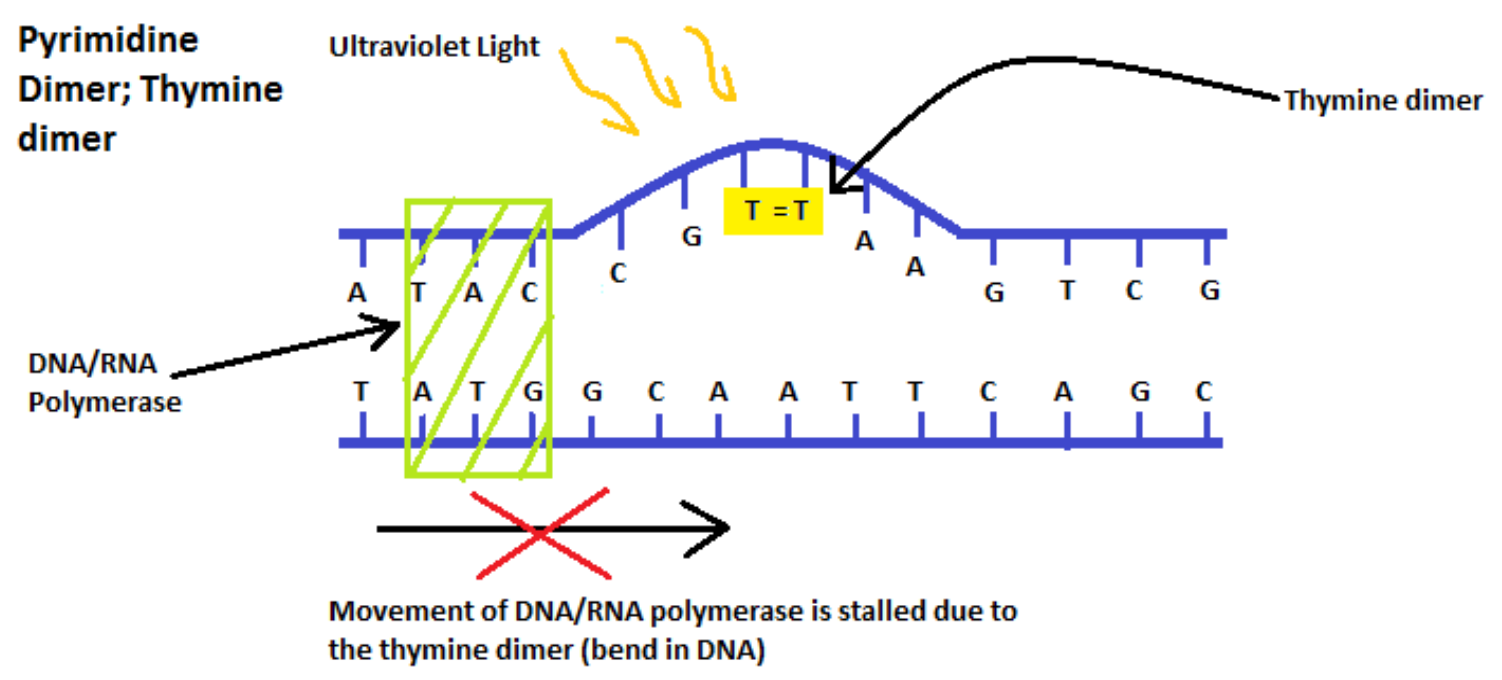

Figure 2.15: UVB Induces Pyrimidine Dimmers and Stops Movement of DNA/RNA

\section{Polymerase (Block)}

Skin cells have a DNA repair mechanism call Nucleotide Excision Repairs (NER) that can remove these pyrimidine dimmers (DNA lesions) (Brash ED 1991). The NER mechanism will remove a short single-stranded DNA segment that contains the pyrimidine dimmers and uses the undamaged single stranded DNA remains as a template to synthesize a complementary sequence to repair the DNA damage as shown in Figure 2.16 (Brash ED 1991). 


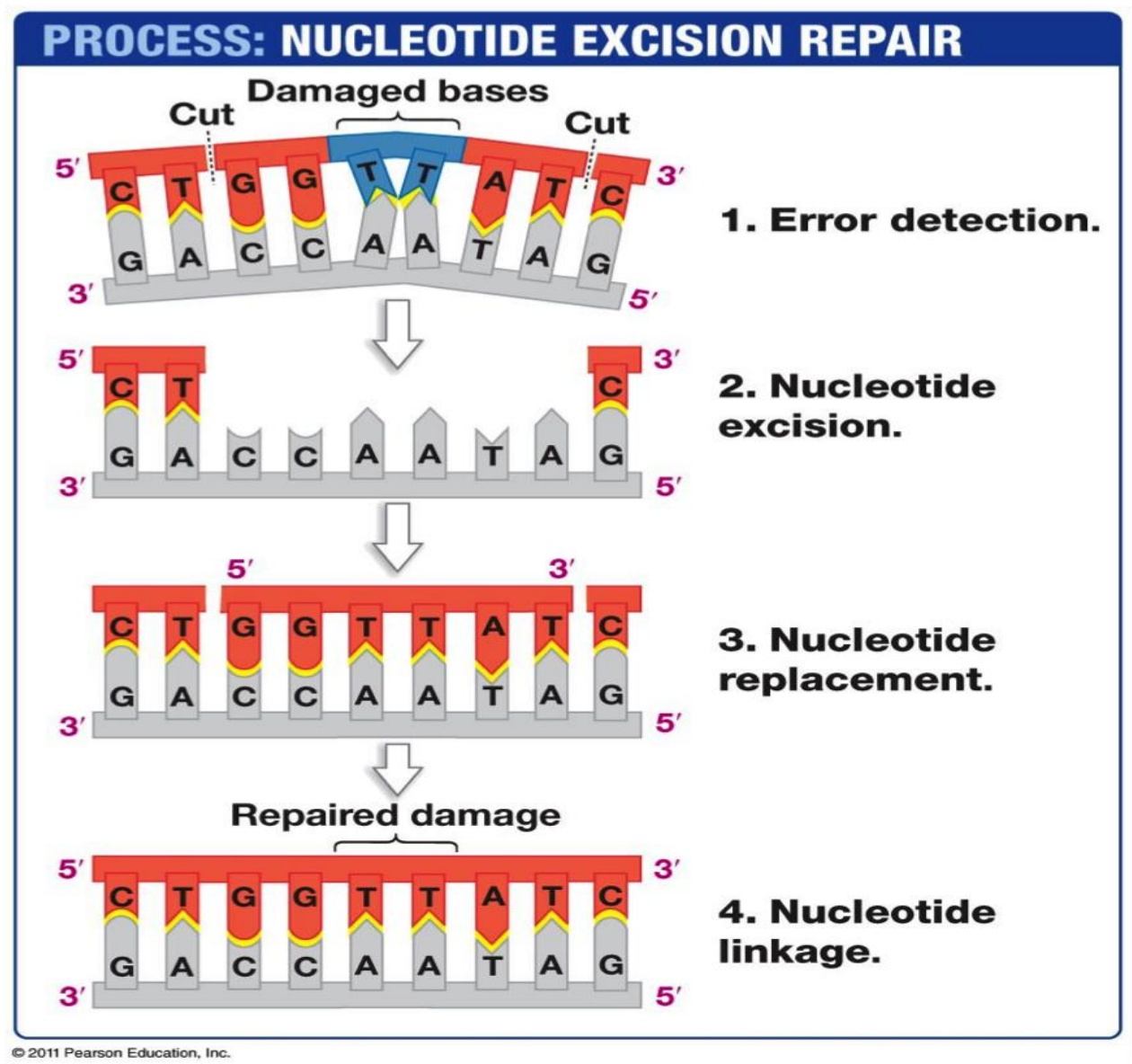

Figure 2.16: Nucleotide Excision Repair (NER) Mechanism (StudyBlue 2014)

However, when skin cells are exposed to UVB radiation repetitively without adequate time for DNA repair, it exceeds the capability of NER mechanisms to remove all pyrimidine dimmers and repair DNA (Brash ED 1991). This leads to mutations $\mathrm{C} \rightarrow \mathrm{T}$ and CC $\rightarrow \mathrm{TT}$ at Pyrimidine Dimmers (Brash ED 1991). These mutations occur according to the A rule: when DNA polymerase interacts with lesions in the DNA template that it cannot interpret, it inserts Adenine (A) residues by default (Brash ED 1991) as shown in Figure 2.17. All the complement bases of pyrimidine dimmers (CC, CT, TC, TT) are Adenine (A) if the NER mechanism fails to repair the DNA lesions (Brash ED 1991). This leads to the mutation of $\mathrm{C} \rightarrow \mathrm{T}$ and $\mathrm{CC} \rightarrow \mathrm{TT}$ at pyrimidine dimmers, which are recognized as the UV fingerprint mutations (Brash 1988). 


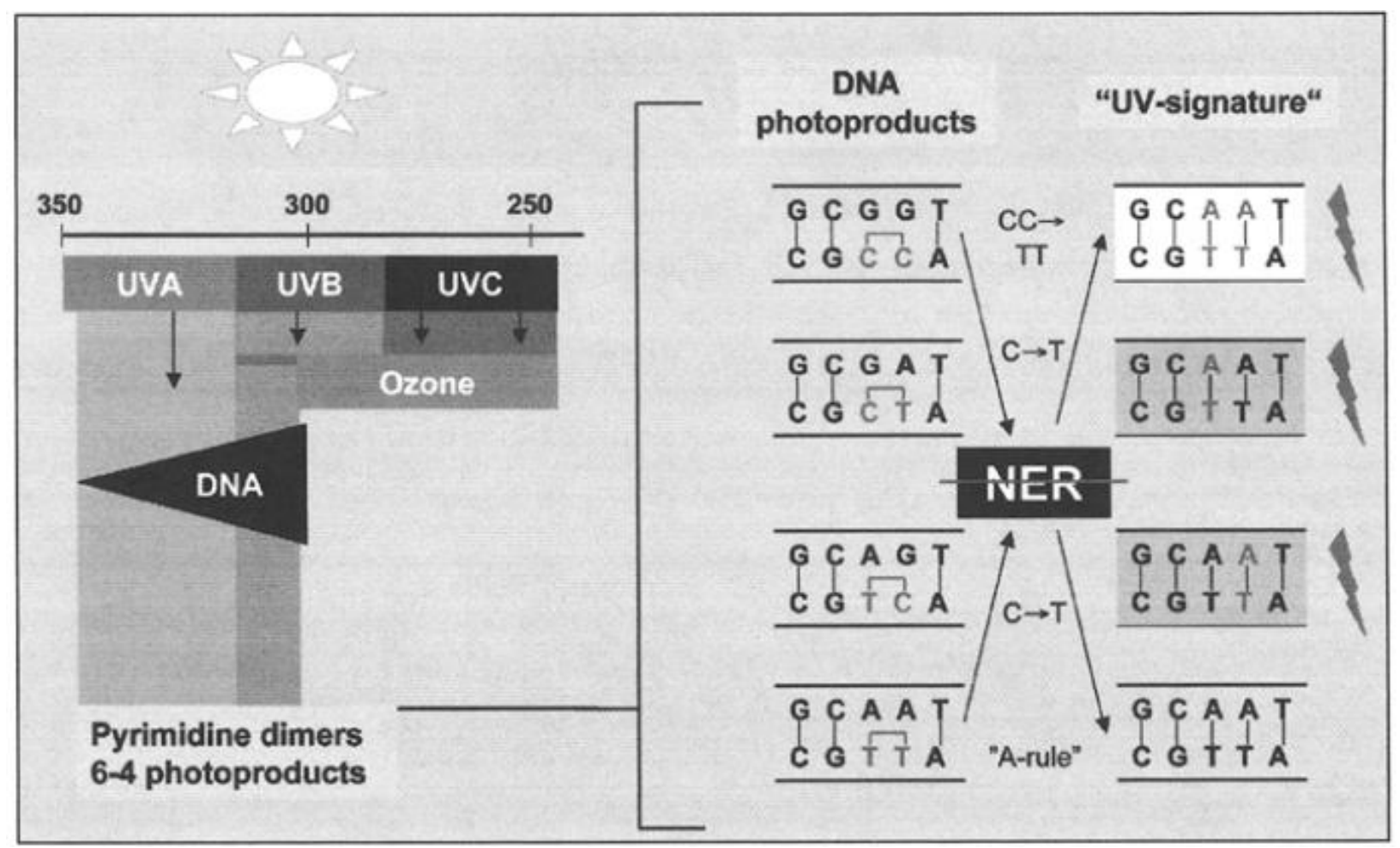

Figure 2.17: UVB induced Mutations $\mathrm{C} \rightarrow \mathrm{T}$ and $\mathrm{CC} \rightarrow \mathrm{TT}$ at Pyrimidine Dimmers (Rass and Reichrath 2008)

UVB radiation induces pyrimidine dimmers and (6-4) photoproducts, which can lead to UV fingerprint mutation $\mathrm{C} \rightarrow \mathrm{T}$ and $\mathrm{CC} \rightarrow \mathrm{TT}$ at pyrimidine dimmers (Brash ED 1991). These mutations can affect genes that codes for important proteins or enzymes that control cell cycle, DNA repair and apoptosis. After exposing to chronic UVB radiation for years, many more mutations will accumulate in these critical genes and will trigger affected cells to grow out of control and form malignant tumors (Brash ED 1991).

UVA radiation causes DNA damage indirectly by producing reactive oxygen species such as superoxide anion, singlet oxygen and hydrogen peroxide (Boiteux 1993). These 
molecules induce other DNA lesions include cytosine photohydrates, purine photoproducts, sing strand breaks in DNA, DNA-protein crosslinks, and altered bases in DNA (Boiteux 1993).

\section{Inducing Expression of p53, a Tumor Suppressor Protein}

DNA damage will trigger the cells to induce the expression of p53, a tumor suppressor protein (A.J. Levine 1991). UV radiation causes phosphorylations of many serine residues on p53 include Ser15, Ser20, Ser33, Ser37, Ser46 and Ser392 (J.D.Siliciano 1997, N.H. Chehab 1999, M.Kapoor 2000). The phosphorylation of Serine residues on p53 disrupts the interaction of p53 and its negative regulator Mdm2, enhances the transcriptional activity of p53 and promotes p53 to move from cytoplasm to nucleus (Melnikova and Ananthaswamy 2005).

\section{Inducing Cell Cycle Arrest, DNA Damage Repair and Apoptosis}

Once inside the nucleus, p53 will trigger many other pathways including cell cycle arrest to repair DNA damage, DNA damage repair, inhibition of angiogenesis and metastasis, and apoptosis as shown in Figure 2.18 (Vladislava O. Melnikova 2004).

P53 proteins cause cell cycle arrest at the G1 phase by activating the p21/WAF1/CIP1 pathway. P21 proteins bind to and inactivate the cyclinD/cdk4, cyclin D/cdk6 and cyclin E/cdk2 complexes which are important in the progression of cells from G1 to S phase. This event causes the cells to be arrested in G1 phase to allow more time for DNA repair to occur (J.W. Harper 1993).

P53 proteins also trigger DNA damage repair pathways such as nucleotide excision repair (NER) and base excision repair (BER) (B.J. Hwang 1999, S.A. Amundson 2002). In NER, p53 activates proteins p48XPE, XPC and GADD45 (Vladislava O. Melnikova 2004). These proteins bind to the damage DNA and initiate the process of repairing DNA (B.J. Hwang 1999, S.A. Amundson 2002). 
Intensive DNA damage caused by UV radiation also triggers the expression of p53. P53

then induce the increase in expression of proapoptotic genes that cause mitochrome c release from mitochondria. Cytochrome c then interacts with Apaf-1 proteins, recruits procaspase 9, activates the apoptosomal complex and leads to apoptosis (T. Miyashita 1995).

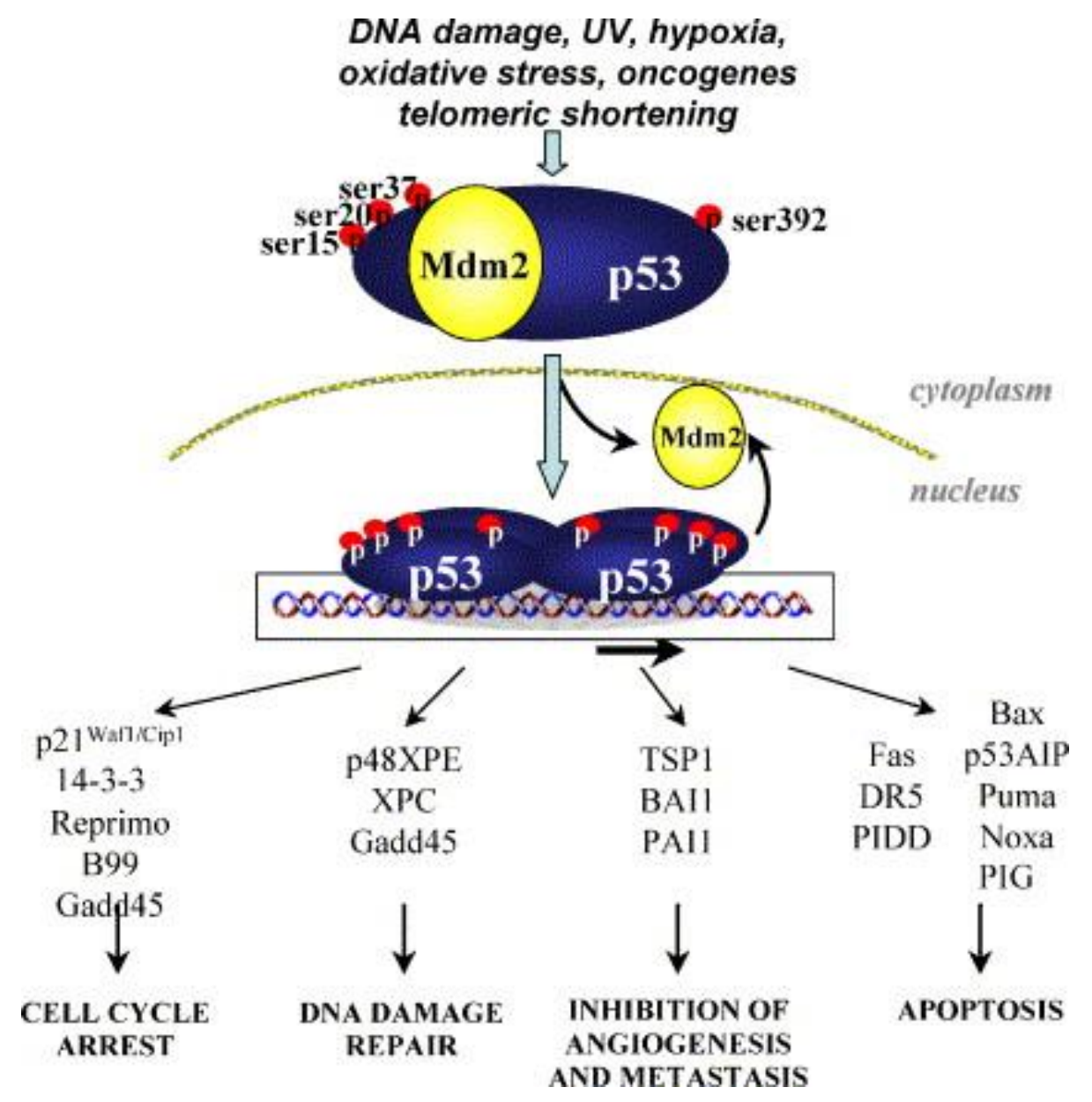

Figure 2.18: p53 Initiates Different Cellular Pathways to response to UV-induced DNA

Damage (Melnikova and Ananthaswamy 2005) 


\subsubsection{Cellular Changes after Exposing to Chronic UV}

When skin cells are exposed to chronic UV radiation, it will promote cells to progress to skin cancer more rapidly by inducing many irreversible cellular changes. First, it will cause more mutations in p53 tumor suppressor gene (H. Nakazawa 1994). Research studies showed that a high frequency of p53 mutations was found in premalignant actinic AK lesions, which are precursors of squamous cell carcinoma. Ziegler et al. found that $66 \%$ of AK lesions had p53 mutations (A. Ziegler 1994). Second, chronic UV radiation also causes skin cells to be highly resistant to apoptosis. Exposure to chronic UV radation changed the expression of Fas receptors, (programmed cell death receptors) and affect their interaction with the Fas ligands (A. Ouhtit 2000). This led to a decrease in apoptosis. Research studies showed that after 1 week of continuous exposure to UV radiation, the transcription of Fas receptors were inhibited in mice model. This resulted in a decrease in apoptotic cells (A. Ouhtit 2000). Third, clones of keratinocytes carrying mutated p53 expanded after exposing to UVB radiation for a long time (R.J.W. Berg 1996, W.Zhang 2001). These mutated keratinocytes can grow rapidly because they are resistant to apoptosis and can proliferate faster than normal keratinocytes (V.A. Tron 1998, A.V. Mudgil 2003). Research studies showed that a single UV exposure could stimulate the growth of mutated p53 keratinocytes but induce apoptosis in normal keratinocytes (V.A. Tron 1998, A. V. Mudgil 2003). Finally, chronic UV exposure also caused mutations in the patched gene (PTCH) and INK4a/ARF tumor suppressor genes (Y. Matsumura 2002). Researchers found mutations in PTCH genes in basal cell carcinomas patients (Y. Matsumura 2002). Studies also showed that $76 \%$ of 40 human squamous cell carcinoma (SCC) had alterations in the INK4a/ARF locus (V. L. Brown 2004). Although the exact mechanisms of how normal keratinocytes developed into malignant tumors remain unknown, these cellular and 
molecular changes were found to contribute to the progression of UV-induced DNA damage keratinocytes into skin cancer after chronic exposure to UV radiation.

\subsection{Cell Cycle}

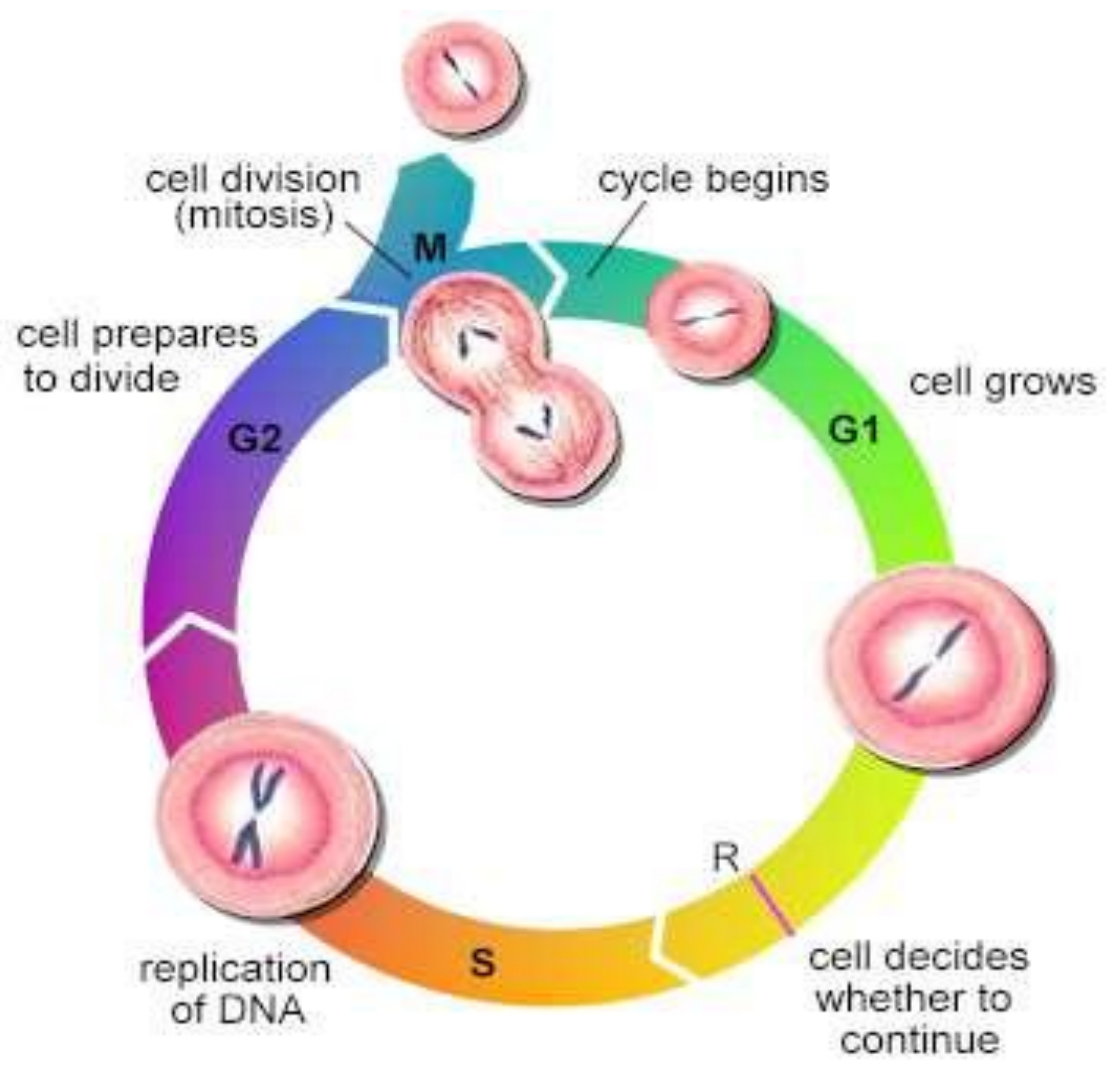

Figure 2.19: Cell Cycle (Scicurious 2014)

The human body contains about 100 trillion cells. All these cells, except for the red blood cells, undergo the cell cycle to divide and form new cells (Scicurious 2014). The cell cycle process accounts for the development of a single cell fertilized egg into a mature organism, the renewal of hair and skin cells and new cells of some internal organs. The cell cycle can be divided into 4 phases: G1, S, G2, and M as shown in Figure 2.19. During the G1 (Gap 1) phase, the cell grows in size and checks to ensure that its internal system is functioning normally (Scicurious 2014). There is a check point at the end of G1 phase. The cell has to reach a certain 
size and any damages to its DNA structure has to be corrected before the cell can move on to S phase. If something is wrong or the damages of DNA cannot be corrected, the cell will stop progressing through the cell cycle and initiate apoptosis (programmed cell death). During the $\mathrm{S}$ (Synthetic) phase, the cell replicates its DNA molecules. After that, the cell will enter the G2 (Gap 2) phase. During the G2 phase, the cell will continue to grow and check that everything inside the cell is ready before the cell divides in the $\mathrm{M}$ phase. During the $\mathrm{M}$ (mitosis) phase, the cell divides into 2 identical daughter cells. Each daughter cell then starts the cell cycle again to form new cells and enters the G1 phase. Sometimes, cells will leave the cell cycle and enter a phase called $\mathrm{G}_{0}$ (quiescent) temporarily or permanently. Usually, cells enter $\mathrm{G}_{0}$ phase when they are not ready for cell division because they are too busy carrying out other functions such as secreting or attacking pathogens (virus, bacteria, etc) (Science, 2012).

\subsection{Protein p21 and Its Cellular Functions}

\subsubsection{Protein p21 Background}

Protein p21, also known as Cip1 or Waf1, is a cyclin-dependent kinase inhibitor, was first discovered in 1993 (El-Deiry, Tokino et al. 1993, Wade Harper, Adami et al. 1993). Protein p $21^{\text {Cip1/Waf1 }}$ is coded by the gene CDKN1A, it contains 164 amino acids and has a molecular weight of $20 \mathrm{KDa}$. The $\mathrm{p} 21^{\mathrm{Cip} 1 / \mathrm{Waf1} 1}$ was identified as the first inhibitor of cyclin-dependent kinases (CDKs). This protein can inhibit cyclin-dependent kinases CDK2, CDK3, CDK4 and CDK6, which are proteins that play important roles in the progression of cell cycle. Since p21 protein was able to bind and interact with CDKs, it was named CIP1, which abbreviated for CDK interacting protein 1 . Moreover, $\mathrm{p} 21$ protein was also known as the product of a gene 
activated by wild-type p53. Therefore, p21 was named WAF1, which stood for wild-type p53 activated factor (Gartel and Tyner 1999).

\subsubsection{Protein p21 Cellular Functions}

$\mathrm{p} 21^{\mathrm{Cip} 1 / \text { Waf1 }}$ protein can be found in both nucleus and cytoplasm. Depending on the localization, $\mathrm{p} 21^{\mathrm{Cip} 1 / \mathrm{Waf} 1}$ protein participates in important cellular pathways and plays an important role in 5 different cellular biological processes: cell cycle, DNA replication/repair, gene transcription, apoptosis and cell motility (Jana Cmielova 2011).

When the cell is exposed to genotoxic stress such as ionizing radiation, UV radiation, chemical mutagens and cytostatics, it can lead to DNA damages in the nucleus. Cells try to repair the DNA damage as soon as possible to preserve its genomic stability and prevent the mutated DNA to be passed on to daughter cells (Cazzalini, Scovassi et al. 2010). Under normal physiological conditions, p53 proteins are mostly present in the cytoplasm. However, shortly after DNA damage, p53 protein is accumulated in the nucleus. In the nucleus, p53 acts as a transcriptional factor and induces the expression of p21 proteins (Solozobova, Rolletschek et al. 2009). Protein p21 then stops the cell cycle at the G1/S checkpoint by interacting with CDK2 proteins so that cell has time to repair DNA. P21 also interacts with PCNA proteins to prevent replication of the damaged DNA. Cells that lack p21 proteins or were mutated and lost the ability to induce expression of p21 will continue with DNA synthesis and end up with abnormal or damaged DNA in its daughter cells (Garner and Raj 2008).

The G1/S checkpoint is a mechanism cell uses to prevent the replication of damaged DNA. Under normal conditions, at the end of the G1 phase, the CDK2/Cycline E complex is responsible for the complete phosphorylation of $\mathrm{Rb}$ proteins (Retionoblastoma proteins). The 
fully phosphorylated $\mathrm{Rb}$ proteins release the $\mathrm{E} 2 \mathrm{~F}$ factors that will induce the expression of $\mathrm{S}$ phase genes. This will lead the cell through the G1/S checkpoint (Satyanarayana A 2008). However, when human skin cells are exposed to sunlight, UV radiation can cause DNA damage in human skin cells, DNA damage then leads to the accumulated expression of p53 proteins in the nucleus, the $\mathrm{p} 53$ proteins then induce the expression of $\mathrm{p} 21$ proteins. $\mathrm{P} 21$ proteins can inhibit the activity of CDK2, so the CDK2/Cyclin complex can't phosphorylate $\mathrm{Rb}$ proteins. This leads to an accumulation of hypophosphorylated Rb proteins (Garner E 2008). The hyposphosrylated $\mathrm{Rb}$ proteins do not release $\mathrm{E} 2 \mathrm{~F}$ factors, which in turn inhibit the expression of S phase genes and stop the cell cycle at the G1/S checkpoint. This is the mechanism of how p21 proteins arrest the cell cycle at the G1/S checkpoint to prevent cell from replicating the DNA damage (Ju Z 2006).

Protein p21 also interacts with PCNA proteins and involves in another mechanism to prevent the replication of the damaged DNA from occurring. Under normal conditions, at the end of G1 phase, the expression level of PCNA proteins increase and PCNA move from the cytoplasm into the nucleus. PCNA is a cofactor of DNA polymerase, which involves in DNA replication (Lee, Kim et al. 2009). After DNA damage occurs, p21 proteins expression increases in the nucleus. These $\mathrm{p} 21$ proteins can react to a part of PCNA and inhibit PCNA to bind to DNA polymerase. Without the cofactor PCNA, DNA polymerase can't replicate and make another copy of the damaged DNA (Li, Xie et al. 2006) (Prives and Gottifredi 2008). This is a mechanism of how $\mathrm{p} 21$ proteins prevent cells from synthesizing another copy of the damaged DNA molecules.

Moreover, p21 proteins can prevent the replication of the damaged DNA by binding to transcriptional factors such as NF-KB, Myc, STAT3, and estrogen receptors or by regulating the 
activity of transcriptional co-factors such as p300/CBP (Dotto 2000, Perkins 2002, Coqueret 2003).

\subsection{Milk Phospholipids}
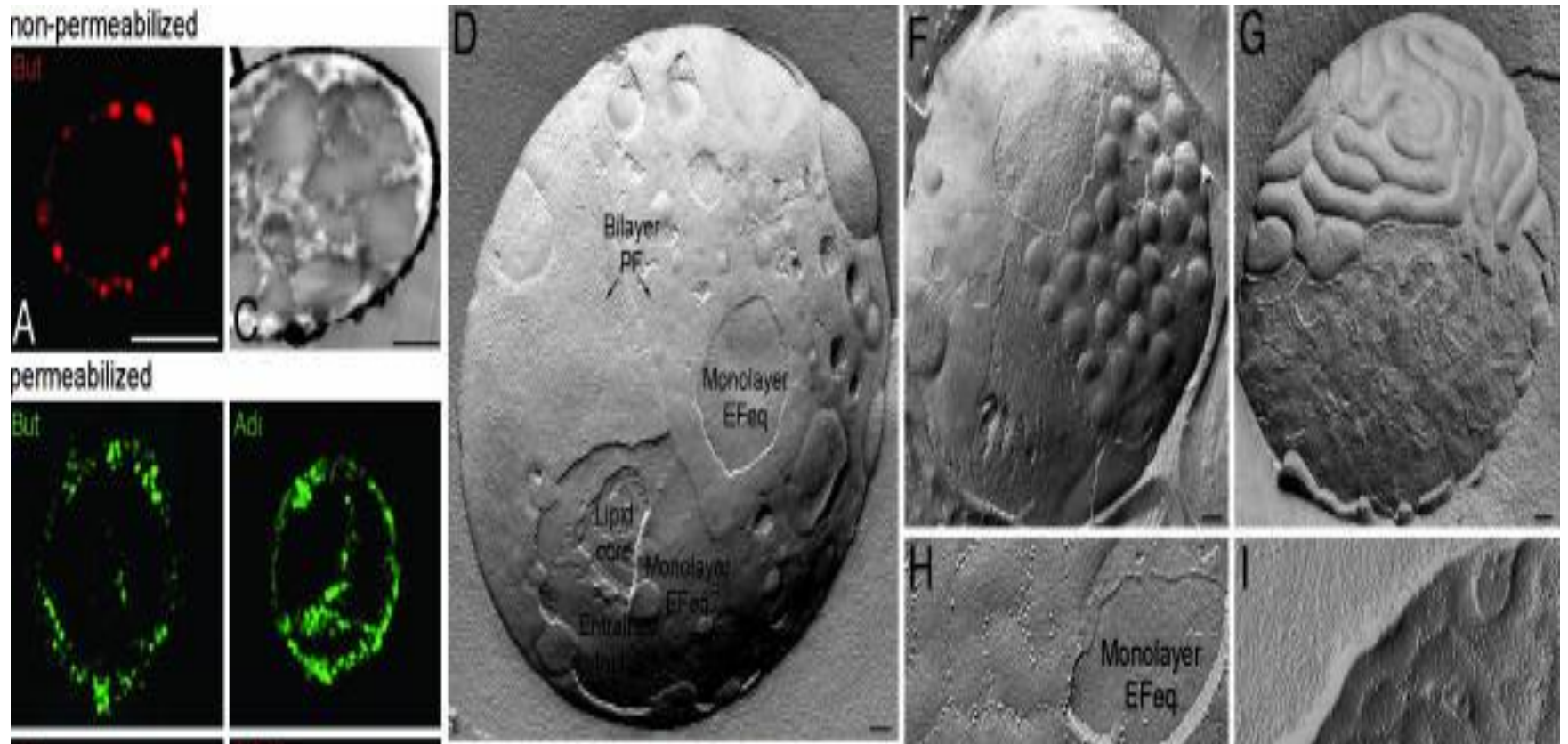

permeabilized
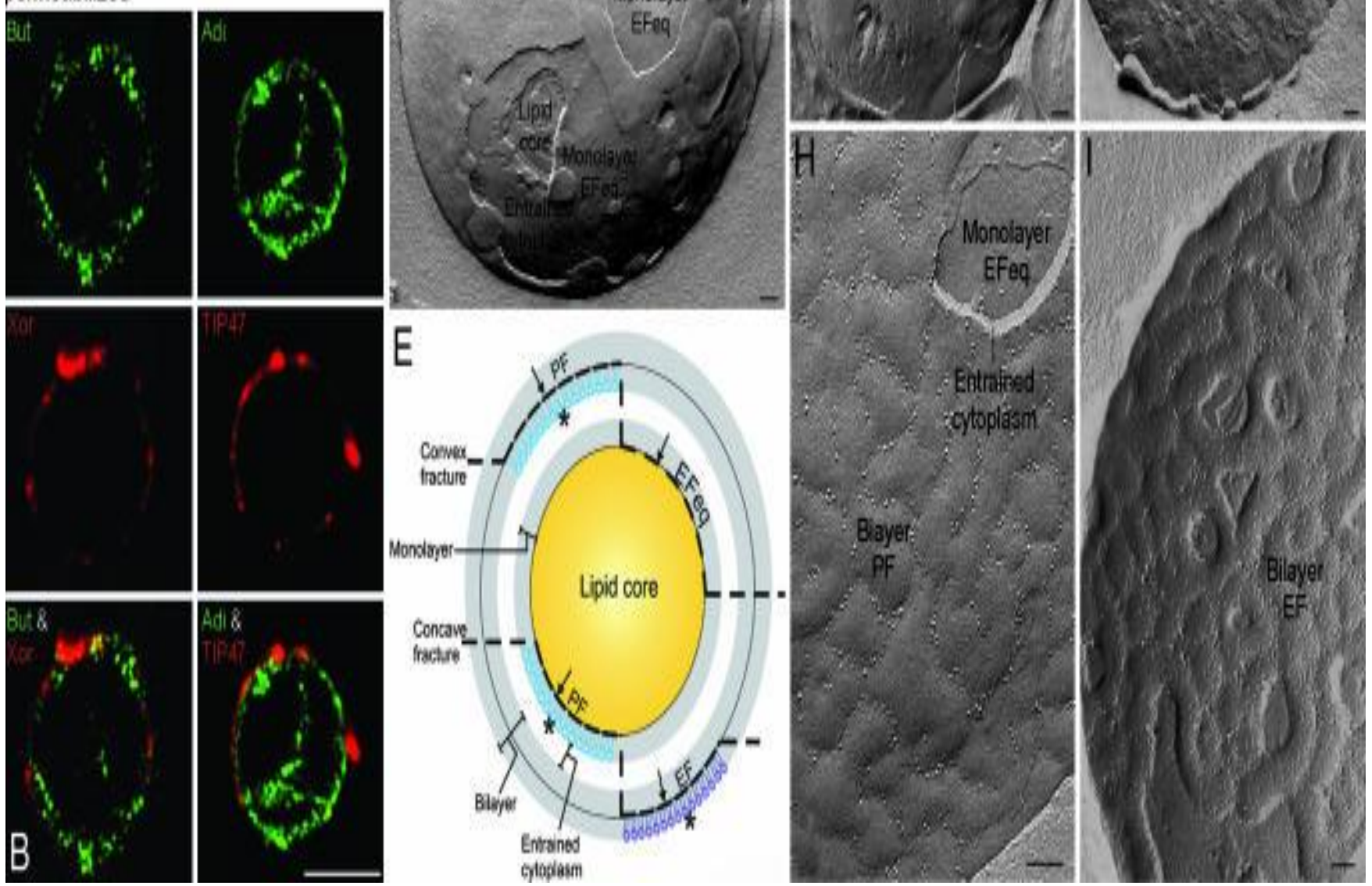

Figure 2.20: The Structure and Composition of Milk Fat Globule Membrane. Source:

(Robenek, Hofnagel et al. 2006) 


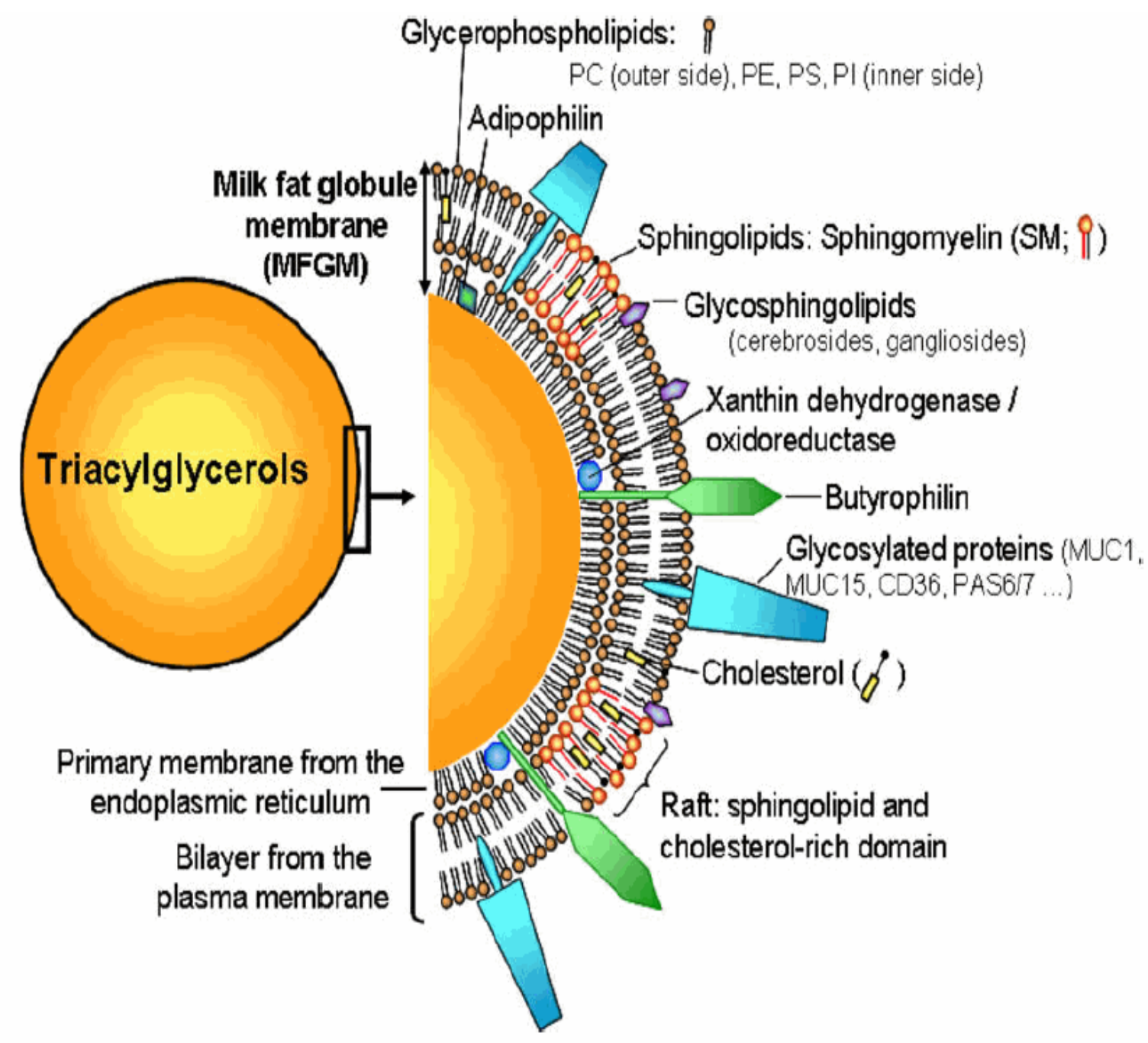

Figure 2.21: Structure of the Milk Fat Globule Membrane. Source: (Christelle Lopez 2010)

Milk is the most important food source for all mammal newborns. Most nutritional values of milk reside in small droplets (mean diameter $4 \mu \mathrm{m}$ ) called milk fat globules (Keenan 2001, Heid and Keenan 2005). The structure of the milk fat globule is shown in Figure 2.20 above. Milk fat globule is secreted by the epithelial cells of the mammary glands. Milk fat globule contains triacylglycerols, an important source of energy at its core and biological active molecules such as polar lipids and glycoproteins at its membrane (Spitsberg 2005). Research studies also found that the components of the milk fat globule membrane (MFGM) are involved 
in anti-infection or anti-adhesion which ultimately protects the newborns from bacterial and viral infection.

The MFGM has been studied extensively because it contains many important phospholipids that have beneficial health effects such as regulation of the inflammatory reactions, protective effects against gastrointestinal infections and colon cancer, and reducing cardiovascular risk factors (Kullenberg 2012).

The MFGM consists of 3 phospholipid membrane monolayers. The milk fat globules are formed by the accumulation of the milk lipids in the endoplasmic reticulum (ER), the milk lipids then bud off the ER in the form of small vesicles (Mather and Keenan 1998).Therefore, the innermost layer of the milk fat globules membrane is the monolayer of phospholipid layer from the cytoplasmic leaflet of the ER membrane (Patton and Keenan 1975). These small vesicles containing lipids are then secreted outside of the cells (Murphy 2001). As a result, the outermost layer of the milk fat globule membrane is the membrane bilayer consisting of the extracellular and cytoplasmic leaflets of the plasma membrane.

Most of the milk fat globule membrane and its phospholipids come from the apical plasma membrane of the mammary gland secretory cell. The components of the milk fat globule membrane are shown in Figure 2.21. About $60 \%$ - $70 \%$ of milk phospholipids are present in the external bilayer membrane of the milk fat globule membrane. These phospholipids are organized as a liquid-disordered phase coexisting with a liquid-ordered phase, called the lipid raft, which is rich in sphingomyelin and cholesterol (Gallier, Gragson et al. 2010, Lopez 2010). Glycerophospholipids and sphingolipids, constitute $0.5 \%-1 \%$ of milk fat, are the most important milk phospholipids because they have many positive health benefits (Gallier, Gragson et al. 2010, Lopez 2010). 
The MFGM is composed of glycoproteins (20-60\%), glycerophospholipids (15-33\%), sphingolipids, glycolipids, triacyclyerols, sterols (0.3\%), enzymes and other minor components (Keenan T.W 1995). The most important glycerolphospholipids of the MFGM are phophatidylcholine PC (35-36\%), phosphatidylelethanolamine PE (27-30\%), phosphatidylinositol PI (5-11\%), and phosphatidylserine PS (3-4\%). The molecular structures of these phospholipids are shown in Figure 2.22.<smiles>[R]C(=O)OCC(COP(=O)([O-])OCC[N+](C)C)OC([R])=O</smiles>

phosphatidylcoline (PC)<smiles>[R]C(=O)OCC(CO[R]([O-])([O-])OC1(O)C(O)C(O)C(O)C(O)C1O)OC([R])=O</smiles>

phosphatidylinositol (PI)<smiles>[R]C(=O)OCC(COP(=O)([O-])OCC([NH3+])C(=O)O)OC([R])=O</smiles>

phosphatidylserine (PS)<smiles>[R]C(=O)OCC(COP(=O)([O-])OCC[NH3+])OC([R])=O</smiles>

phosphatidylethanolamine (PE)

\section{Figure 2.22: The Molecular Structures of Important Glycerophospholipids in the Milk Fat Globule Membrane. Source: (Contarini and Povolo 2013)}

Sphingolipids contain a long chain base, called the sphingoid base (sphingosine or phytosphingosine), fatty acids and sugars or phosphoric acid or alcohols (Beare-Rogers, Dieffenbacher et al. 2001). Sphingosine is the main sphingoid base in the mammalian 
sphingolipids. When a sphingosine links to a saturated fatty aid chain, it forms a ceramide.

Moreover, when a ceramide links to a phosphorylcholine head group, it forms a sphingomyelin as in Figure 2.23 below. The major sphingolipid of the MFGM is sphingomyelin SM (25\% of total polar lipids) (Christie 1995, Lopez, Briard-Bion et al. 2008). The MFGM also contains many glycoproteins such as the butyrophillin (20-40\% of the total MFGM proteins), and heavily glycosylated mucin-like glycoproteins MUC1 and MUC15, PAS6/7 and CD36 (Keenan T.W 2006).

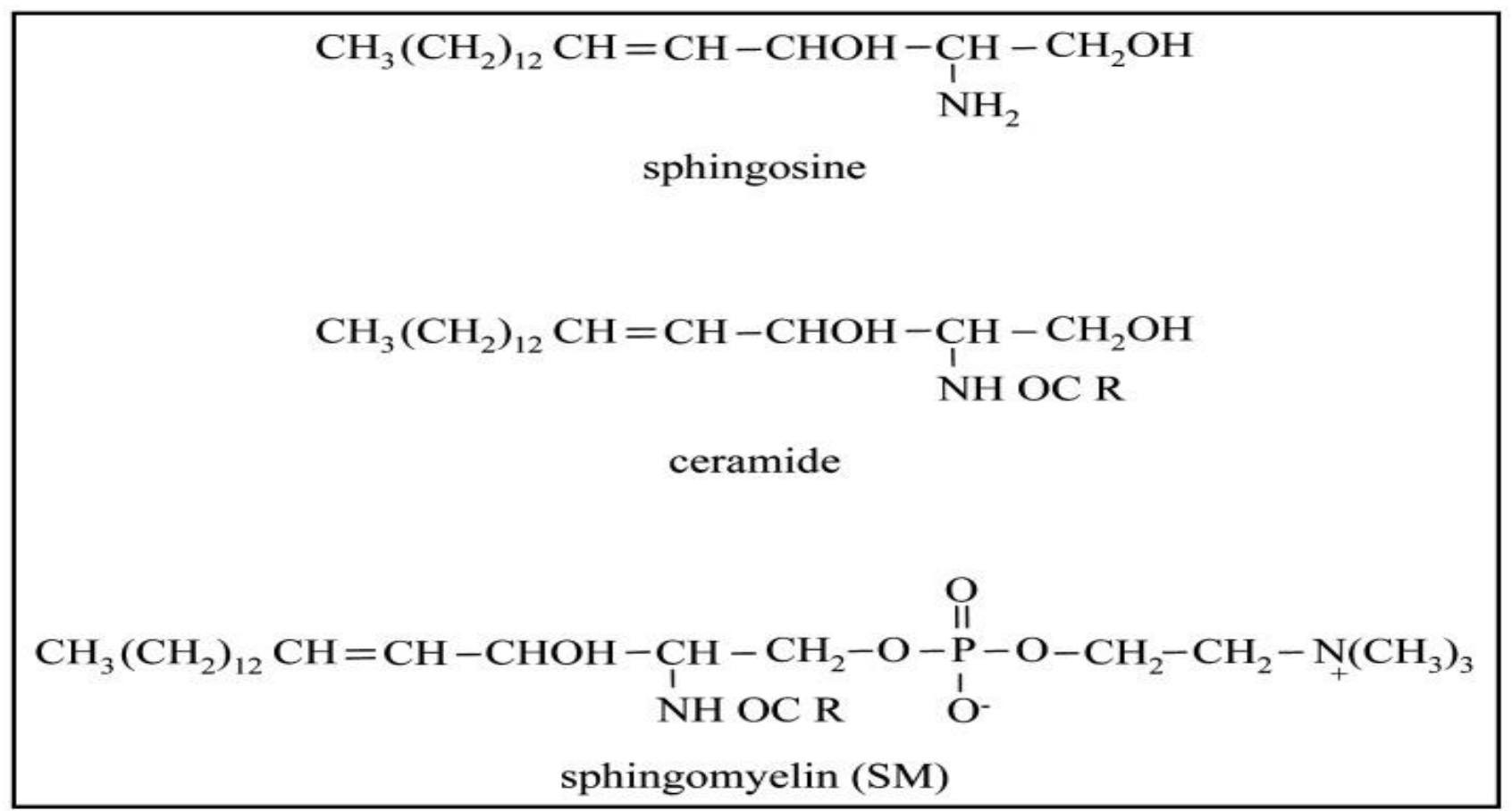

Figure 2.23: The Molecular Structures of Sphingomyelin and Its Components. Source: (Contarini and Povolo 2013)

\subsection{Health Benefits of Bovine Milk Phospholipids}

\subsubsection{Reduced Risks of Type 2 Diabetes and Heart Disease}

Pereira et al., 2002 investigated the association between dairy intake (consumption of milk and dairy products) and the ten-year cumulative incidence of insulin resistance syndrome 
(IRS) over 3157 adults aged 18-30. They found that an increased consumption of dairy intake is associated with a reduced incidence of obesity, glucose intolerance, hypertension and dyslipidemia, which are components of IRS. The results from this study suggested that an increased in dairy intake can lower the incidence of IRS, which in turn lower the risk factors of type 2 diabetes and heart disease (Pereira Ma 2002).

\subsubsection{Protective Effects against Gastrointestinal Infections and Febrile Episodes}

Veereman-Wauters et al. 2012 found that consuming milk that was enrich with milk fat globule membrane $(0.25 \mathrm{~g}$ in $100 \mathrm{~mL}$ of milk) had health beneficial effects for young children and significantly reduced the number of short febrile episodes (Veereman-Wauters, Staelens et al. 2012).

Moreover, research studies also found that sphingolipids has protective effects against gastrointestinal infections in vitro. They found that $100 \mathrm{mmol} / \mathrm{L}$ of lysophingomyelin was very bactericidal against Campylobacter jejuni, Listeria monocitogenes and Clostridium perfringens, and also decrease the viable counts of E.coli and Salmonella enteritidis (Sprong, Hulstein et al. 2001, Sprong, Hulstein et al. 2002).

\subsubsection{Protective Effects against Chronic Stress and Improving Working Memory}

One research group did a study on the effect of consuming bovine milk drink that was enriched with phospholipids on 75 chronically stressed men aged 30 to 50 . They found that subjects that received milk with $0.5 \%$ phospholipids had a stronger increase of cortisol after awakening and they also had a better memory performance than subjects in the control group (Schubert, Contreras et al. 2011). These results suggested that bovine milk phsopholipids have 
protective effects against chronic stress and can help improve working memory in individuals suffering from chronic stress.

\subsubsection{Suppression of Colon Tumors}

Recent research studies showed that sphingolipids are promising chemopreventive or chemotherapeutic agents for colon cancer because they regulate cell growth, cell differentiation and cell death. They are parts of the daily diet and a high dose of sphingomyelin is not harmful to rodents. Moreover, many in vitro studies also demonstrated the involvement of sphingolipid metabolites in cancer treatment. Increasing the ceramide and or sphingosine content in cells either via hydrolysis of complex sphingolipids or de novo synthesis can induce cell apoptosis (a programmed cell death) (Duan 2009).

Lemonnier et. al research study in 2002 found that sphingomyelin can suppress colon tumors in mice model (Lemonnier L 2002). Throughout the intestinal tract, sphingolipids from the diet are hydrolyzed to ceramide and free sphingoid bases. Intestinal cells then rapidly uptake these metabolites. Ceramides and sphingoid bases regulate cell growth, differentiation, and death. The intracellular targets of these metabolites are important enzymes that involved in transformation and unrestricted cell growth such as members of the phosphatidilinositol-3 kinase and mitogen-activated protein kinase signaling pathway. Previous studies have shown that non-pharmacological amounts in the diet can inhibit early stages of chemically induced colon cancer in mice model. In Lemonnier et.al 2002 study, researchers investigated the chemopreventive and chemotherapeutic effects of sphingomyelin supplements by feeding mice $0.05 \%$ sphingomyelin before and after tumor initiation. The average daily intake of sphingolipids is about $0.3-0.4 \mathrm{~g} /$ day $(0.01-0.02 \%$ of the diet by weight) (Vesper H 1999). 
Therefore, the amount of sphingomyelin in the mouse diet in this study can also be achieved in human diet. In the sphingomyelin early (SM-E) group, 50 mice were fed a diet that was supplemented with $0.05 \%$ sphingomyelin right after arrival. Colon cells have a life span of 3-5 days, so all cells were exposed to sphingomyelin before tumor initiation. One week after arrival, the mice were injected with 1,2-dimethylhydrazine (DMH) $(30 \mathrm{mg} / \mathrm{kg}$ body weight) once per week for 6 weeks to trigger colon tumor formation. In the untreated control (UT) group, 14 mice were not injected with the carcinogen DMH and were fed the AIN 76A diet without supplements during the entire research study. In the sphingomyelin late (SM-L) group, 50 mice were on the AIN 76A diet during 6 weeks of tumor initiation, then received diet supplemented with $0.05 \%$ sphingomyelin one week after the last carcinogen injection. In the control group, 60 mice were on the AIN 76A diet without sphingomyelin supplements during the entire study (Lemonnier L 2002).

At forty five weeks after the last carcinogen injection, the animals were killed and their colons were opened longitudinally. The number, location and size of tumors were noted. They found that the tumor incidence in the control group was $23.3 \%(14 / 6)$, in the sphingomyelinearly (SM-E) was 6\% (3/50) and in the sphingomyelin-late (SM-L) was 4\% (2/50). Half of the tumors in these groups were adenomas and the other half were carcinomas. The difference in the tumor number and tumor incidence between the SM-E and SM-L groups was not statistically significant. This suggested that sphingomyelin is potent in suppressing colon tumors when administering before and after tumor initiation (Lemonnier L 2002). 


\subsection{Western Blot}

Western blot also known as immunoblot or protein blot is a core technique in the cell and molecular biology research field and in medical diagnostics. Many commercial western blot kits are available and used to diagnose HIV, Hepatitis B, and lyme diseases. In principle, western blot is an antibody detection technique used to detect and quantify the expression of a specific protein in a complex mixture of proteins extracted from cells. Western blot procedure often involves four main steps. First, proteins are extracted from cells. Second, proteins are separated from each other based on their sizes on a gel and then proteins are transferred to a membrane. Third, primary and secondary antibodies are added to the membrane to detect the protein of interest. The secondary antibodies are often conjugated with an enzyme such as alkaline phosphatase or horadish perosidase. Finally, a substrate is added, the enzyme that was conjugated with the secondary antibody will react with the substrate and produce signals as blue or violet bands on the membrane. The intensities of the blue or violet bands on the membrane correspond to the expression level of the target protein (KOMABIOTECH 2014).

\subsubsection{Protein Extraction from Cells}

First, proteins are extracted from cells using lysis buffer. The lysis buffer will break open the cell's membrane so that proteins can be released. Then, the tube containing the sample will be centrifuged. After centrifugation, the proteins will be present in the supernatant in the top and cellular debris will be present in the pellet at the bottom. The supernatant will be removed and kept in a new tube as shown in Figure 2.24 below (NOVUSBIO 2014) . 


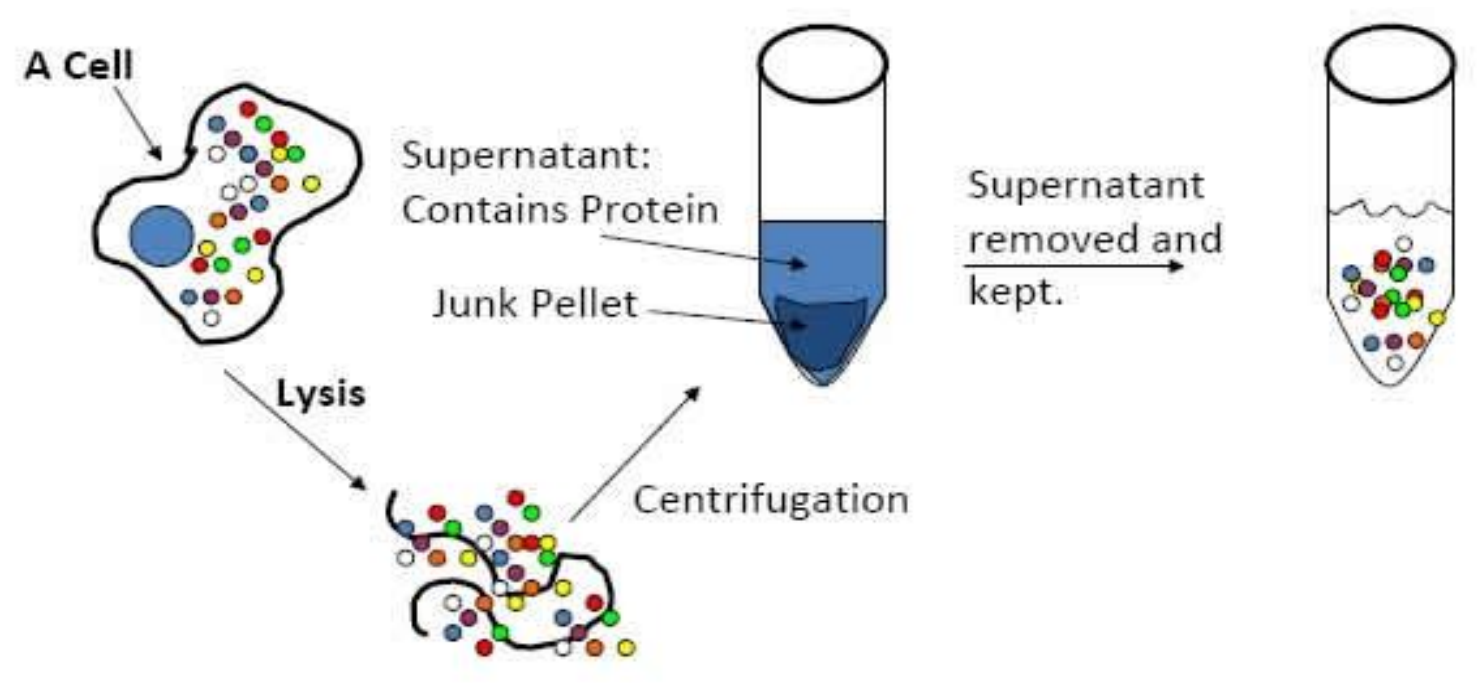

Figure 2.24: Protein Extraction Process (NOVUSBIO 2014)

\subsubsection{Proteins are separated by sizes using SDS-PAGE gel electrophoresis}

As shown in Figure 2.25 below, before protein samples are loaded on a gel, loading buffer is usually added to the samples. Loading buffer contains SDS (Sodium Dodecyl Sulfate). The samples are then heated to a near-boiling temperature, which denatures the proteins from a globular structure to a linear structure and allows the SDS to bind to the proteins. Since the SDS that binding to the proteins carries negative charges, the proteins become negatively charged (NOVUSBIO 2014). 

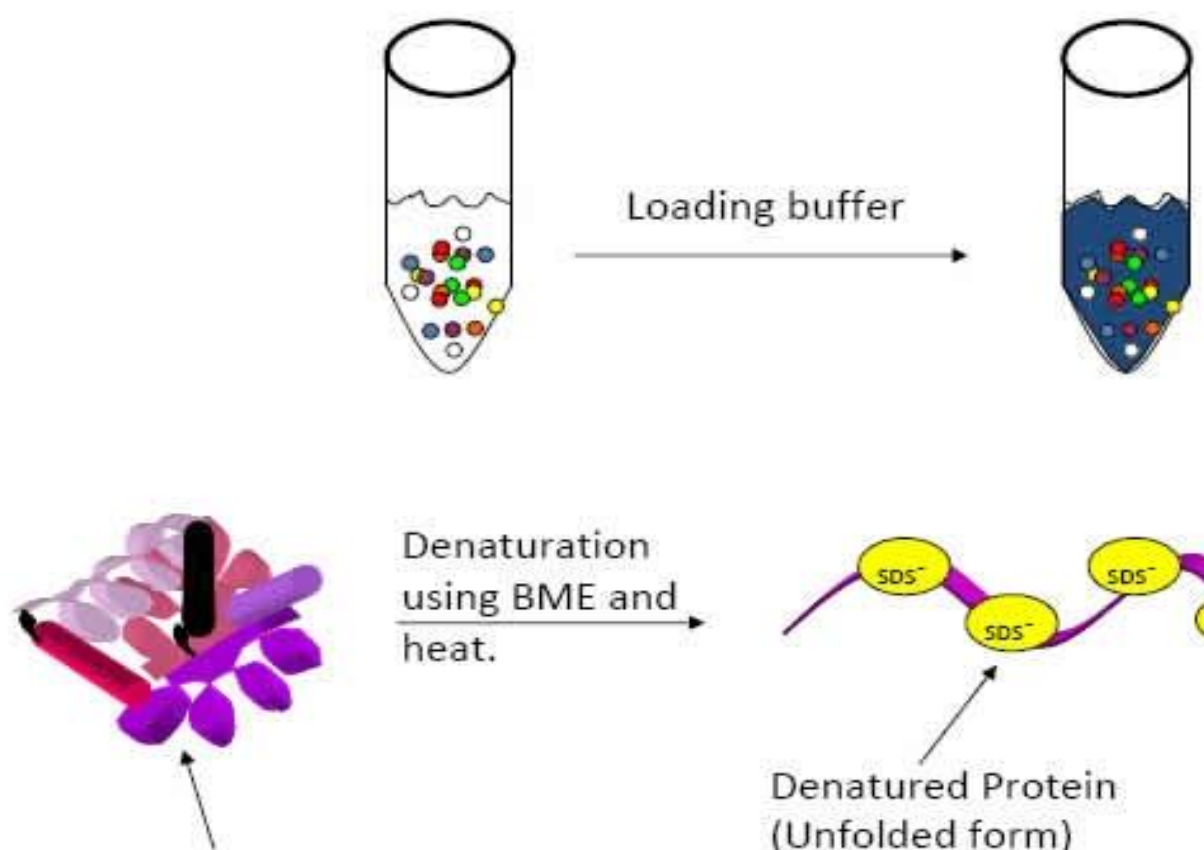

Native Protein

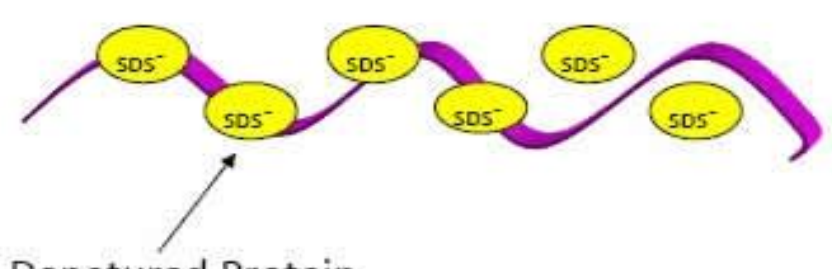

Denatured Protein

(Unfolded form)

(Folded form)

Figure 2.25: Proteins Denaturation Process by SDS and Heat Treatment (NOVUSBIO

2014)

After this, different protein samples are loaded into different wells of a gel as shown in Figure 2.26. A ladder contains molecular weight markers are usually loaded onto the first well. The ladder contains protein mixtures of known molecular weights, this allows researchers to determine the molecular weight of other proteins on the gel. After the ladder and all the protein samples are loaded, a current is run across the gel with the positive pole at the bottom of the gel. Since the proteins bind to the negatively charged SDS, the proteins will be pulled down through the gel to the positive pole. The larger the protein, the slower it will move. Therefore, the large proteins will be at the top and all the small proteins will be at the bottom of the gel (BioRad 2014). 


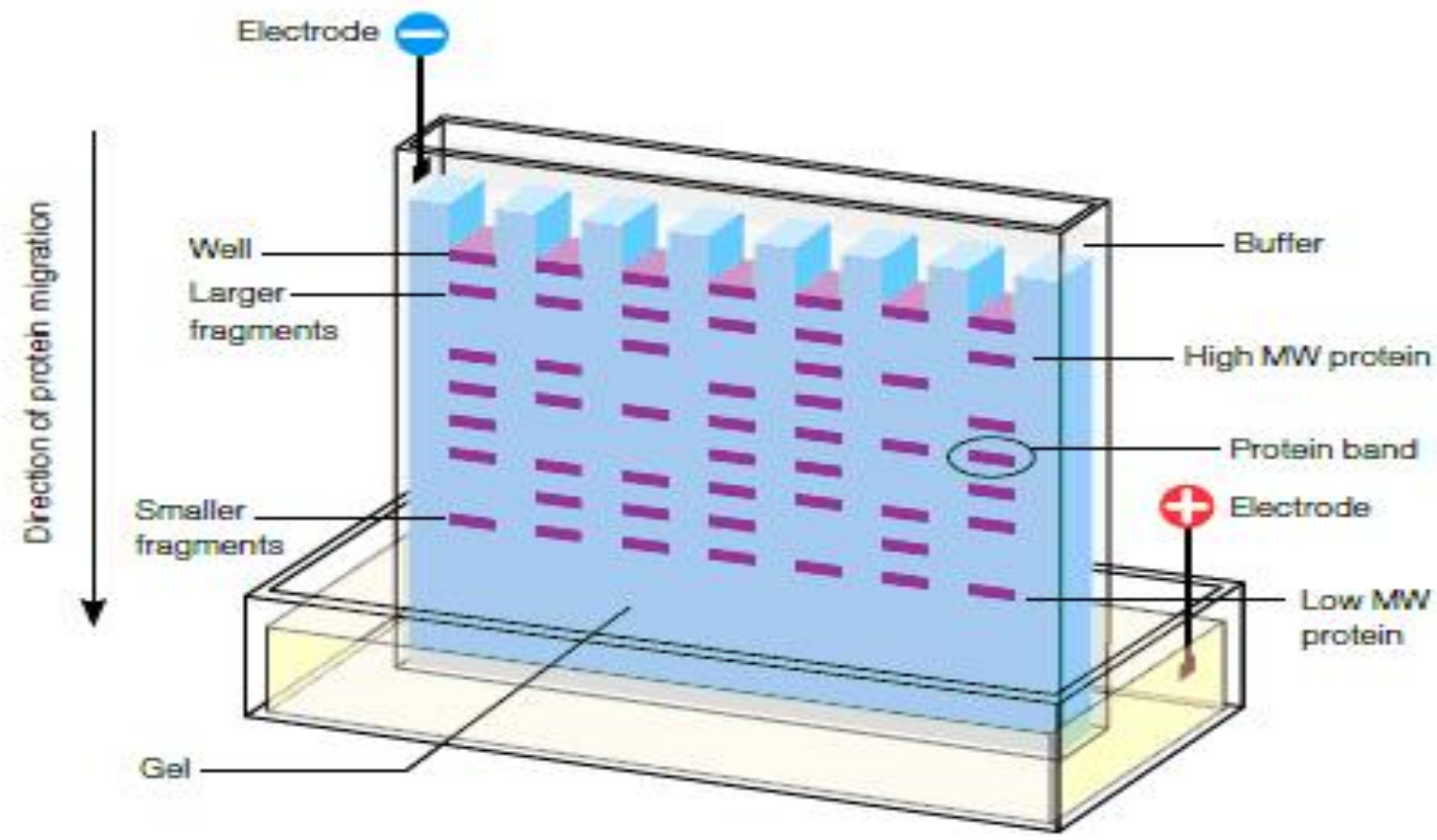

Figure 2.26: Proteins are Separated by Sizes Using SDS-PAGE Gel Electrophoresis

(BioRad 2014)

As shown in Figure 2.27, after the gel is run, it is placed against a membrane and a current is passed across the gel to the membrane to transfer the proteins from the gel to the membrane.

\subsubsection{Primary and Secondary Antibodies are Added to the Membrane}

Since antibodies are also proteins, they can bind non-specifically to the membrane. Therefore, before adding antibodies, a non-specific protein such as BSA (bovine serum albumin) is added to block empty spaces on the membrane. BSA will bind to the surface of the membrane where proteins are not already present. This will prevent antibodies from binding to the surface of the membrane and giving non-specific signals. After this, the primary antibody will be added to the membrane. The primary antibody will only bind to the protein of interest. Then, the secondary antibody is added to the membrane. The secondary antibody will bind to the primary antibody (KOMABIOTECH 2014). 


\subsubsection{A Substrate is Added and Produce Signals on the Membrane}

Finally, a substrate is added. The enzyme on the secondary antibody will react with the substrate and give either a blue or violet color. The blue or violet bands on the membrane correspond to the proteins of interests. 


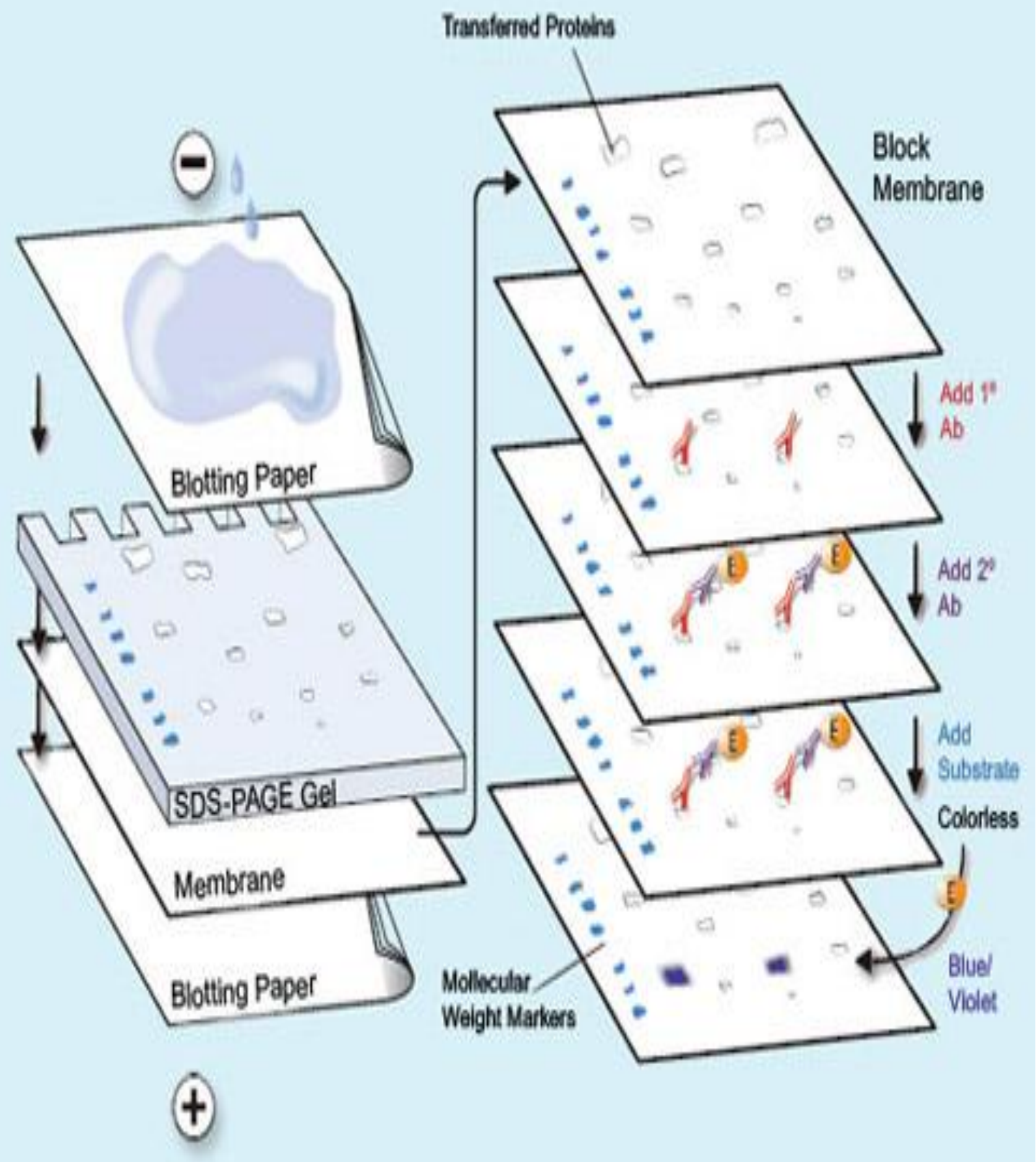

Figure 2.27: The Process of Detecting the Target Proteins on the Membrane (KOMABIOTECH 2014) 


\section{Chapter 3: Technical Challenges and Solutions}

\subsection{First Challenge - Developing a Protocol to induce p21 Expression in Keratinocytes Using UV Light}

Preliminary research studies showed that it was very crucial to expose keratinocytes to the right dose of UV light to induce cells to express p21 proteins. If keratinocytes cells were treated with a high UV dose, it would cause severe DNA damage in cells and trigger cells' apoptosis (programmed cell death). On the other hand, if keratinocytes cells were exposed to a low UV dose, only a small amount of cells would be affected and express p21 proteins to stop the cells' cycles to repair DNA damage. As a result, p21 proteins may be too little to be detected by immunofluorescent or by western blot methods. To solve this technical challenge, keratinocytes were exposed to different UV dosages including $30 \mathrm{~mJ} / \mathrm{cm}^{2}, 20 \mathrm{~mJ} / \mathrm{cm}^{2}$ and 10 $\mathrm{mJ} / \mathrm{cm}^{2}$. It was found that when exposing cells to a UV dosage of $10 \mathrm{~mJ} / \mathrm{cm}^{2}$, cells expressed very clear p21 signals and many cells were expressing p21 proteins when examining under the confocal microscopes using the immunofluorescent method.

The following method was used to induce p21 expression in keratinocytes by exposing them to UV light in the lab. Before UV radiation, keratinocytes were grown until they reach about $80-90 \%$ confluence in the 6 -wells plates in the $37^{\circ} \mathrm{C}$ incubator. First, all the light in the room was turned off. Then, the UV light apparatus was turned on for at least 10 minutes before radiation to ensure that the UV light was emitting a stable and constant dose rate. A UV light probe was placed right under the UV light to measure the emitting power in the unit of $\mathrm{mJ} / \mathrm{s}$. The obtained average emitting power is used to calculate the time needed to expose cells at a $\mathrm{UV}$ dose of $10 \mathrm{~mJ} / \mathrm{cm}^{2}$. 
The exposure time is calculated using the following formula:

$$
\begin{aligned}
\text { Exposure time }(\text { seconds }) & =(\text { Desired Dose }) \times(\text { Area of Detector }) /(\text { Average Wattage }) \\
& =\left(\mathrm{mJ} / \mathrm{cm}^{2}\right) \times\left(\mathrm{cm}^{2}\right) /(\mathrm{mJ} / \mathrm{s})
\end{aligned}
$$

Before UV radiation, all the cell growth media was removed from the cell plates. Keratinocytes in the plates were then washed with sterile PBS buffer for 2 times and the PBS was removed completely from the plates. Then, the cell plates were placed directly under the UV light for a specific calculated exposure time. When the appropriate time was reached, the UV light was turned off and the cell plates were immediately removed from the UV light apparatus. Then, a new pre-warmed cell growth media $\left(37^{0} \mathrm{C}\right)$ was added to the cell plates. The new cell growth media is as the same amount as the old cell media. The cell plates were then incubated in a $37^{\circ} \mathrm{C}$ incubator for another 24 hours before cells were lysed to extract proteins.

\subsection{Second Challenge - Determining Minimum Amount of Keratinocytes Needed for Each Treatment}

The second challenge was to determine the minimum amount of keratinocytes needed for each treatment sample. It is very expensive in terms of materials cost and labor time to grow keratinocytes in the lab. Therefore, it would be very efficient to know the minimum amount of keratinocytes needed for each treatment sample to ensure that there would be sufficient proteins and p21 proteins transferred to the PVDF membrane downstream. Preliminary research studies were conducted to determine the minimum amount of cells needed. Cells from 2 wells (1/3 plate), 6 wells ( 1 plate) and 12 wells ( 2 plates) were used for 1 sample treatment. The results showed that cells from 6 wells ( 1 plate) would yield sufficient proteins and p21 proteins to be detected on the PVDF membrane as part of the Western blot essay. Cells from 6 wells (1 plate) 
yielded an average total protein concentration of $13086 \mu \mathrm{g} / \mathrm{mL}$ and cells from 2 wells (1/3 plate) yielded an average total protein concentration of $2703 \mu \mathrm{g} / \mathrm{mL}$. Experiment results also showed that the amount of $\mathrm{p} 21$ proteins extracted from 6 wells (1 plate) was sufficient enough to be detected on the PVDF membrane. The amount of p21 proteins extracted from 2 wells ( $1 / 3$ plate) was not sufficient enough to be detected. The results were illustrated on the PVDF membrane in Figure 3.4 below. In batch 1, cells from 6 wells (1 plate) were used for each sample treatment and in batch 2, cells from 2 wells (1 plate) were used for each sample treatment. In batch 1, 131 $\mu \mathrm{g}$ of proteins from each sample were loaded into each lane (lanes 3-6). In batch 2, $54 \mu \mathrm{g}$ of proteins from each sample were loaded into each lane (lanes 7-10) as in Figure 3.4 below. P21 proteins signals from batch 1 were detected very clearly in lanes $3-6$. However, p21 proteins signals from batch 2 were not detected in lanes 7-10. These results showed that if cells from 6 wells ( 1 plate) were used as 1 sample treatment, there would be sufficient p21 proteins and clear p21 signals would be detected on the PVDF membrane.

\subsection{Third Challenge - Developing a Working Western Blot Protocol to Show p21 Signals}

Finally, the third challenge was to develop a working Western Blot protocol to show clear signals of p21 from each treatment on the PVDF membrane so that researchers can evaluate the effects of milk phospholipids in protecting skin cells from UV induced DNA damage. Three different experiment parameters that can be optimized in the Western blot assay include: transferring time for proteins to move from SDS-PAGE gel to PVDF membrane, primary and secondary antibody concentrations, and developing time for signals to appear clearly with a minimized background noise on the PVDF membrane. 


\subsubsection{First Experiment Parameter: Transferring Time}

Transferring time parameter needs to be optimized because too long or too short transferring time will affect whether or not the p21 signals are detectable on the PVDF membrane. In the Western blot assay, after cells were exposed to UV light and incubated in the $37^{0} \mathrm{C}$ incubator for 24 hours, proteins would be extracted by using lysis buffer to open up the cells. Protein concentration from each treatment sample would be measured using BCA assay and the same amount of proteins would be loaded into each lane of the SDS-PAGE gel. Proteins would be separated based on their molecular weight by running gel electrophoresis. The smaller proteins would travel farther down the gel faster than the bigger proteins. Since the interested p21 proteins are buried among the agarose molecules of the gel, it is hard to use antibodies to bind to and detect $\mathrm{p} 21$ proteins. Therefore, after gel electrophoresis, proteins are transferred from an SDS-PAGE gel to a PVDF membrane using the Invitrogen iBlot Dry Blotting System as shown in the Figure 3.1 below.

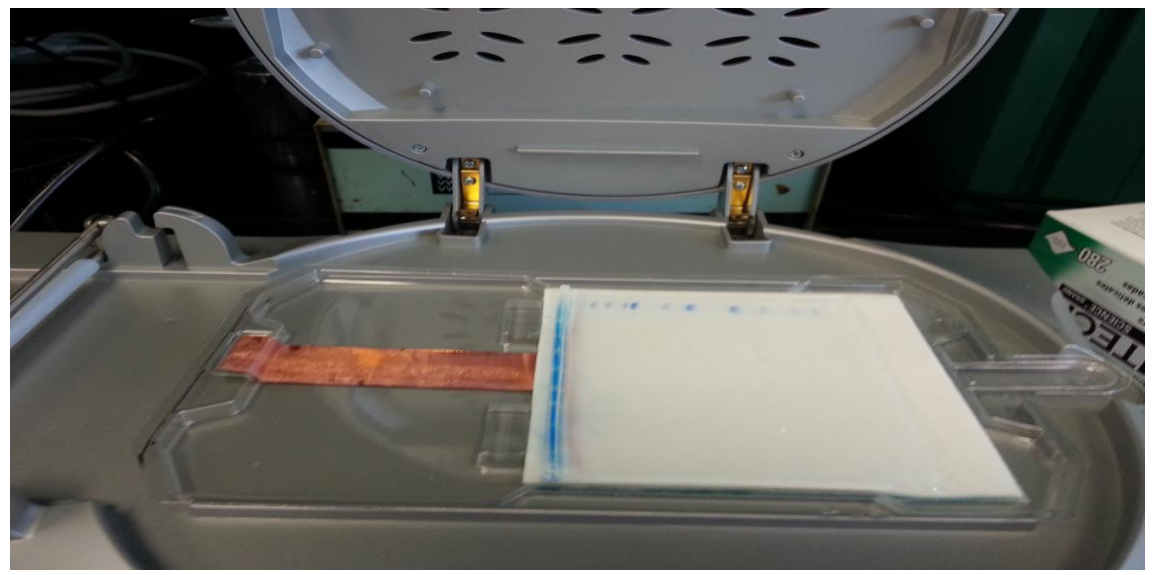

Figure 3.1: The Transferring Process of Proteins from Gel to PVDF Membrane Using

\section{Invitrogen iBlot Dry Blotting System}

The transferring time is very critical. If the transferring time is too short, not all p21 proteins would be able to move from the gel to the PVDF membrane and may result in no 
signals or faint signals of p21 detected on the membrane later. If the transferring time is too long, p21 proteins may run over through the pores of PVDF membrane and results in no signals or faint signals of $\mathrm{p} 21$ on the membrane. Preliminary experiments were performed to determine the optimal transferring time. Molecular weight proteins and proteins from UV treated samples were loaded in every 2 lanes of the gel. After gel electrophoresis, a cut was made at every 2 lanes of the gel and the proteins were transferred from the gel strips containing 2 lanes to the PVDF membrane. Different transferring time periods were tested for each gel strip of 2 lanes include $2,3,3.5,4,4.5,5$, and 5.5 minutes. Proteins were transferred from gel to membrane but they are not visible on the membrane. Therefore, after the transferring process, the PVDF membrane was stained in coomassive blue dye and washed in destaining solution. The coomassive blue dye would bind to proteins and form a protein-dye complex. The protein-dye complexes give a blue color and the proteins are therefore visible on the membrane. The results were shown in Figures 3.2 and 3.3 below. 


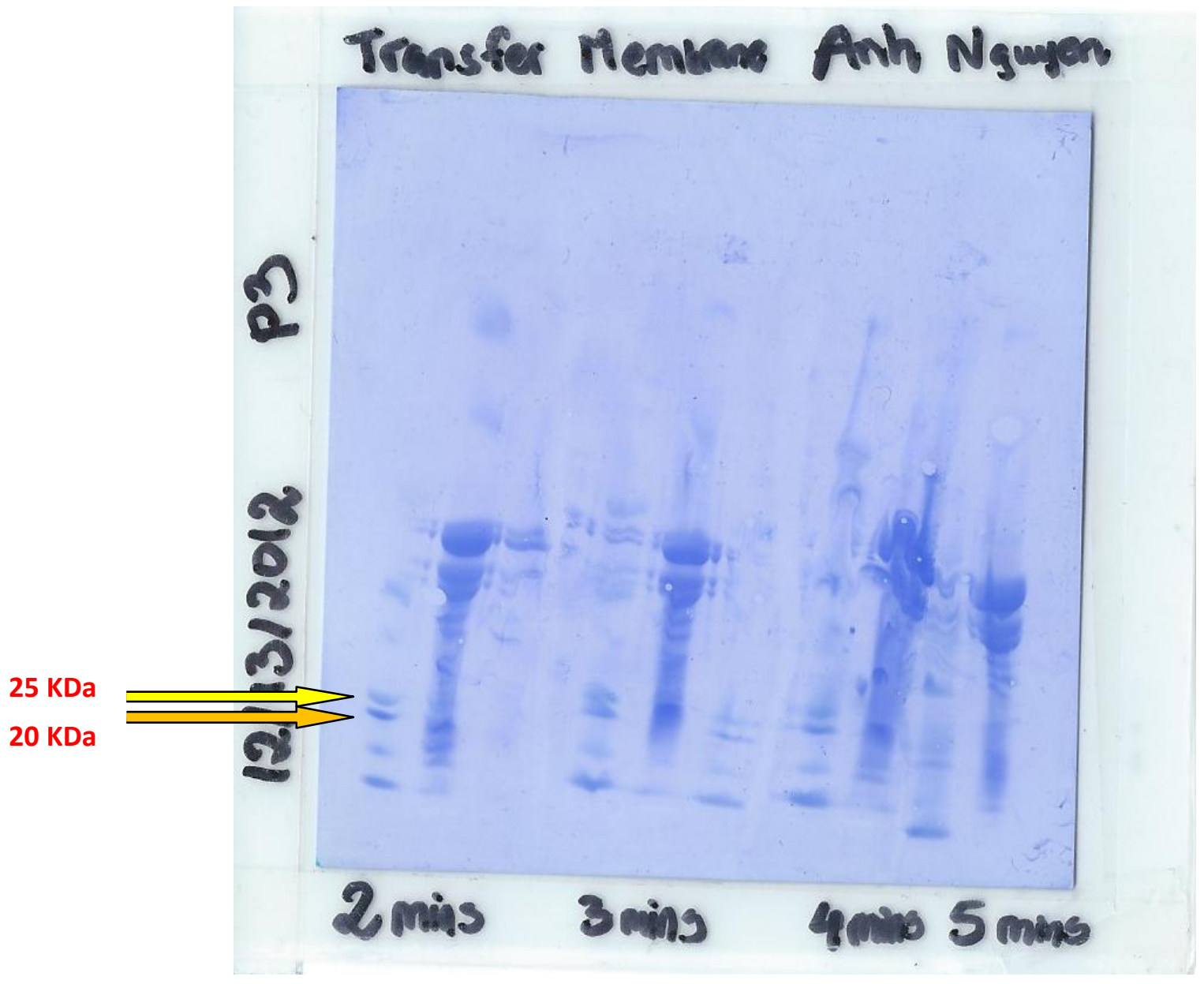

Figure 3.2: Proteins were transferred from Gel to PVDF Membrane in 2, 3, 4 and 5 Minutes 


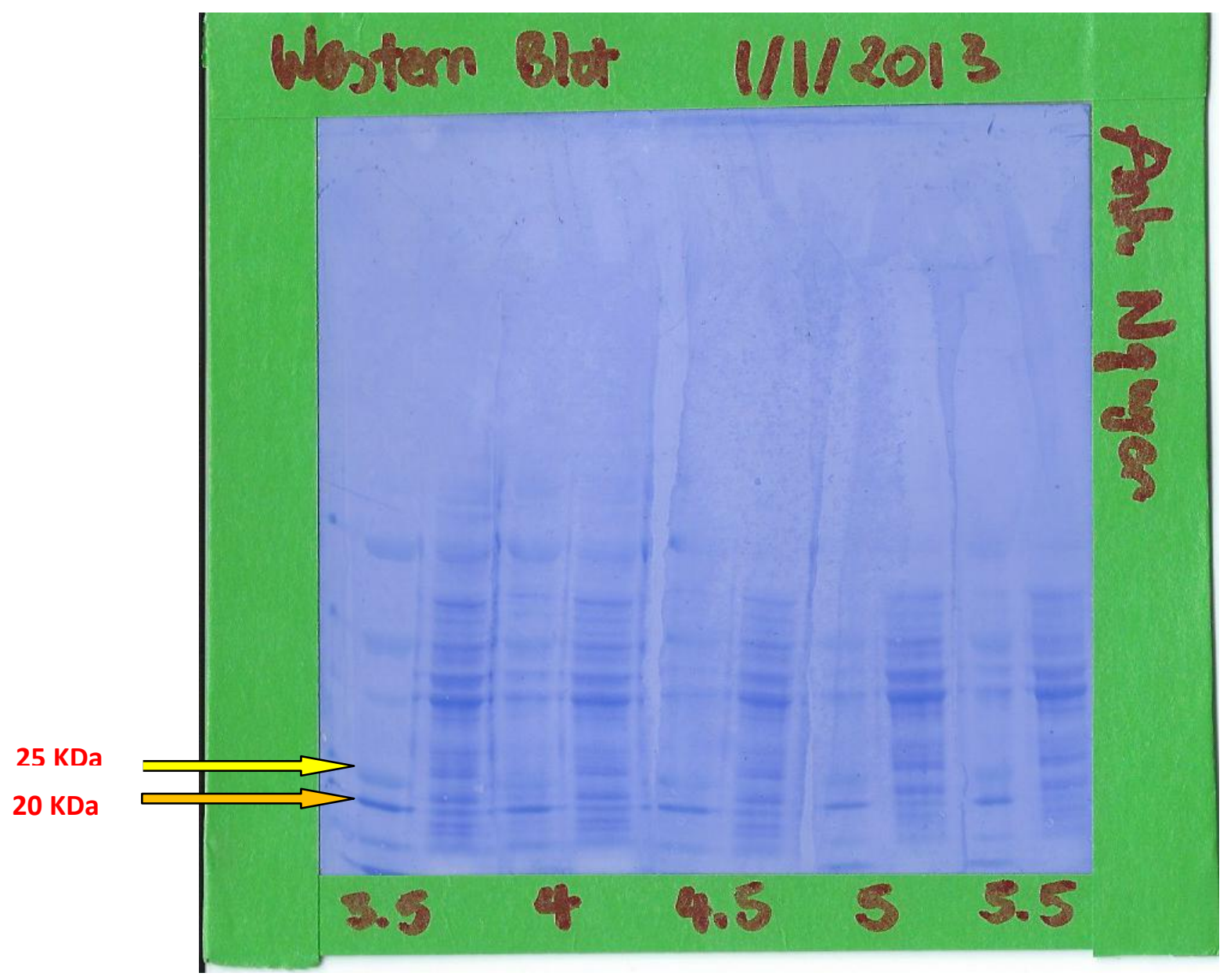

Figure 3.3: Proteins were Transferred from Gel to PVDF Membrane in 3.5, 4, 4.5, 5, and

\subsection{Minutes}

Proteins p21 were expected to appear between the 20 and 25 KDa markers. Based on the PVDF membranes in Figures 3.2 and 3.3 above, the transferring times 3.5 minutes and 4.5 minutes gave very strong proteins bands between the 20 and 25 KDa markers. Therefore, these 2 transferring times were chosen to test for the detection of $\mathrm{p} 21$ proteins using $\mathrm{p} 21$ antibody proteins. The results were shown in Figures 3.4 and 3.5 below. Figure 3.4 showed the proteins bands on the membrane after the membrane after the proteins were transferred from gel to membrane in 3.5 minutes. Figure 3.5 showed the proteins bands on the membranes after the proteins were transferred from gel to membrane in 4.5 minutes. 


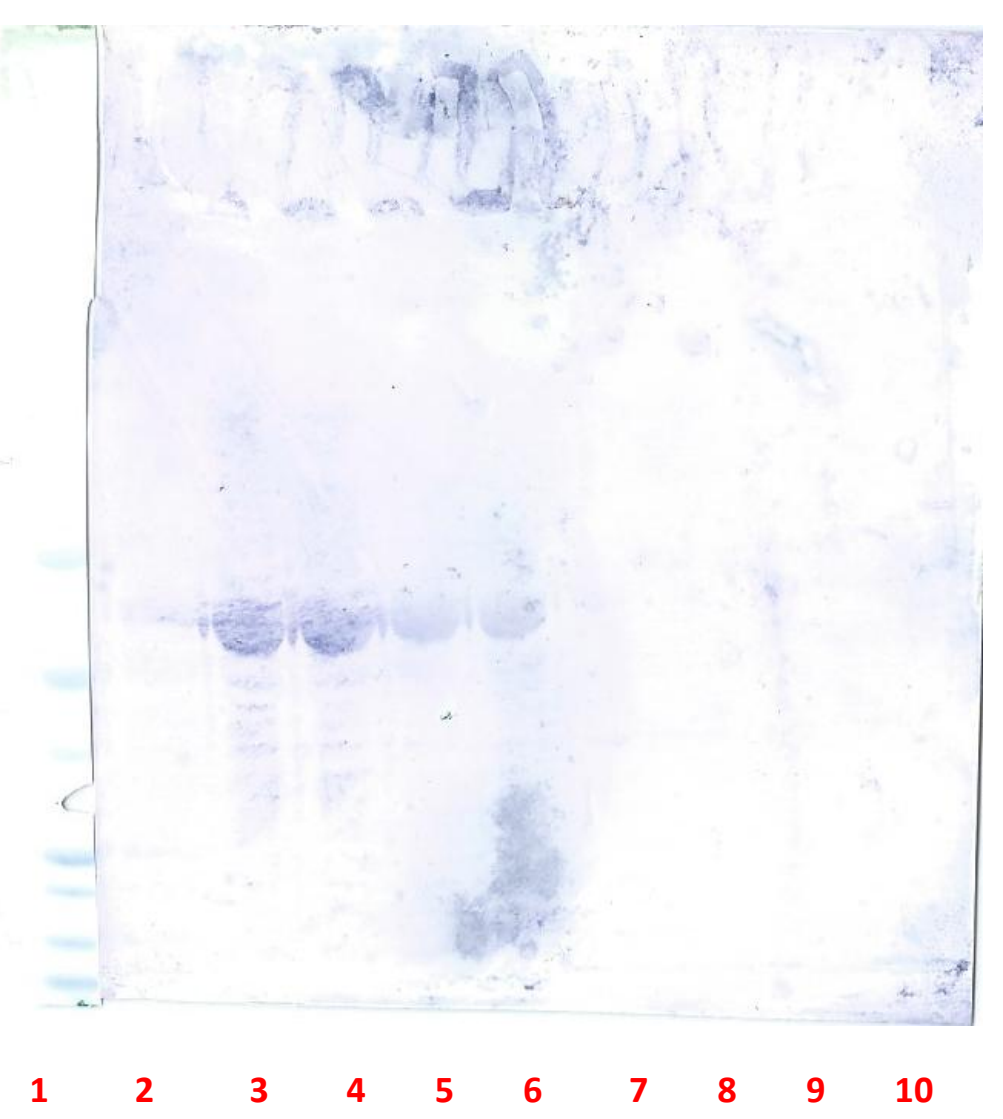

Figure 3.4: Proteins were Transferred from Gel to PVDF Membrane in 3.5 Minutes and p21 Signals were Detected

\begin{tabular}{|c|c|c|c|c|c|c|c|c|c|c|}
\hline Lane & 1 & 2 & 3 & 4 & 5 & 6 & 7 & 8 & 9 & 10 \\
\hline Sample & MW & HELA & UV \#1 & UV \#1 & $\begin{array}{c}\text { NO UV } \\
\quad \# 1\end{array}$ & $\begin{array}{c}\text { NO UV } \\
\quad \# 1\end{array}$ & UV \#2 & UV \#2 & $\begin{array}{c}\text { NO UV } \\
\# 2\end{array}$ & $\begin{array}{c}\text { NO UV } \\
\# 2\end{array}$ \\
\hline $\begin{array}{c}\text { Transferring } \\
\text { Time (minutes) }\end{array}$ & 3 & 3 & 3 & 3 & 3 & 3 & 3 & 3 & 3 & 3 \\
\hline [Protein] $(\mu \mathrm{g} / \mathrm{mL})$ & N/A & 2000 & 13086 & 13086 & 13086 & 13086 & 2703 & 2703 & 2703 & 2703 \\
\hline $\begin{array}{l}\text { Amount of } \\
\text { Protein }(\mu \mathrm{g})\end{array}$ & N/A & 20 & 131 & 131 & 131 & 131 & 54 & 54 & 54 & 54 \\
\hline
\end{tabular}




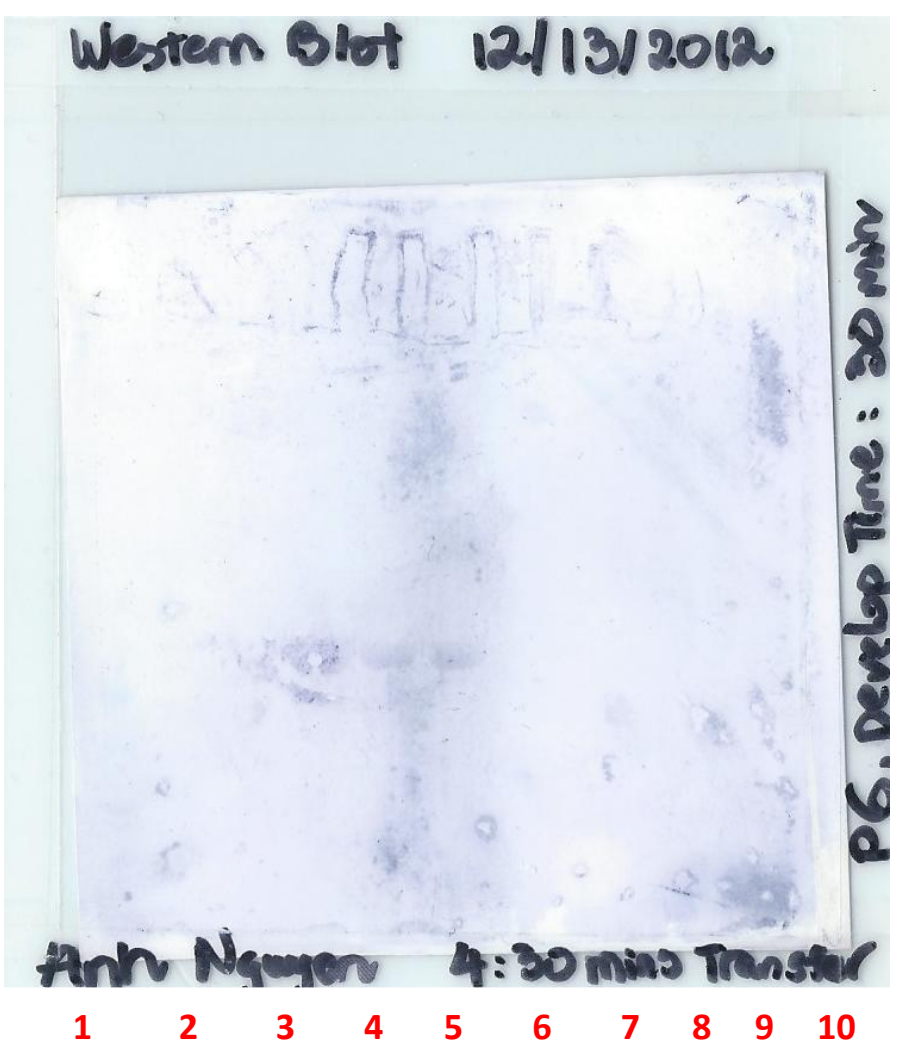

Figure 3.5: Proteins were Transferred from Gel to PVDF Membrane in 4.5 Minutes and p21 Signals were Detected

\begin{tabular}{|c|c|c|c|c|c|c|c|c|c|c|}
\hline Lane & 1 & 2 & 3 & 4 & 5 & 6 & 7 & 8 & 9 & 10 \\
\hline Sample & MW & HELA & UV \#1 & UV \#1 & $\begin{array}{c}\text { NO UV } \\
\# 1\end{array}$ & $\begin{array}{c}\text { NO UV } \\
\quad \# 1\end{array}$ & UV \#2 & UV \#2 & $\begin{array}{c}\text { NO UV } \\
\quad \# 2\end{array}$ & $\begin{array}{c}\text { NO UV } \\
\quad \# 2\end{array}$ \\
\hline $\begin{array}{c}\text { Transferring } \\
\text { Time (minutes) }\end{array}$ & 4.5 & 4.5 & 4.5 & 4.5 & 4.5 & 4.5 & 4.5 & 4.5 & 4.5 & 4.5 \\
\hline [Protein] $(\mu \mathrm{g} / \mathrm{mL})$ & N/A & 2000 & 13086 & 13086 & 13086 & 13086 & 2703 & 2703 & 2703 & 2703 \\
\hline $\begin{array}{l}\text { Amount of } \\
\text { Protein }(\mu \mathrm{g})\end{array}$ & N/A & 20 & 131 & 131 & 131 & 131 & 54 & 54 & 54 & 54 \\
\hline
\end{tabular}


Based on the results in Figure 3.4, when transferring proteins from gel to PVDF membrane in 3.5 minutes, the p21 signals were obtained very clearly. The UV samples (lanes 34) also showed a significant increase in p21 signals compared with the No UV samples (lanes 56) as expected. Therefore, the optimal transferring time was determined to be 3.5 minutes using the P3 program on the iBlot Dry Blotting System.

\subsubsection{Second Experiment Parameter: Primary and Secondary Antibody Concentration}

It is important to optimize the primary and secondary antibody concentration to produce the best possible signals. If too little antibodies were used, the p21 signals may be too faint. If too much antibodies were used, it may result in non-specific binding of antibodies. Therefore, an antibody titration experiment Dot blot was performed to determine the optimal concentration of antibody. Two micro litters of proteins from HELA sample were placed as dots on the PVDF membranes as dots and different combination of primary and secondary antibodies were tested on each dot. The p21 primary antibody used was the p21 rabbit polyclonal antibody from GeneTex (catalog \# GTX27960). The p21 primary antibody was mixed with the antibody diluents mix from Invitrogen iBlot Western Detection Kit. The secondary antibody used was anti-rabbit antibodies and were provided with the Invitrogen iBlot Western Detection Kit. The secondary antibody was also mixed with the antibody diluents mix from the Invitrogen kit. After adding the antibodies, the membrane was developed using the chromogenic solution from Invitrogen iBlot Western Detection Kit. Different combinations of primary and secondary antibodies were tested and the membrane strips were shown as in the Figure 3.6 below. 

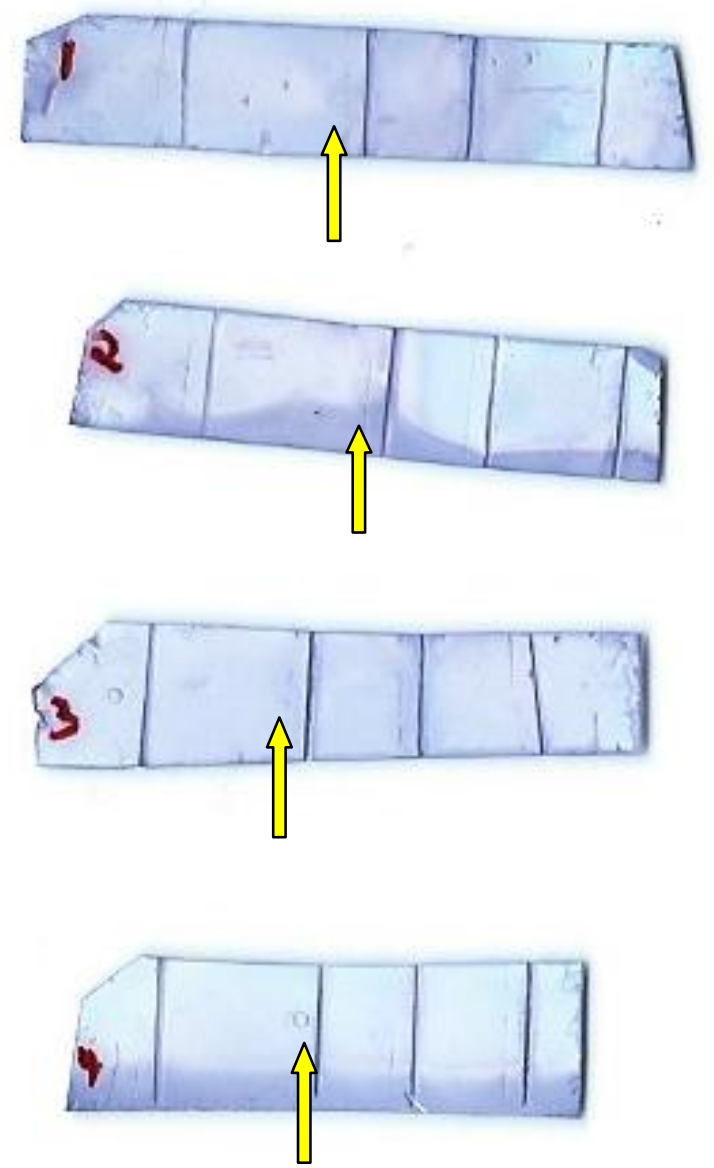

Figure 3.6: Antibody Titration on Dot Blot Membrane

\begin{tabular}{|c|c|c|c|c|}
\hline Membrane Strip & 1 & 2 & 3 & 4 \\
\hline Primary Antibody & $1: 100$ & $1: 200$ & $1: 300$ & $1: 400$ \\
\hline Second Antibody & $1: 1000$ & $1: 1000$ & $1: 1000$ & $1: 1000$ \\
\hline
\end{tabular}


From the antibody titration results as shown in Figure 3.6, it was determined that the combination of 1:200 primary antibody and 1:1000 secondary antibody would give the best p21 signals on a PVDF membrane (strip 2). Therefore, in the final Western blot protocol, this combination of antibodies concentrations were used to detect $\mathrm{p} 21$ proteins among different samples.

\subsubsection{Third Experiment Parameter: Developing Time}

After the primary and secondary antibodies were added to the PVDF membrane, p21 proteins were still not visible until the chromogenic solution was added to the membrane. The enzymes on the secondary antibodies react with the substrates in the chromogenic solution and form visible bands on the membrane. The period during which the PVDF membrane was incubated with the chromogenic solution is called the developing time. If the developing time is too short, the p21 signals may be very faint. If the developing time is too long, it may result in a high back ground noise, which in turn makes it harder to recognize the signals and compare the signals among different treatments. Different developing time periods were tested. These include 15 minutes, 30 minutes and 60 minutes (1 hour). The results are shown in Figures 3.7, 3.8, 3.9 below. Based on the results in Figure 3.8, developing time 30 minutes showed the best p21 signals with a minimal background noise on the PVDF membrane. Therefore, developing time 30 minutes was implemented in the final Western blot protocol. 


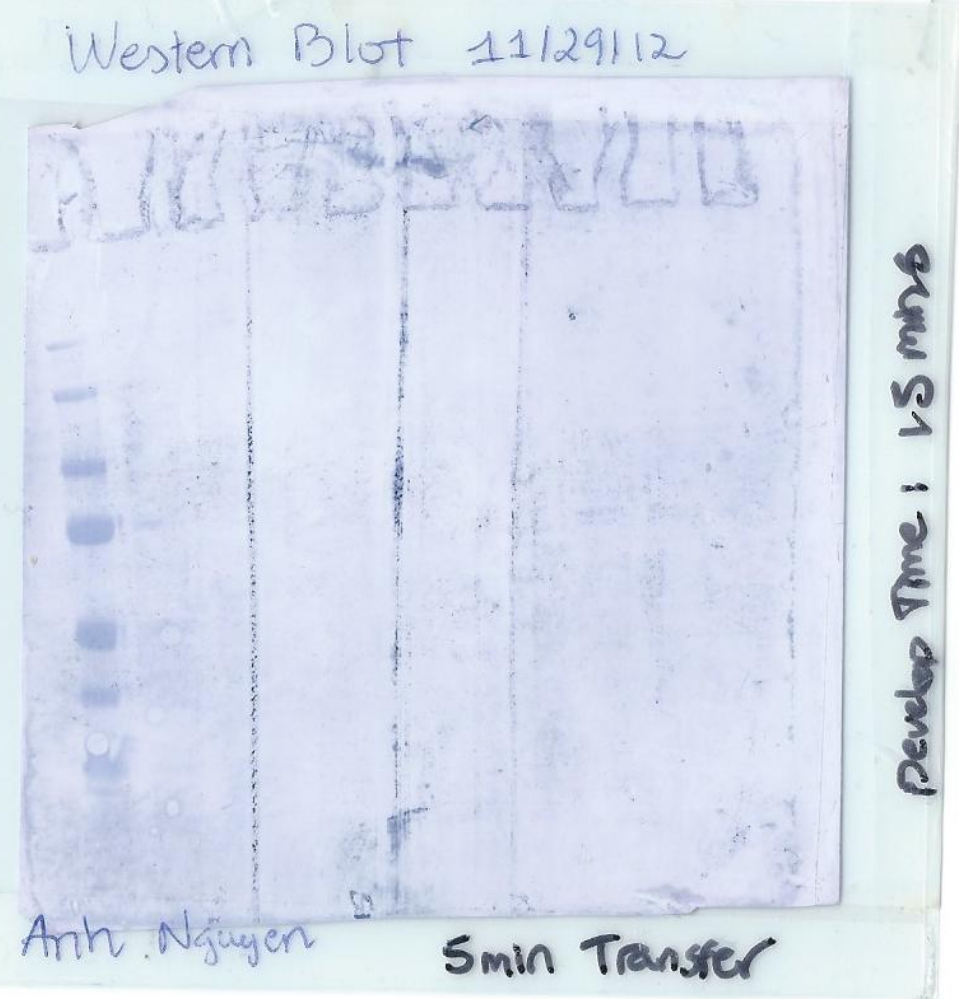

$\begin{array}{llllllllll}1 & 2 & 3 & 4 & 5 & 6 & 7 & 8 & 9 & 10\end{array}$

Figure 3.7: PVDF Membrane was Developed in 15 Minutes

\begin{tabular}{|c|c|c|c|c|c|c|c|c|c|c|c|}
\hline Lane & 1 & 2 & 3 & 4 & 5 & 6 & 7 & 8 & 9 & 10 \\
\hline Sample & MW & HELA & UV & UV & UV & UV & NO UV & NO UV & NO UV & BLANK \\
\hline $\begin{array}{c}\text { Developing Time } \\
\text { (minutes) }\end{array}$ & 15 & 15 & 15 & 15 & 15 & 15 & 15 & 15 & 15 & 15 \\
\hline
\end{tabular}




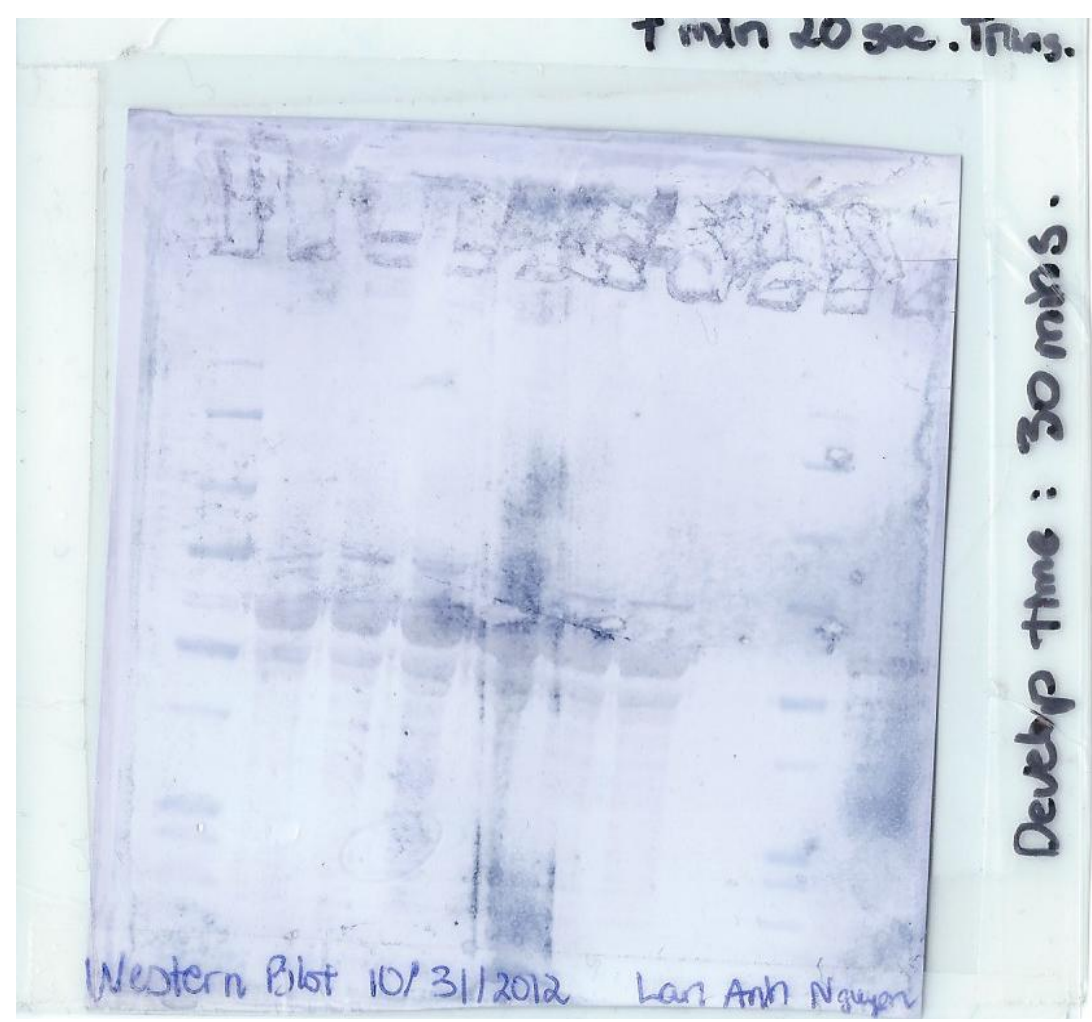

$$
\begin{array}{llllllllll}
1 & 2 & 3 & 4 & 5 & 6 & 7 & 8 & 9 & 10
\end{array}
$$

Figure 3.8: PVDF Membrane was Developed in 30 Minutes

\begin{tabular}{|c|c|c|c|c|c|c|c|c|c|c|c|}
\hline Lane & 1 & 2 & 3 & 4 & 5 & 6 & 7 & 8 & 9 \\
\hline Sample & MW & UV & No UV & UV & No UV & UV & NO UV & UV & NO UV & MW \\
\hline $\begin{array}{c}\text { Developing Time } \\
\text { (minutes) }\end{array}$ & $\mathbf{3 0}$ & $\mathbf{3 0}$ & $\mathbf{3 0}$ & $\mathbf{3 0}$ & $\mathbf{3 0}$ & $\mathbf{3 0}$ & $\mathbf{3 0}$ & $\mathbf{3 0}$ & $\mathbf{3 0}$ & $\mathbf{3 0}$ \\
& & & & & & & & & & \\
\hline
\end{tabular}




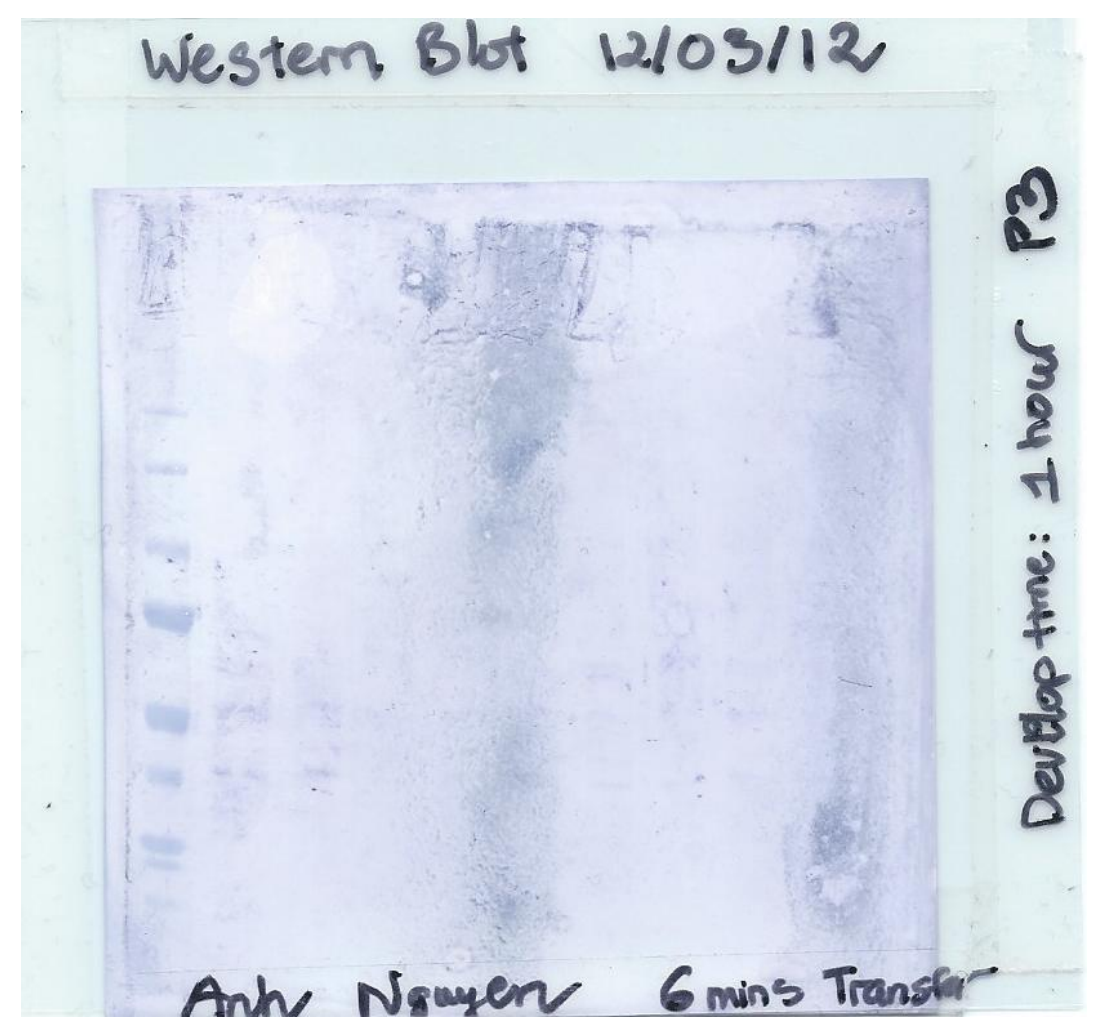

$\begin{array}{llllllllll}1 & 2 & 3 & 4 & 5 & 6 & 7 & 8 & 9 & 10\end{array}$

Figure 3.9: PVDF Membrane was Developed in 60 Minutes

\begin{tabular}{|c|c|c|c|c|c|c|c|c|c|c|c|c|c|}
\hline Lane & 1 & 2 & 3 & 4 & 5 & 6 & 7 & 8 & 9 & 10 \\
\hline Sample & MW & HELA & UV & UV & UV & UV & NO UV & NO UV & NO UV & NO UV \\
\hline $\begin{array}{c}\text { Developing Time } \\
\text { (minutes) }\end{array}$ & 60 & 60 & 60 & 60 & 60 & 60 & 60 & 60 & 60 & 60 \\
\hline
\end{tabular}




\section{Chapter 4: Methods}

4.1. Overview of the Experiment Process

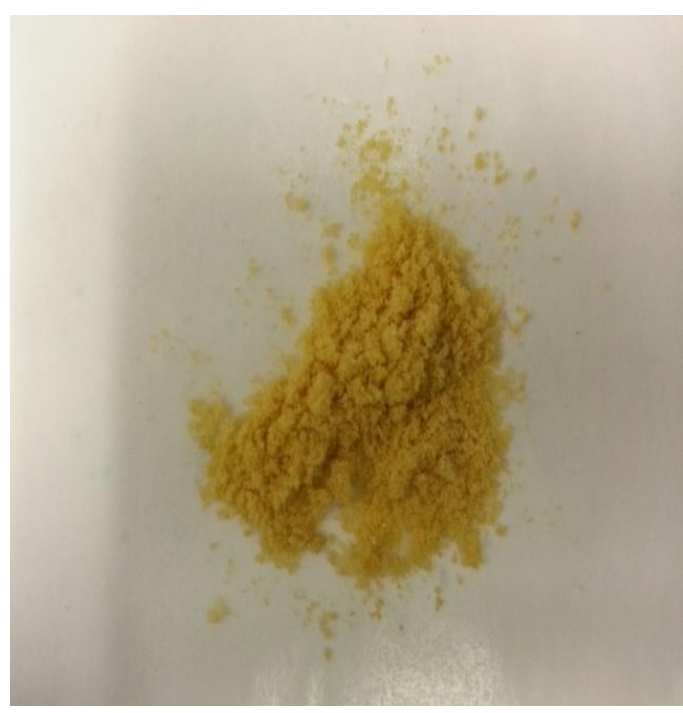

Step 1: Prepare Cell Media that contains $1 \%$ milk phospholipids concentrate

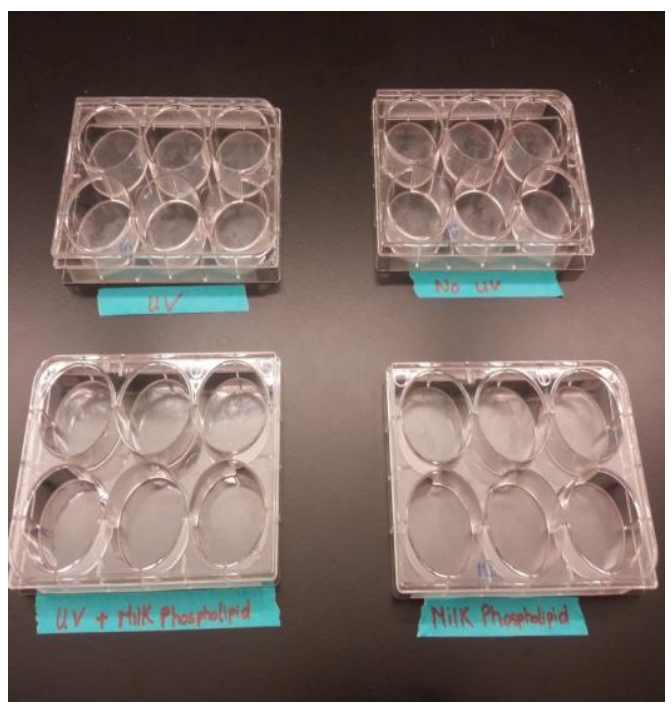

Step 2: Skin Cells were grown in four 6-well Plates

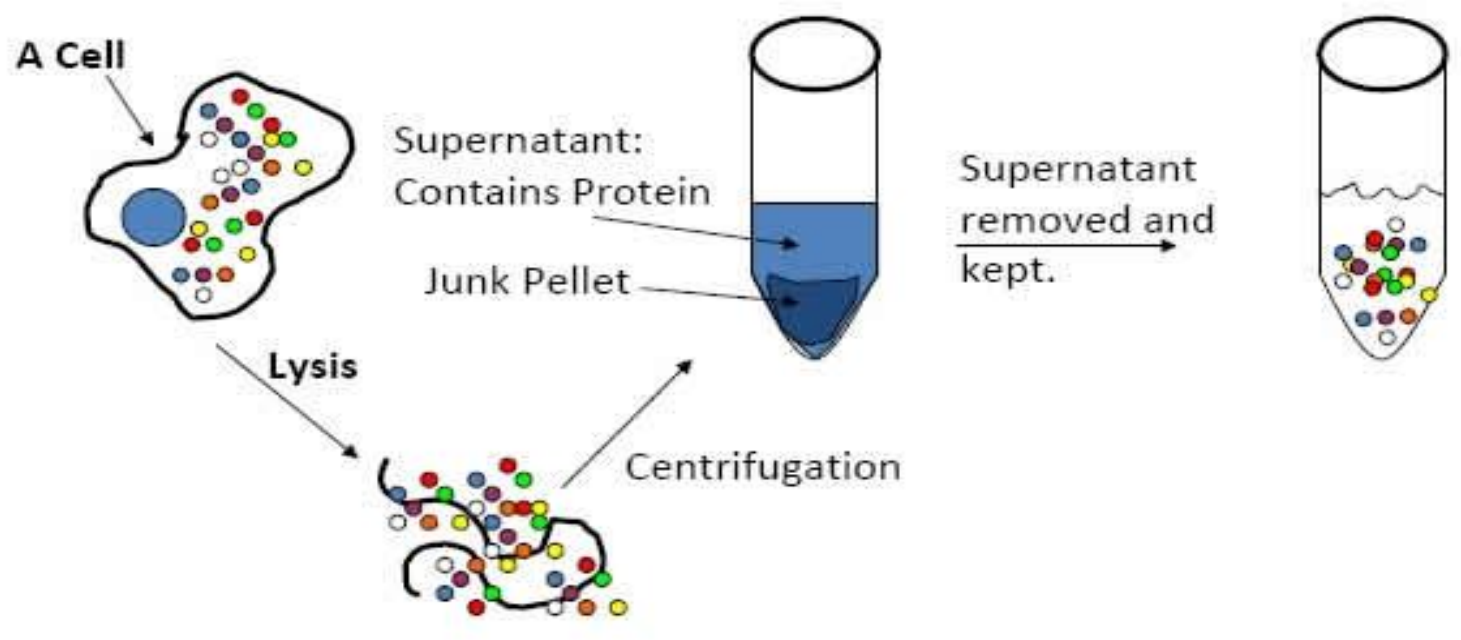

Step 3: Total Cells Proteins were extracted 


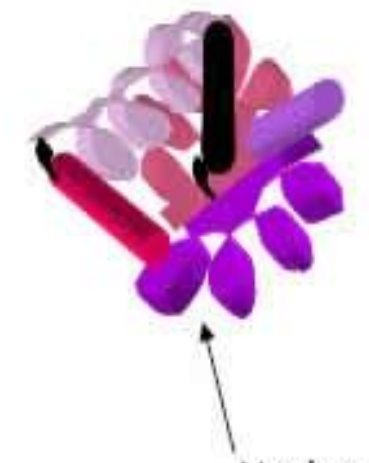

Native Protein
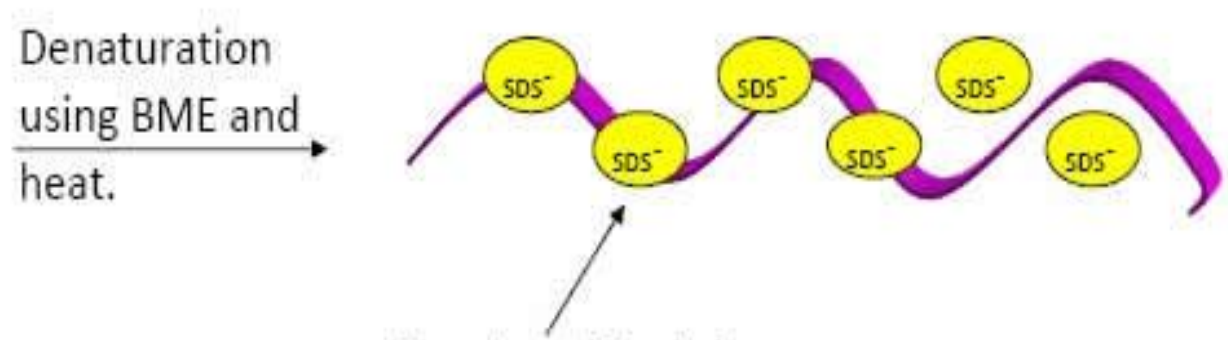

(Folded form)

Denatured Protein

(Unfolded form)

Step 4: Cell Proteins were denatured by SDS detergent

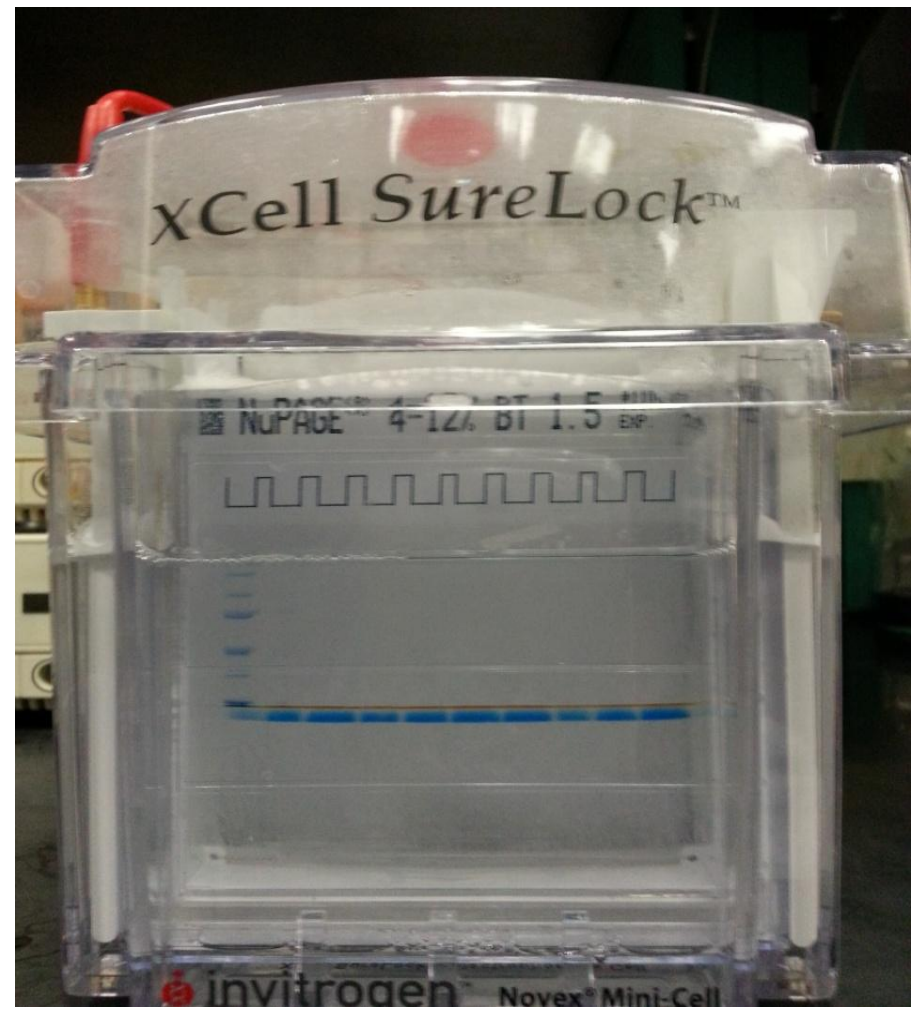

Step 5: Proteins were separated by Their Sizes 


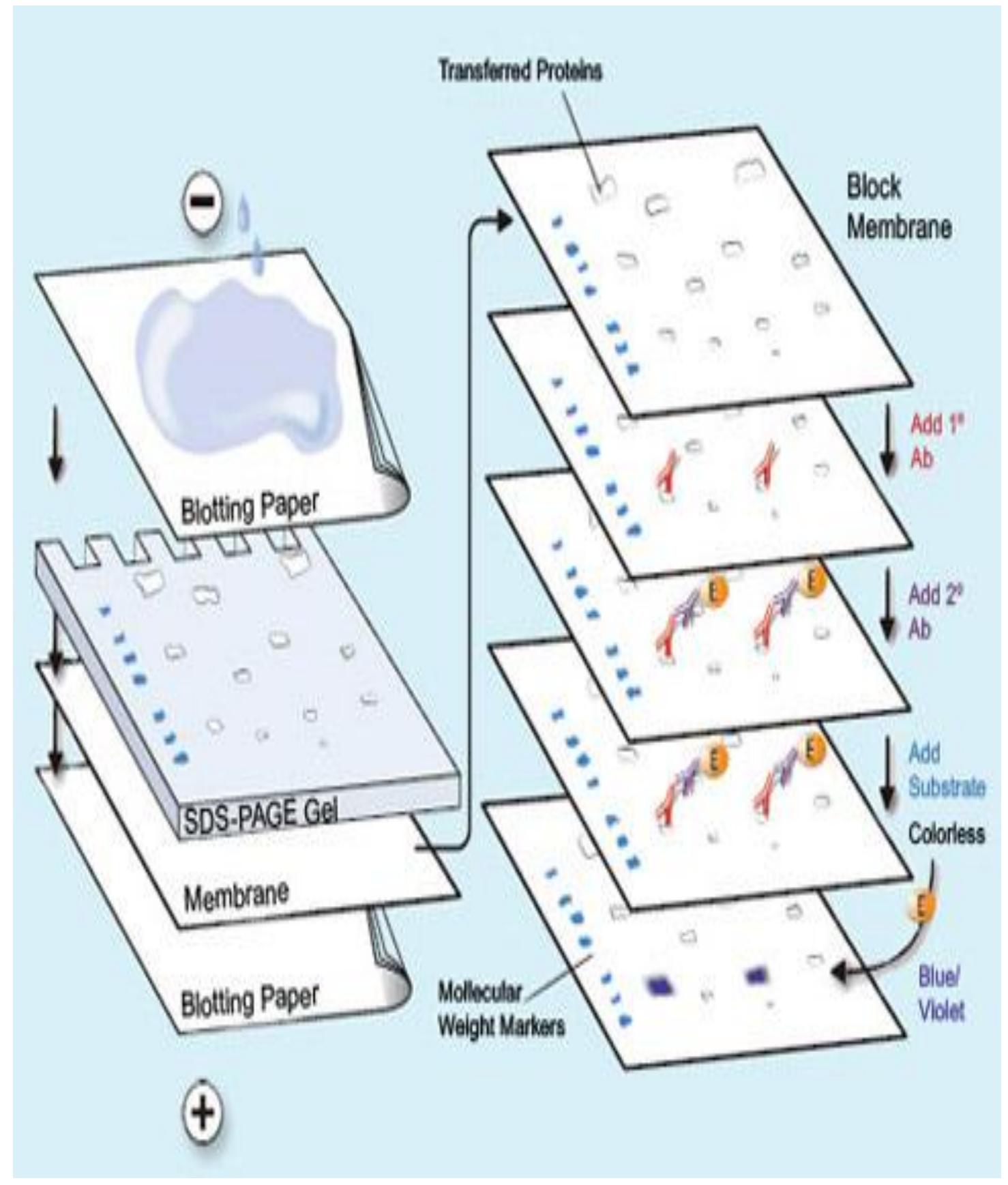

Step 6: Antibodies was used to detect protein p21 and ImageJ software was used to analyze the p21 signals

Figure 4.1: Overview of Western Blot Assay (KOMABIOTECH 2014) 


\subsection{Milk Phospholipids Preparation}

Milk phospholipids concentrate (PC-700, Fonterra Limited, Edgecumbe, New Zealand) was tested in this study. This mixture contains complex phospholipids with high levels of sphingomyelin extracted from bovine's milk fat globule membrane and concentrated at levels 5000 times higher than that normally found in milk. The milk phospholipids powder was shown in Figure 4.2 below. A solution of $1 \%(\mathrm{w} / \mathrm{v})$ of milk phospholipids was prepared by mixing 0.5 $\mathrm{g}$ of the milk phospholipids powders into $50 \mathrm{~mL}$ of the cell culture maintainance media (EPI100-NMM, MatTeK Corporation, Ashland, MA) in a conical tube. After that, the tube was put into a $55^{\circ} \mathrm{C}$ water bath for about 20 minutes until all the solids are completely dissolved. The solution was then filtered 2 times using a $10 \mathrm{cc}$ syringe and $0.45 \mu \mathrm{m}, 0.2 \mu \mathrm{m}$ syringe filters.

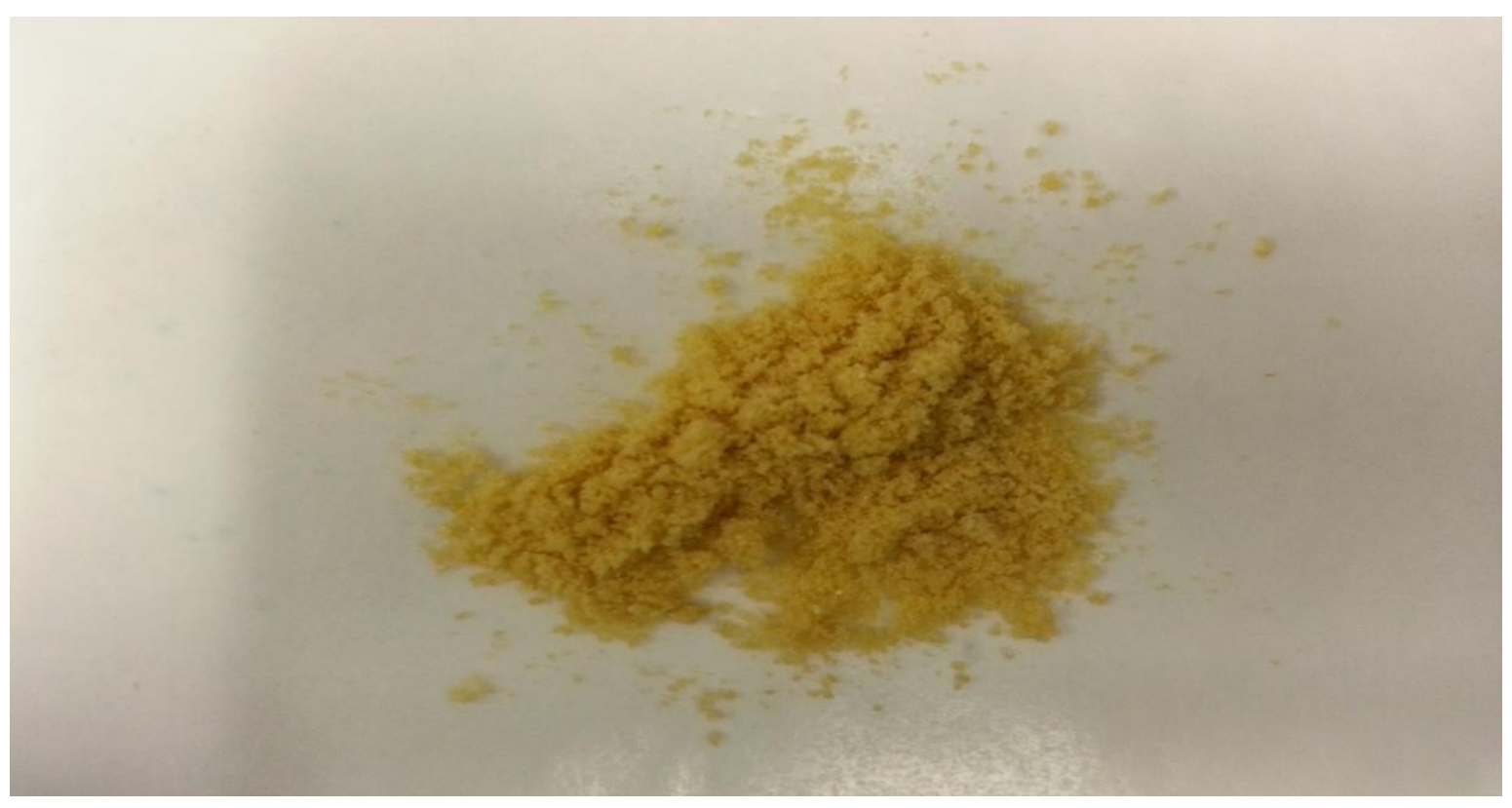

Figure 4.2: Milk Phospholipids Powder 


\subsection{Samples Preparation and Incubation}

In this study, human skin cells keratinocytes were purchased from and used in the experiments. Keratinocytes cells were grown in a $37^{\circ} \mathrm{C}, 5 \% \mathrm{CO}_{2}$ incubator and reached $90 \%$ confluent in four 6-well plates. The four 6-well plates were labeled as No UV, UV, MP + UV, and MP as shown in Figure 4.3. The No UV plate contains cell samples that will not be treated with UV light. The UV plate contains cell samples that will be exposed to UV light. The MP + UV plate contains cell samples that will be treated with milk phospholipids for 24 hours first then exposed to UV light. The MP plate contains cells that will be treated with milk phospholipids for 24 hours. First, the MP+UV and MP plates were taken out of the incubator and placed in the sterile laminar hood. The cell media solutions were removed from all wells of these 2 plates. Then, $1.5 \mathrm{~mL}$ of the $1 \%$ milk phospholipids solution was added to each well. After that, the 2 plates were brought back and incubated in the $37^{\circ} \mathrm{C}, 5 \% \mathrm{CO}_{2}$ incubator for 24 hours.

After 24 hours of incubation, the UV and MP+UV plates were transported from the incubator to the sterile hood for UV treatment. The UV lamp UVP EL Series, UVL-28 Lamp (UVP, LLC, Upland, CA) was disinfected with $70 \%$ ethanol then transported inside the hood and warmed up by turning the power to the setting $302 \mathrm{~nm}$ for 10 minutes. The UV detector ThorLabs Optical Power Meter (Thorlabs, Newton, NJ) used to measure the UV wattage reading from the UV lamp was also disinfected and brought inside the sterile hood. The exposure time for a $10 \mathrm{~mJ} / \mathrm{cm}^{2} \mathrm{UV}$ dosage was calculated using the area of the detector $0.7088 \mathrm{~cm}^{2}$ and the average wattage reading $0.242 \mathrm{~mJ} / \mathrm{s}$. The exposure time was calculated using the following formula.

$$
\begin{aligned}
\text { Exposure Time } & =(\text { Desired Dose })(\text { Area of Detector }) /(\text { Average wattage }) \\
& =\left(10 \mathrm{~mJ} / \mathrm{cm}^{2}\right)\left(0.7088 \mathrm{~cm}^{2}\right) /(0.242 \mathrm{~mJ} / \mathrm{s})=29(\text { seconds })
\end{aligned}
$$


After UV exposure, both plates UV and MP+UV were transported back to the $37^{\circ} \mathrm{C}, 5 \% \mathrm{CO}_{2}$ incubator immediately and incubated for 24 hours. The No UV plate contained cells that were not exposed to UV and the MP contained cells that were treated with $1 \%$ milk phospholipids were also incubated in the incubator for another 24 hours.

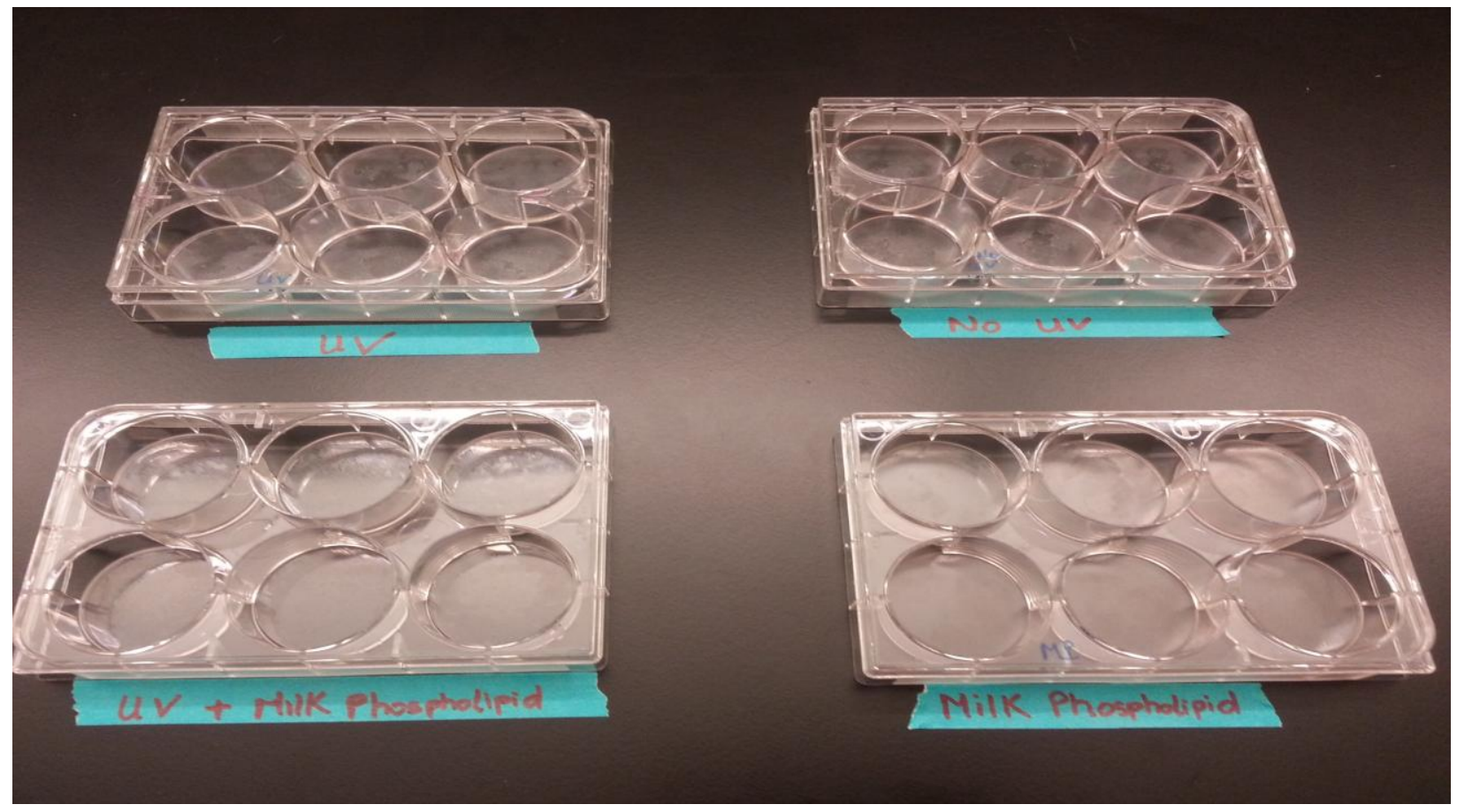

Figure 4.3: Four 6-Well Plates Containing Human Keratinocytes Under Different Treatments-UV, NO UV, Milk Phospholipid+UV, and Milk Phospholipid

\subsection{Total Cells Protein Extraction Using SDS Lysis Buffer}

The next step in the experiment is to extract all proteins from cells. After 24 hours of incubation, all 4 plates were taken out of the incubator and the cell media was taken out of all wells. Each plate was then washed with PBS one time. A $0.1 \%$ SDS (w/v) lysis buffer was prepared freshly according to the recipe in the appendix. Then, $100 \mu \mathrm{L}$ of lysis buffer is added to each well. The keratinocyte cells from 4 plates No UV, UV, MP+UV and MP were then scrapped off from the wells and transferred to four different $1.5 \mathrm{~mL}$ centrifuge tubes. The 4 
centrifuged tubes were kept on ice at all times. After that, 4 tubes containing cells were put on an orbital shaker for 30 minutes. Then, the 4 tubes were centrifuged at 12,000 RPM for 30 minutes in a $4^{0} \mathrm{C}$ cold room. The centrifugation process separated the proteins from other cell debris. After the centrifugation process, total cells proteins were present at the top of the centrifuged tubes, in the supernatant. The cell debris parts were at the bottom of the centrifuge tubes, in the white pellet. After 30 minutes centrifuged, the supernatants were removed and kept in 4 new centrifuge tubes as shown in Figure 4.4 below.

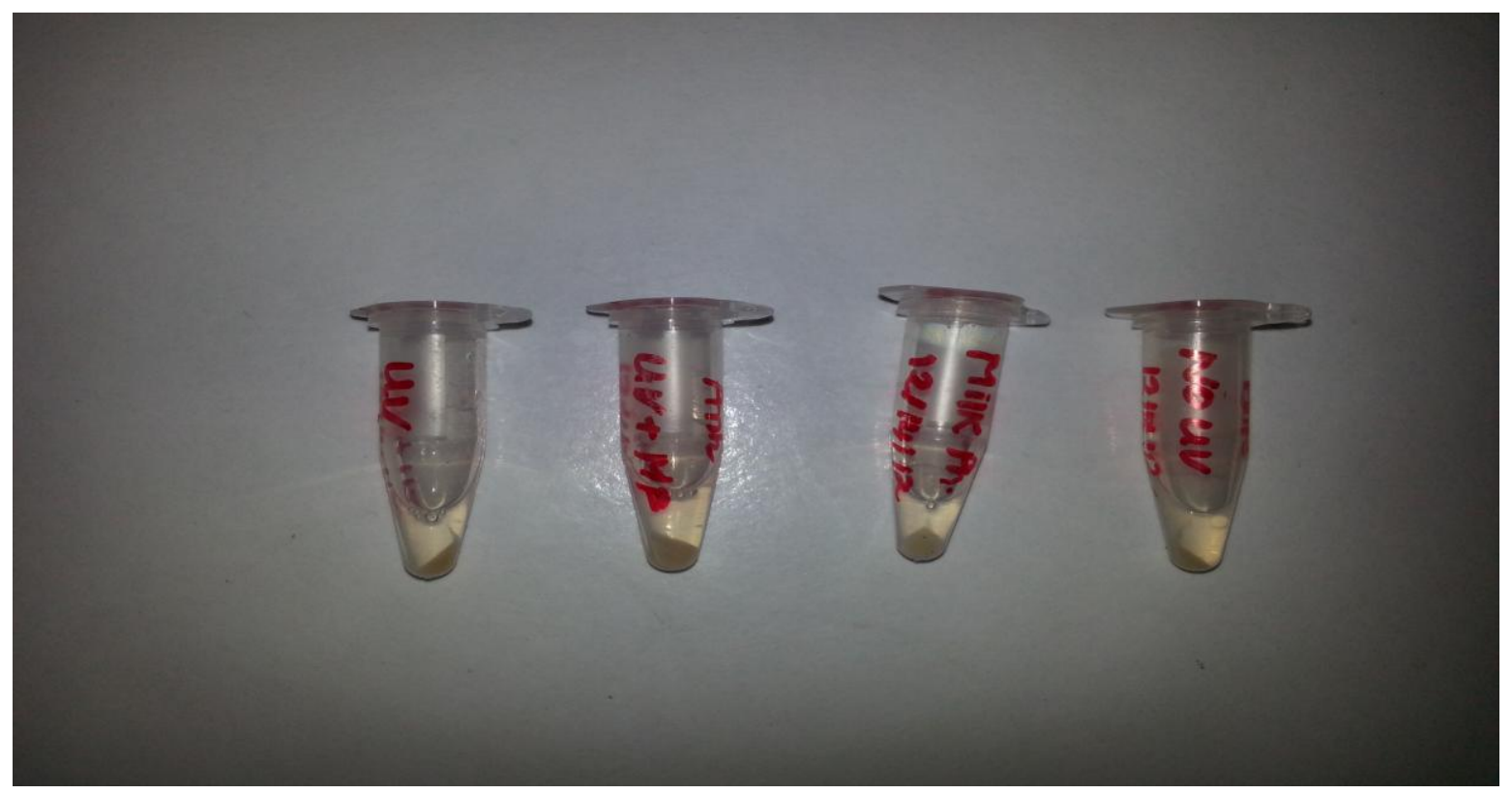

Figure 4.4: Four Centrifuge Tubes Containing Extracted Proteins in the Supernatant and Cell Debris in the Pellet

\subsection{Quantification of Total Cell Protein Concentration Using BCA Assay}

BCA assay, also known as Bicinchoninic Acid Assay, is a very common technique used to measure the protein concentration in different samples. The BCA assay involves measuring the absorbance at $562 \mathrm{~nm}$ of a series of known protein concentrations. Then, a standard linear 
curve illustrating the relationship between proteins' absorbance at $562 \mathrm{~nm}$ and protein concentrations is generated. The unknown concentration of the sample protein is determined by interpolating from the standard linear curve that was constructed previously. In this experiment, the BCA assay was employed to quantify protein concentration of total proteins extracted from 4 different samples No UV, UV, MP+UV and MP. The BCA method was adapted from the Pierce Microplate BCA Assay Kit - Reducing Agent Compatible (Pierce). In order to minimize the amount of sample proteins needed for this assay, the protein assay was performed on a 96-well microplate. First, a series of known concentration of BSA (Bovine Serum Albumin) proteins was prepared from the stock BSA solution $2 \mathrm{mg} / \mathrm{mL}$ as in Table 4.1 .

\begin{tabular}{|cccc|}
\hline Vial & PBS volume $(\mu \mathrm{L})$ & BSA source $(\mu \mathrm{L})$ & Concentration $(\mu \mathrm{g} / \mathrm{mL})$ \\
\hline A & 0 & 200 of Stock & 2000 \\
\hline B & 66 & 200 of Stock & 1500 \\
\hline C & 100 & 100 of Vial A & 1000 \\
\hline D & 100 & 100 of Vial B & 750 \\
\hline E & 100 & 100 of Vial C & 500 \\
\hline F & 100 & 100 of Vial D & 250 \\
\hline G & 100 & 100 of Vial F & 125 \\
\hline
\end{tabular}

Table 4.1: Protein Standard Samples in the BCA Assay 
After the preparation of different concentrations of BSA samples, the BCA working reagent was prepared using the following formula.

Working Reagent $=(\#$ controls $+\#$ standards $+\#$ unknowns $) \times(2$ replicates $) \times(0.26 \mathrm{~mL})$

In this experiment, the volume of the working reagent was calculated as the following.

\section{Working Reagent $=(2$ controls +7 standards +16 uknowns $) \times(2$ replicates $) \times(0.26 \mathrm{~mL})$ $=17.68 \mathrm{~mL}$}

The working reagent is made by mixing Reagent A and Reagent B (included in the Pierce BCA Assay Kit) according to the 50:1 ratio. Therefore, $18627 \mu \mathrm{L}$ of reagent A was mixed with 373 $\mu \mathrm{L}$ of reagent B to yield $19000 \mathrm{uL}$ or $19 \mathrm{~mL}$ of working reagent with a clear green color. The next step is to prepare a series of different dilutions 1:10, 1:15, 1:20 and 1:30 of 4 unknown protein samples: No UV, UV, MP+UV and MP. After that, $9 \mu \mathrm{L}$ of each replicate of the BSA standards, unknown samples, and the control PBS samples was added to the center of each well in the 96-well microplate. Then, $260 \mu \mathrm{L}$ of the working reagent was added to each well. The 96well microplate was then covered with a plastic wrap and incubated in a $37^{\circ} \mathrm{C}$ incubator for 30 minutes. After the incubation time, the plate was cooled down at room temperature for 5 minutes. The absorbance of different protein samples in the plate was now ready to be read by the SPECTRAmax PLUS384 UV/Vis spectrophotometer (Molecular Devices, Sunnyvale, CA). The spectrophotometer was turned on and warmed up for 15 minutes before; the wavelength was also set to $562 \mathrm{~nm}$. The 96-well microplate was put inside the plate holder then the absorbance of protein samples at $562 \mathrm{~nm}$ was measured by selecting the "Read Plate" button on the computer software. The absorbance at $562 \mathrm{~nm}$ of all the protein samples in the plate was then displayed on the computer screen. The readings of a series of known concentration of BSA were used to create a linear standard curve with y corresponds to the absorbance at $562 \mathrm{~nm}$, and x corresponds 
to the protein concentration in $\mu \mathrm{g} / \mathrm{mL}$. An equation illustrating the relationship between absorbance and concentration in the form of $y=a x+b$ was obtained from the standard curve. The concentration of the unknown protein sample was calculated by plugging the absorbance value into $\mathrm{y}$ to find the concentration $\mathrm{x}$.

\subsection{Sodium Dodecyl Sulfate Polyacrylamide (SDS-PAGE) Gel Electrophoresis}

The SDS-PAGE gel is commonly used to separate proteins based on their molecular weights. In this experiment, a commercial pre-cast gel, Invitrogen NuPAGE Novex 4-12\% BisTris gel, catalog \# NP0335BOX, was used. First, the white tape at the bottom of the pre-cast NuPAGE gel cassette was removed and the cassette was inserted into the Invitrogen XCell SureLock ${ }^{\mathrm{TM}}$ Mini-Cell Electrophoresis, catalog \# EI0001 (Invitrogen). The tank was then filled with running buffer (recipe in the Appendix) up to the fill line. After setting up the gel apparatus, the next step was to prepare protein samples before loading into the gel. From the BSA protein assay, the unknown concentrations of different protein samples were determined. The UV sample had a concentration of $4176 \mu \mathrm{g} / \mathrm{mL}$, the No UV sample had a concentration of 9484 $\mu \mathrm{g} / \mathrm{mL}$, the MP + UV sample had a concentration of $13663 \mu \mathrm{g} / \mathrm{mL}$ and the MP sample had a concentration of $10759 \mu \mathrm{g} / \mathrm{mL}$. To compare the expression of p21 proteins, the same amount of protein $145 \mu \mathrm{g}$ from each sample would be loaded into each well as in the following table. Before loading the samples into the gel, the samples were mixed with NuPAGE LDS sample buffer (4X) and distilled water according to the recommendation in Table. Then samples were put into a $90^{\circ} \mathrm{C}$ bath for 10 minutes, so that the native globular structures of proteins would be denatured into linear structures. Once all proteins were denatured into linear molecules, they could be separated based on their size or molecular weights on a SDS-PAGE gel. Molecular 
weight marker (MW marker) contained 10 different proteins with known molecular weights. By comparing the mobility of these known 10 proteins in the MW marker, researchers could determine the molecular weight of the protein of interest. In this experiment, the Bio-Rad Precision Plus Protein Standards, catalog \# 161-0373, was used as the MW marker (Bio-Rad). The HELA (Human Epithelial Carcinoma Cell Line), Whole Cell Lysate from Abcam, catalog \# ab150035 was used as a positive control for p21 proteins (Abcam). The molecular weight marker and the protein samples were loaded into different lanes of the gel as shown in Table 4.2 below. Sample buffer and water were also added to the protein samples and loaded on the gel. Table 4.3 showed the amount of sample, sample buffer and water that were added into each lane of the gel.

\begin{tabular}{|c|c|c|c|c|c|c|c|c|c|c|}
\hline & $\begin{array}{c}\text { Lane } \\
1\end{array}$ & $\begin{array}{c}\text { Lane } \\
2\end{array}$ & $\begin{array}{c}\text { Lane } \\
\mathbf{3}\end{array}$ & $\begin{array}{c}\text { Lane } \\
4\end{array}$ & $\begin{array}{c}\text { Lane } \\
5\end{array}$ & $\begin{array}{l}\text { Lane } \\
6\end{array}$ & $\begin{array}{c}\text { Lane } \\
7\end{array}$ & $\begin{array}{c}\text { Lane } \\
8\end{array}$ & $\begin{array}{c}\text { Lane } \\
9\end{array}$ & $\begin{array}{c}\text { Lane } \\
10\end{array}$ \\
\hline Sample & $\begin{array}{c}\text { MW } \\
\text { marker }\end{array}$ & Blank & Blank & UV 4 & $\begin{array}{l}\text { No } \\
\text { UV } 4\end{array}$ & $\begin{array}{c}\mathrm{MP}+ \\
\mathrm{UV}\end{array}$ & MP & HELA & Blank & Blank \\
\hline Protein $(\mu \mathrm{L})$ & 10 & 0 & 0 & 35 & 15 & 11 & 14 & 10 & 0 & 0 \\
\hline
\end{tabular}

Table 4.2: Summary of Different Samples Loaded in the Gels

\begin{tabular}{|c|c|}
\hline Reagent & $\begin{array}{l}\text { Reduced Sample Volume } \\
(\mu \mathrm{L})^{*}\end{array}$ \\
\hline Sample & 10 \\
\hline $\begin{array}{c}\text { NuPAGE }^{\circledR} \text { LDS Sample Buffer } \\
(4 \mathrm{X})\end{array}$ & 2.5 \\
\hline Distilled $\mathrm{H}_{2} \mathrm{O}$ & 6.5 \\
\hline TOTAL VOLUME & 20 \\
\hline
\end{tabular}

* Volumes can be adjusted according to the desired loading volumes.

Table 4.3: NuPAGE ${ }^{\circledR}$ Novex Bis-Tris Mini Gel Sample Preparation Guide 
The red and black cables then were plugged in then the "Run" button was selected. The gel electrophoresis apparatus was run at $200 \mathrm{~V}$ for about 45 minutes until the blue dye front reached the bottom of the gel. There should be rising bubbles coming from the bottom of the gel as soon as the "Run" button was selected and during the gel electrophoresis process. If there was no bubbles coming up, cables connection and gel apparatus setup should be checked. After the gel electrophoresis was complete, the gel apparatus was disconnected and disassembled. The gel was removed and the cassette was cracked open by using a gel knife. The gel was placed into distilled water for the protein transferring process afterward. The gel electrophoresis set up was shown in Figure 4.5 below. 


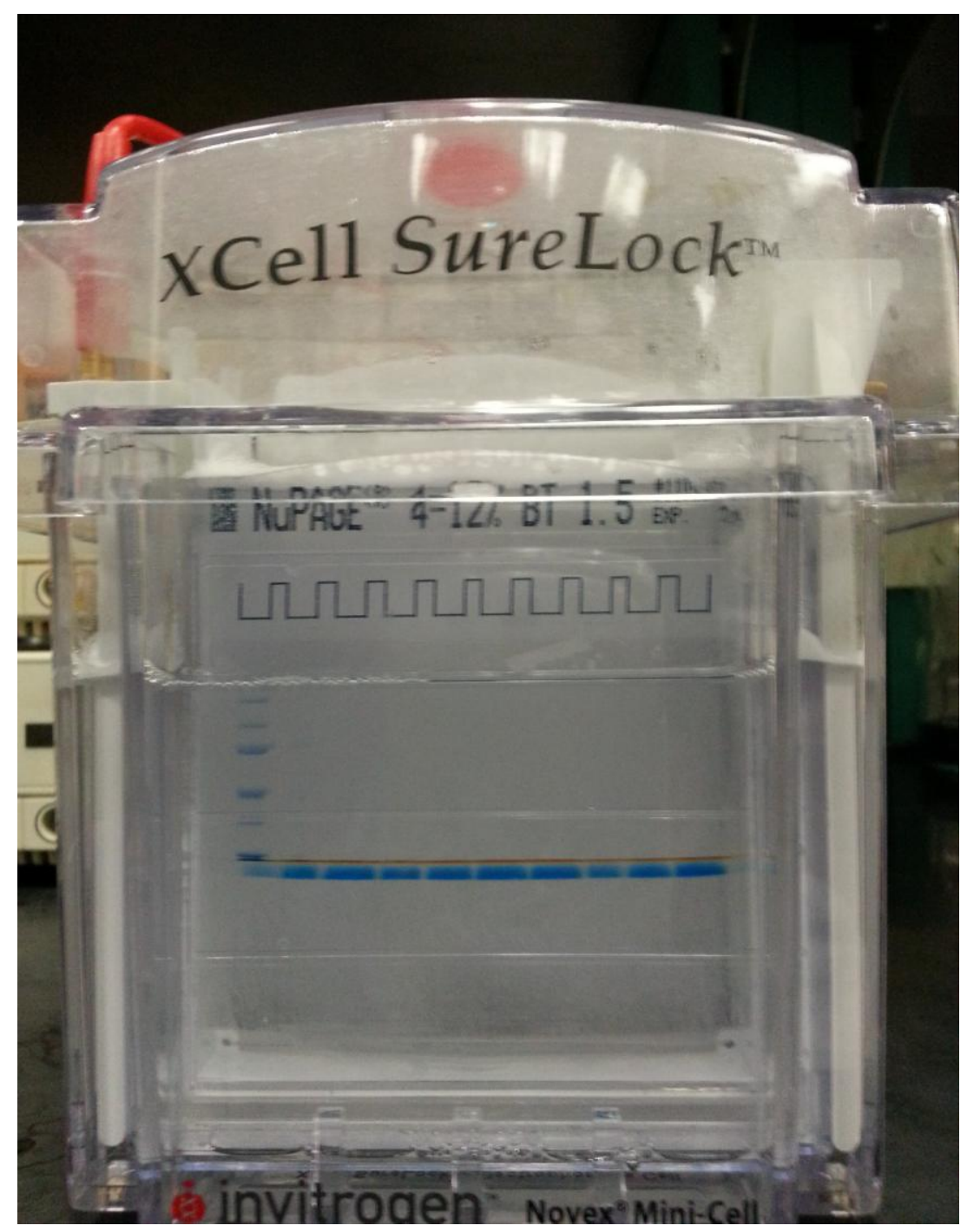

Figure 4.5: Gel Electrophoresis Process

\subsection{Protein Transferring from the Gel to the PVDF Membrane}

While the gel was running, the IBlot 7-Minute Blotting System machine (Invitrogen, catalog \# 1001) was turned on and warmed up for 10 minutes (Invitrogen). The program P3 and running time 3.5 minutes were selected on the machine. Figure 4.6 showed a picture of the IBlot 7-Minute Blotting System machine that was used. 


\section{Figure 1-iBlot ${ }^{\text {TM }}$ Gel Transfer Device}

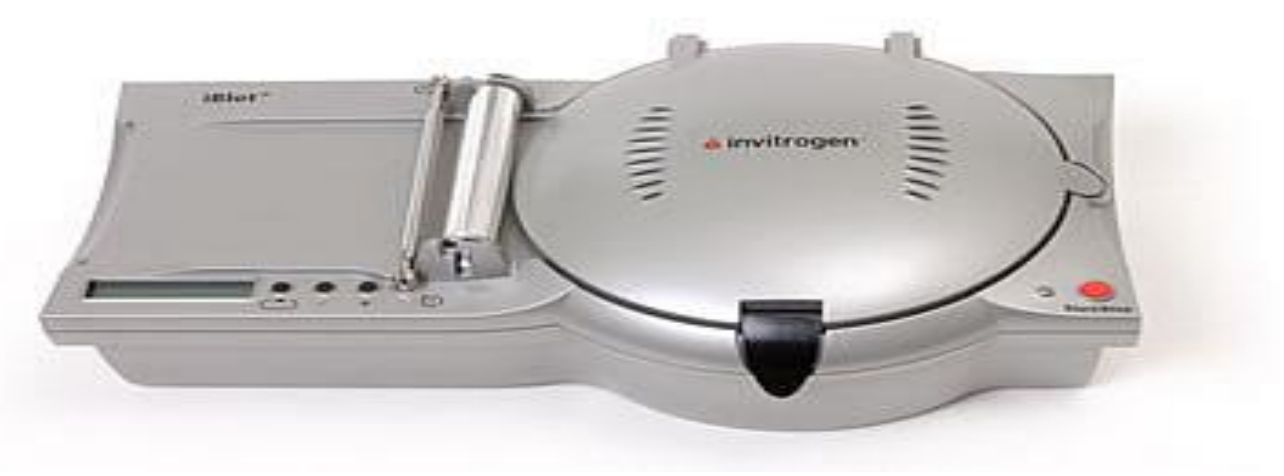

Figure 4.6: Invitrogen iBlot Gel Transfer Device

The iBlot Transfer Stack, PVDF mini (Invitrogen, catalog \# IB4010-02) was used to transfer proteins from the gel to a PVDF membrane. A complete transfer stack consists of one anode and one cathode stack. First, the lid of the iBlot Gel Transfer Device was opened up. Second, the anode stack was unsealed and the stack was kept in the plastic tray. Third, the anode stack (in the plastic tray) was placed on the blotting surface of the Iblot Gel Transfer Device. Then, the gel was placed on the transfer membrane of the anode stack. After that, an iBlot filter paper was soaked in distilled water and placed on top of the gel. All the air bubbles were removed using a blotting roller. Next, the cathode stack was unsealed and placed on top of the blotting pre-soaked filter paper. All the air bubbles were again removed by using a blotting roller. Then, a disposable sponge with the metal contact was placed on the upper right corner of the lid. Finally, the lid was closed and the latch was secured in place. At this time, a red light would be on to indicate that a closed circuit was achieved. The protein transferring process was then started by pressing the "Start/Stop" button on the machine. The red light would then change to green light to indicate that the protein transferring process was happening. At the end of the transferring process, the current would automatically shut off, followed by a beeping sound and a flashing red light. After 
that, the "Start/Stop" button was pressed, the lid was opened and the iBlot gel transfer stack was removed. The disposable sponge and the cathode stack were discarded. The anode stack, containing the PVDF membrane, was kept in the red plastic tray for the western immunoblotting procedure following immediately. Figure 4.7 showed how the proteins were transferred from gel to the membrane underneath it using the IBlot 7-Minute Blotting System machine.

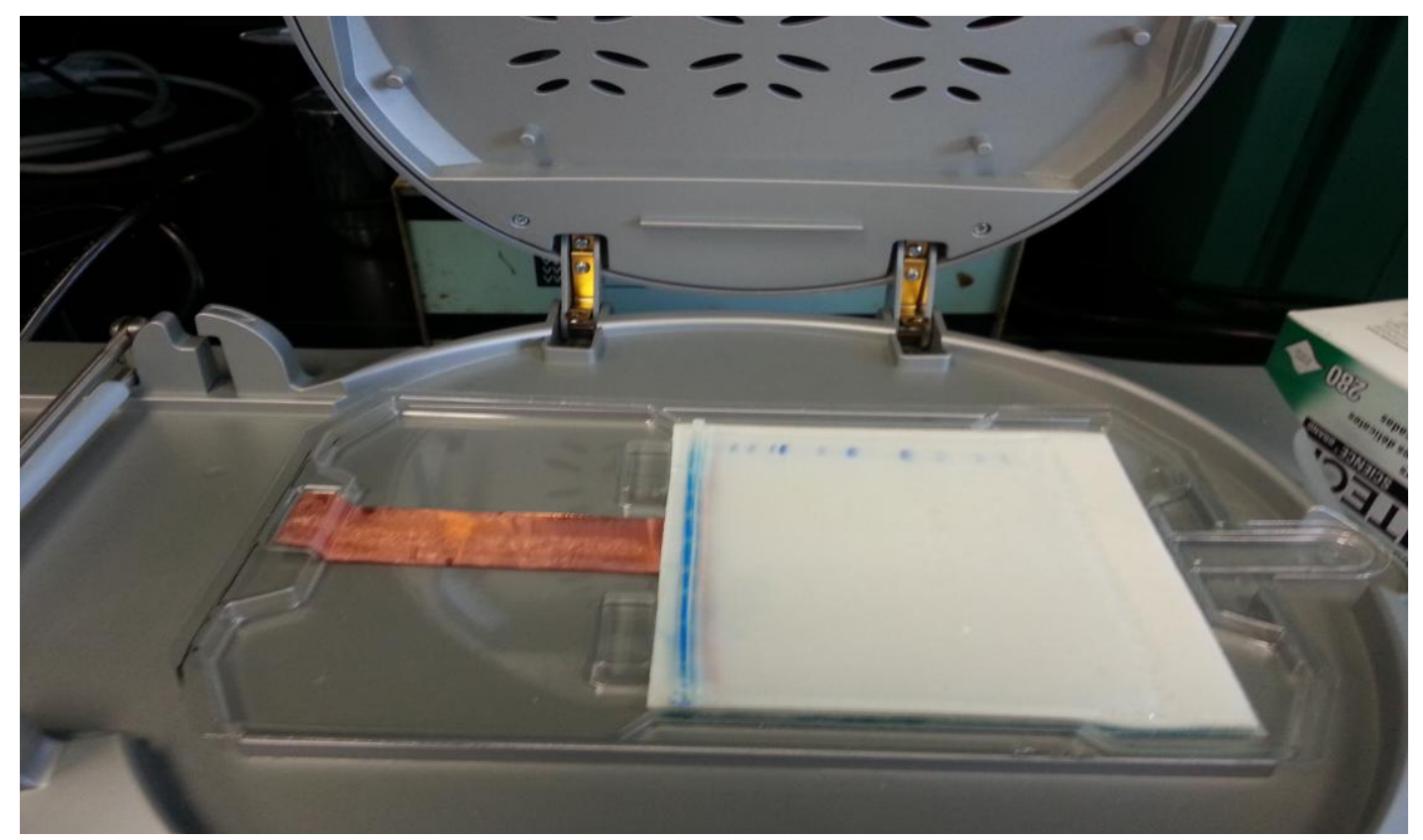

\section{Figure 4.7: The Process of Protein Transferring from a Gel to a PVDF Membrane}

\subsection{Western Immunoblotting Detection Procedure}

The first step of the western immunoblotting detection procedure would be to prepare solutions to detect p21 signals on the PVDF membrane. First, the wash solution was diluted by mixing $6 \mathrm{~mL}$ of wash solution (included in the Invitrogen detection kit) with $90 \mathrm{~mL}$ of distilled water. Second, the antibody diluents mix was prepared by mixing $4.5 \mathrm{~mL}$ of antibody diluents additive with $10.5 \mathrm{~mL}$ of antibody diluents solution. Third, the primary antibody solution was prepared by mixing p21 primary antibody (GeneTex, rabbit polyclonal antibody, catalog \# 
GTX27960) with $5 \mathrm{~mL}$ of antibody diluents mix (GeneTex). Fourth, the secondary antibody was prepared by mixing secondary antibody (included in the Invitrogen detection kit) with $5 \mathrm{~mL}$ of the antibody diluent mix. Finally, $5 \mathrm{~mL}$ of the chromogenic substrate (included in the Invitrogen detection kit) was poured into a $50 \mathrm{~mL}$ conical tube.

After all the solutions were prepared, the antibodies could now be ready to be applied to the PVDF membrane to detect the presence of p21 proteins. The Western Detection kit, containing the top and bottom stacks, would be used to detect $\mathrm{p} 21$ signals. First, the program on the iBlot Gel Transfer Device was selected to be P3 and 3.5 minutes and the lid was opened. Second, the antibody diluent solution was applied evenly on a white matrix in a small plastic case. Third, the iBlot Western Detection Stack Bottom was unsealed and placed on top of the blotting surface of the iBlot Gel Transfer Device. Then, the PVDF membrane, with the protein side facing up and laying on top of the iBlot Gel Transfer Anode Stack, was removed using a clean pair of forceps and placed on top of the Western Detection Stack Bottom. All the bubbles were removed using a blotting roller. After that, the white matrix that was pre-soaked with antibody diluent solution was placed on top of the PVDF membrane. Any bubbles created were removed using a blotting roller. The iBlot Western Detection Stack Top was unsealed and placed on top of the white matrix, with the electrode side facing up. The iBlot Disposable Sponge was placed so that the metal contact was at the right corner of the lid. The lid was closed, the latch was secured and the red light was on to indicate a closed circuit. The "Start/Stop" button was selected and the red light changed to green. While the iBlot device was running, $5 \mathrm{~mL}$ of the primary antibody solution was applied to a new matrix. After 2 minutes, there were a beeping sound and a flashing green light to indicate that the blocking step ended. The lid was then opened but the sponge was still left in place. The top stack was then removed and set aside in the red 
plastic tray for re-use in the next step. The used blocking solution matrix was discarded. The new matrix that was pre-soaked with the primary antibody was placed onto the membrane. All the bubbles were then removed with a blotting roller. After that, the top stack was returned to its position over the matrix and all the bubbles were removed with a blotting roller. The lid was closed and the latch was secured. The "Start/Stop" button was selected to start the process of applying primary antibody to the PVDF membrane. While the iBlot device was running, $5 \mathrm{~mL}$ of the secondary antibody solution was then applied onto a new matrix. After 3 minutes, the device stopped; there were a beeping sound and a flashing green light to indicate the end of the primary antibody step. The lid was opened but the sponge was still left in place. The top stack was removed and set aside in the red tray for re-use in the next step. The used primary antibody matrix was discarded. The new matrix that was pre-soaked with the secondary antibody solution was placed on top of the membrane. All the bubbles were removed using a blotting roller. The top stack was returned to its position over the matrix and all the bubbles were removed again using a blotting roller. The lid was closed and the latch was secured. The "Start/Stop" button was pressed to start the process of applying the secondary antibody to the PVDF membrane. After 3 minutes, the device stopped. There were a beeping sound and a flashing red light to indicate the end of the transfer procedure. The lid was then opened and the sponge was discarded. The used matrix, top and bottom stacks were also discarded. The iBlot device was turned off. The next step in the procedure was to wash the PVDF membrane. 


\subsection{Washing the Membrane}

The membrane was first placed into a min-sized dish (provided in the kit) containing 20 $\mathrm{mL}$ of the $1 \mathrm{X}$ wash solution. The membrane was rinsed briefly and the solution was discarded. The PVDF membrane was washed for 5 minutes with $20 \mathrm{~mL}$ of $1 \mathrm{X}$ wash solution then the solution was discarded. This wash step was repeated two more times. The membrane was then rinsed with $20 \mathrm{~mL}$ of deionized water then the water was decanted. This wash step was repeated one more time.

\subsection{Chromogenic Detection to Detect p21 Signals}

After the wash step, the p21 signals on the membrane were detected using the chromogenic detection method. The membrane with the protein-side facing up was first placed in a plastic tray. Five millimeters of the chromogen reagent was measured in a cylinder. Then, the chromogen solution was poured over to cover the entire PVDF membrane. The plastic tray containing the membrane was put on a shaker. The membrane was incubated with the chromogenic substrate for 30 minutes until the desired purple band intensity was obtained on the membrane. This reaction was stopped by rinsing the membrane briefly with $20 \mathrm{~mL}$ of distilled water for 2 minutes. This 2 minute water rinse step was repeated 2 more times. The membrane was then air-dried and placed on a clean piece of filter paper.

\subsection{Visualization of p21 Signals on the PVDF Membrane}

The PVDF membrane was placed in the center of the ChemiDoc ${ }^{\mathrm{TM}} \mathrm{XRS}+$ System chamber. The White Light option was turned on and the image of the membrane was focused to achieve the best resolution on the computer screen. After that, the image of the membrane was 
saved as a TIF file and the intensity of the interested protein bands was analyzed later using Image J software.

\subsection{Analysis of p21 Protein Bands Using ImageJ Software}

The western blot membrane image was first opened in ImageJ software and converted to the 8-bit mode by selecting Image-Type- 8 bit. Then, the "Rectangle Selections" tool from the ImageJ toolbar was selected to draw a box around the first lane. After that, the command "Analyze-Gels-Select First Lane" was chosen to set the rectangle in place, the first lane was then highlighted and a number "1" appeared in the middle of it. Then, the mouse was used to click and hold in the middle of the rectangle of the first lane and drag over to the next lane. The command "Analyze-Gels-Select Next Lane" was selected to place a rectangle over the $2^{\text {nd }}$ lane. The second lane was then highlighted and a number 2 appeared in the middle of that lane. The same process was repeated until all 5 lanes were highlighted with a rectangle and numbered. After the last lane was highlighted, the command "Analyze-Gels-Plot Lanes" was selected and the profile plot of each lane would appear. Then, the "Straight Line" command was selected and a line was drawn across the base of each peak to enclose the peak. After all of the peaks were closed off at the base using the "Straight Line" selection tool, the "Wand" tool was then selected and used to click inside the peak. Each peak was then be highlighted and the area measurements of the peaks would show up in the "Results" window. The area measurement of each peak corresponded to the intensity of the p21 protein band in each sample. The area measurement data was copied and pasted into Microsoft Excel. The density of the second peak, corresponding to the intensity of p21 protein band in the No UV sample, was chosen as the standard with the relative density of 1 . The relative density of $\mathrm{p} 21$ protein bands in other samples were calculated 
by dividing the area measurement for each peak by the area of the No UV peak (Miller 2010). The relative densities or the intensities of p21 protein bands in all samples were recorded in Table 5.2. 


\section{Chapter 5: Results}

\subsection{Molecular Weight of p21 Bands on Western Blot Membrane}

The molecular weight of $\mathrm{p} 21$ protein bands on the western blot membrane was

determined by comparing the migration distance of $\mathrm{p} 21$ protein bands with the migration distance of standard proteins (known molecular weight).

Eight standard proteins with known molecular weight were loaded into the first lane of the gel and run under the same conditions with p21 proteins from the 5 samples UV, No UV, UV+MP, MP and HeLa. After proteins were transferred from the gel to the PVDF membrane, and the p21 proteins signals were developed, the migration distance of standard proteins and p21 protein bands was measured from the top of the membrane and recorded in Table 5.1. 
Table 5.1: The Log MW of Proteins and Their Respective Migration Distance (mm)

\begin{tabular}{|ccc|}
\hline Standard Proteins & Log MW & Migration Distance (mm) \\
\hline MW (KDa) & 2 & 23 \\
\hline $\mathbf{1 0 0}$ & 1.875061 & 29 \\
\hline $\mathbf{7 5}$ & 1.69897 & 38 \\
\hline $\mathbf{5 0}$ & 1.568202 & 44 \\
\hline $\mathbf{3 7}$ & 1.397794 & 52 \\
\hline $\mathbf{2 5}$ & 1.30103 & 54 \\
\hline $\mathbf{2 0}$ & 1.176091 & 59 \\
\hline $\mathbf{1 5}$ & 1 & 63 \\
\hline $\mathbf{1 0}$ & & Migration Distance (mm) \\
\hline Unknown Protein & Log MW & 33 \\
\hline $\mathbf{6 2 . 3 4}$ & 1.7948 & \\
\hline
\end{tabular}

Then, a standard curve of $\log$ MW of standard proteins vs. migration distance $(\mathrm{mm})$ was created in Microsoft Excel as shown in Figure 5.1. 
Figure 5.1: The Standard Curve of Log MW vs. Migration Distance (mm)

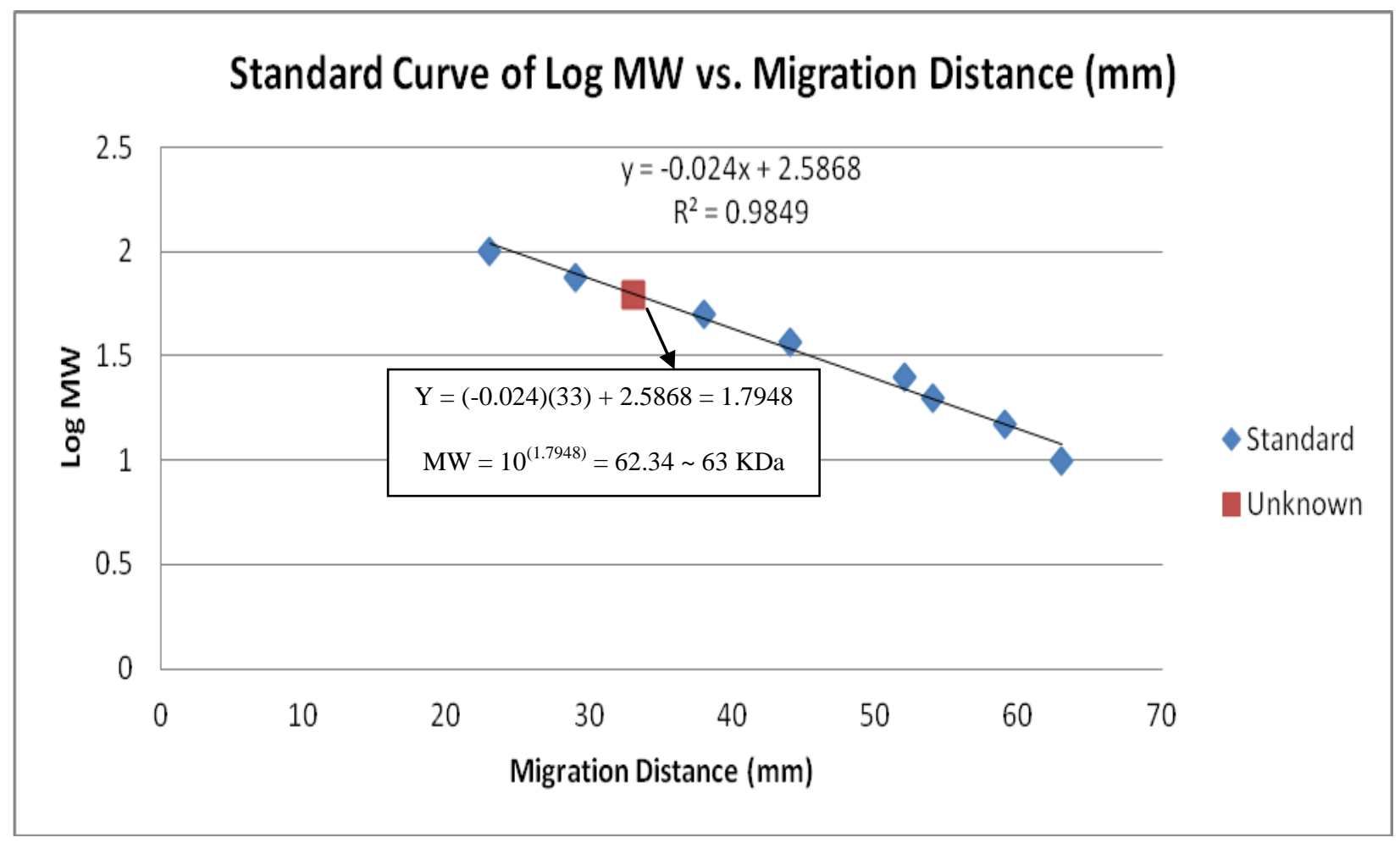

From the standard curve, a linear relationship between Log MW of standard protein markers and migration distances was obtained and described as $\mathrm{Y}=-0.024 \mathrm{x}+2.5868$ with $\mathrm{Y}$ corresponds to Log MW and X corresponds to migration distance. The $\mathrm{R}^{2}$ value is 0.9849 , which is very close to 1 . This suggests a very strong positive linear relationship between Log MW and migration distance.

The molecular weight of the unknown protein bands showed up in Lane 4-Lane 8 was determined by using the formula $Y=-0.024 x+2.5868$. Since the migration distance of the unknown proteins is $33 \mathrm{~mm}$, the value of $\mathrm{X}$ is replaced as 33 and the value of $\mathrm{Y}$ is calculated as 
1.7948. Since Y value corresponds to Log of molecular weight, the molecular weight is calculated as around $63 \mathrm{KDa}$.

$\mathrm{Y}=(-0.024)(33)+2.5868=1.7948$

$\mathrm{Y}=\log \mathrm{MW}$. Therefore, MW $=10^{\mathrm{Y}}=10^{(1.7948)}=62.34 \sim 63 \mathrm{KDa}$.

It is concluded that the unknown protein band corresponds to a multimer of p21 protein. Specifically, three p21 proteins covalently bonded with each other and traveled as a $63 \mathrm{KDa}$ molecule on the gel and on the PVDF membrane. Since the gel was run under denatured and non-reducing conditions, p21 proteins were free to make covalent bonds with each other and formed a multimer of $\mathrm{p} 21$ as seen on the membrane.

\subsection{Analysis of the Intensity of p21 Protein Bands}

The intensity of p21 protein bands from 5 different samples UV, No UV, UV+MP, MP and HeLa was analyzed using ImageJ software and the generated results were shown as in Figure 5.2. The area under each peak corresponds to the intensity of $\mathrm{p} 21$ protein band from different samples. 


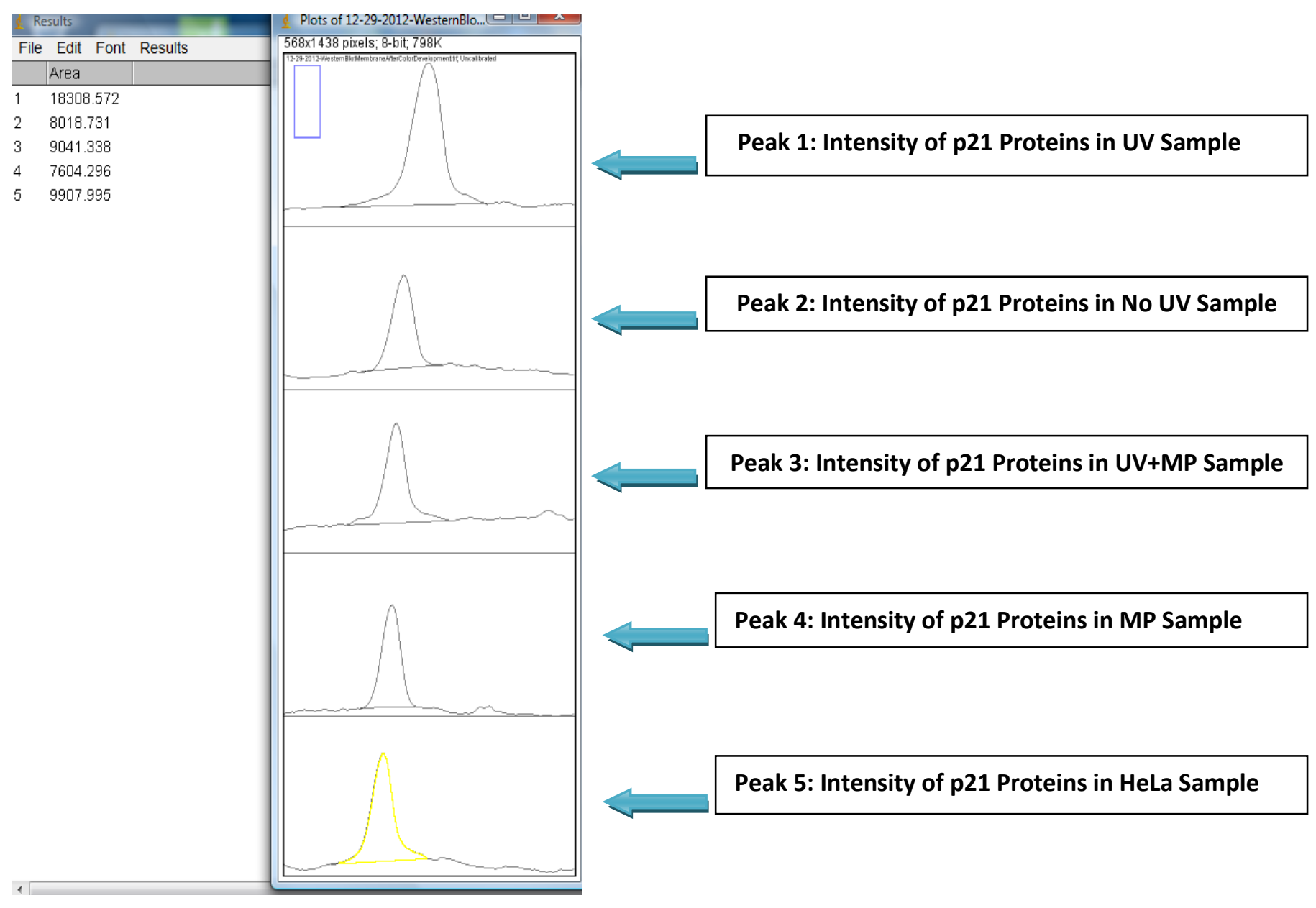

Figure 5.2: ImageJ Analysis of the Intensity of p21 Protein Bands 


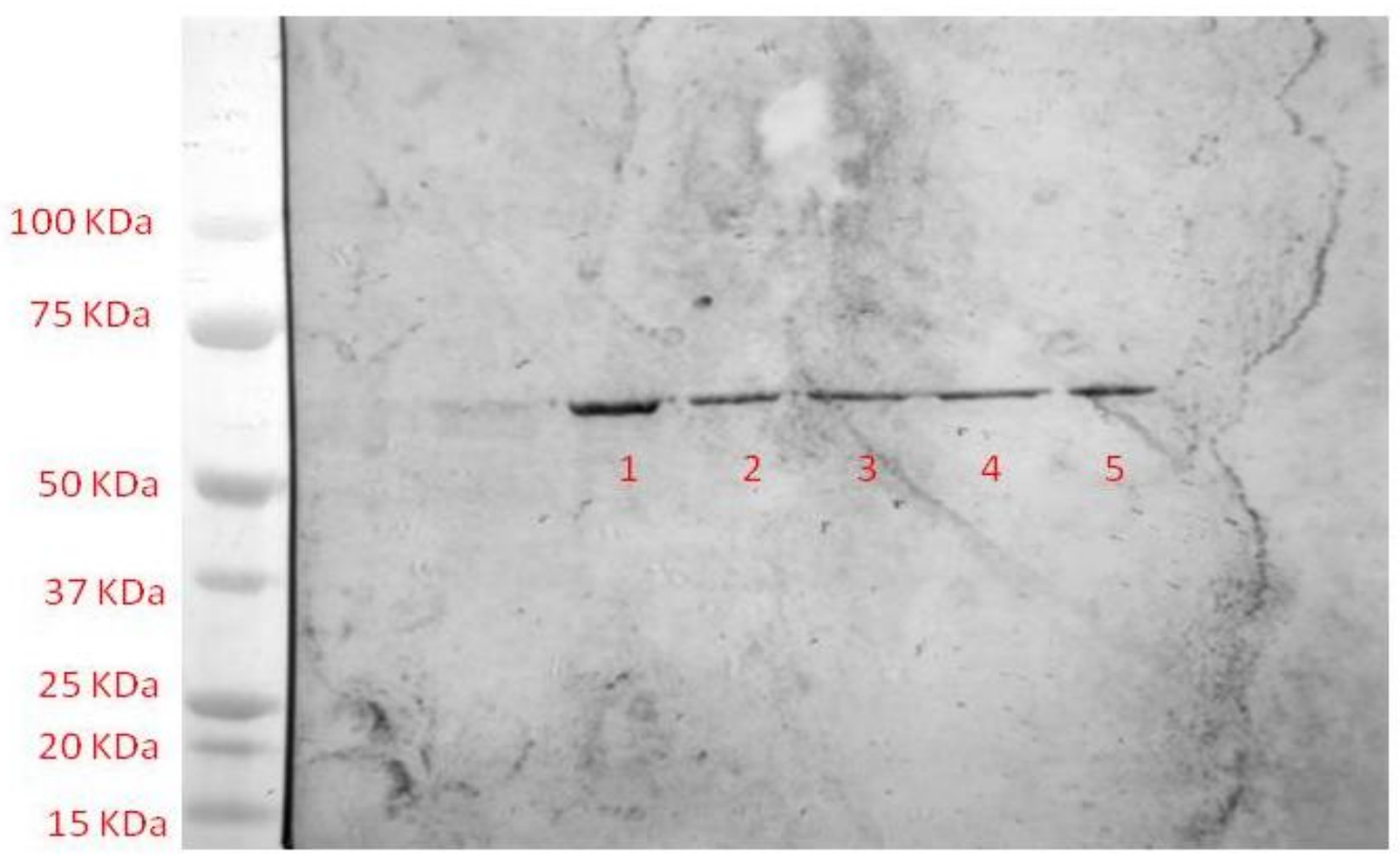

Figure 5.3: Western Blot Membrane Shows p21 Protein Levels in Different Samples

Sample 1 - UV, sample 2 - No UV, sample 3 - UV+MP, sample 4 - MP, sample 5 -

\section{HELA}

\begin{tabular}{|c|c|c|c|c|c|c|c|c|c|c|}
\hline Lane & 1 & 2 & 3 & 4 & 5 & 6 & 7 & 8 & 9 & 10 \\
\hline Sample & MW & Blank & Blank & UV & No UV & $\begin{array}{c}\mathrm{UV}+ \\
\mathbf{M P}\end{array}$ & MP & Hela & Blank & Blank \\
\hline [Protein] $(\mu \mathrm{g} / \mathrm{mL})$ & N/A & $\mathbf{0}$ & $\mathbf{0}$ & 4176 & 9484 & 13663 & 10759 & 2000 & $\mathbf{0}$ & $\mathbf{0}$ \\
\hline $\begin{array}{l}\text { Amount of } \\
\text { Protein }(\mu \mathrm{g})\end{array}$ & N/A & 0 & 0 & 145 & 145 & 145 & 145 & 2 & $\mathbf{0}$ & $\mathbf{0}$ \\
\hline Sample Vol $(\mu \mathrm{L})$ & 10 & $\mathbf{0}$ & $\mathbf{0}$ & 35 & 15 & 11 & 14 & 10 & $\mathbf{0}$ & $\mathbf{0}$ \\
\hline
\end{tabular}


To compare the intensity of p21 protein bands among 5 samples UV, No UV, UV+MP, MP and HeLa as shown in Figure 5.3, the area under the peak of p21 protein band from the No UV sample was normalized to 1 . Then, the area under the peak of $\mathrm{p} 21$ protein band from different samples was divided by the area from the No UV sample, 8018.731. As a result, the relative densities of UV, No UV, UV+MP, MP and HeLa were 2.28, 1, 1.13, 0.948, and 1.236 respectively and were shown in Table 5.2.

\begin{tabular}{|c|c|c|}
\hline Sample & Area & Relative Density \\
\hline No UV & 8018.731 & \\
\hline UV & 18308.572 & \\
\hline & & 2.28 \\
\hline UV + MP & 9041.338 & 1.13 \\
\hline MP & 7604.296 & 0.948 \\
\hline HeLa & 9907.995 & 1.236 \\
\hline
\end{tabular}

Table 5.2: Analysis of p21 Protein Levels in Different Samples Using ImageJ Software. UV - Ultraviolet Light Radiation, MP-Milk Phospholipids, HeLa - Human Epithelial Carcinoma Cell Line 


\section{Chapter 6: Discussion and Conclusion}

\subsection{Discussion}

Under non-reducing conditions, three p21 proteins covalently bonded with each other showed up as 63 KDa molecules on the PVDF membrane. The UV and HeLa samples showed a 2.28 fold and 1.23 fold increase in p21 expression, respectively, compared to the No UV sample control. The MP sample showed a 0.948 fold decrease in p21 expression and the UV+MP sample showed only a 1.13 fold increase in p21 expression compared with the No UV sample control. By comparing with the UV sample, the UV+MP sample has 50.4\% less p21 expression. The MP sample also has only 5\% less p21 expression compared with the No UV sample. This small difference in p21 expression showed that milk phospholipids do not interfere and affect cellular's normal physiological activities negatively. Less p21 expression in the UV+MP sample compare with the UV sample suggested that less DNA damage occurred in the sample that was treated with milk phospholipids. This result strongly suggests that bovine milk phospholipids can protect skin cells from UV induced DNA damage.

The mechanism of how bovine milk phospholipids can protect human skin cells from DNA damage caused by UVB light exposure is still not clear and further research needs to be done to investigate the details of the mechanism. In a research study done by Haruta-Ono et al. in 2012, they found that when radiolabeled sphingomyelin was orally administered to mice for eight weeks, the sphingomyelin was incorporated in to skin sphingolipids and involved in the water-holding capacity of the stratum corneum layer in the epidermis (Haruto-Ono 2012). Based on this research study, it is most likely that the human skin cells probably absorbed milk phospholipids in the cell media and incorporated these phospholipids in the skin cells membranes. This created a better and stronger protective barrier against UV radiation and 
reduced DNA damage in the nucleus. Another possible explanation for a decrease of p21 expression in UV+ MP sample can be that the milk phospholipids interact with the cellular membranes and affect the $\mathrm{p} 53 \rightarrow \mathrm{p} 21$ signaling pathway to arrest the cell cycle at G1 to repair DNA damage. However, more research studies need to be done to elucidate the mechanisms of how milk phospholipids decrease p21 expression and to provide more evidence that a decrease in UV-induced DNA damage is associated with a decrease in p21 expression. Future research studies should investigate the expression of p53, a tumor suppressor protein, $\mathrm{p} 48$ and Gadd45, DNA damage repair proteins. Protein p53 expression is increased after cells are exposed to UV radiation. Proteins $\mathrm{p} 48$ and Gadd45 are induced by the expression of p53. These are important proteins involved in the DNA damage repair pathways in cells as a response to UV-induced DNA damage. Proteins p48 and Gadd45 recognize and bind to damaged DNA and trigger the DNA damage repair cascades. If milk phospholipids actually protect skin cells from less DNA damage induced by UV radiation, it is expected that a decrease in p21, p53, p48 and Gadd45 expressions would occur in UV+MP sample compared with the UV sample. This will provide stronger evidence that milk phospohilipids protect cells from UV-induced DNA damage. Future research studies could also investigate the optimal milk phospholipids concentration that can protect skin cells from UV-induced DNA damage most effectively.

This thesis project shows a working Western blot protocol that can be used to investigate the expression of $\mathrm{p} 21$ and the protective effects of milk phospholipids against UV-induced DNA damage in keratinocytes. This protocol can be optimized to study the expression of p21 in the future by increasing the reducing reagent concentration in all samples to ensure that $\mathrm{p} 21$ proteins are reduced completely and will appear as $21 \mathrm{KDa}$ molecules instead of as a trimmer $63 \mathrm{KDa}$ on the PVDF membrane in this research study. Running buffer used to run gel electrophoresis 
should be new and fresh to make sure that all protein samples are run under reducing conditions. This will prevent $\mathrm{p} 21$ proteins to cross link and form trimmers.

Moreover, the protocol used in this study serves as a framework for future Western blot protocols to build on to investigate the expression of other biomarkers involved in cellular pathways as a response to UV radiation. The optimal UV dosage to induce p21 expression was determined to be $10 \mathrm{~mJ} / \mathrm{cm}^{2}$. It is expected that the same UV dose can induce p53 expression because $\mathrm{p} 21$ is a downstream proteins of $\mathrm{p} 53$. If $\mathrm{p} 53$ expression is induced at $10 \mathrm{~mJ} / \mathrm{cm}^{2}$, it is expected that $\mathrm{p} 48$ and Gadd 45 proteins were also induced at $10 \mathrm{~mJ} / \mathrm{cm}^{2}$ because they are the downstream proteins of $\mathrm{p} 53$. The minimum cells needed for each sample treatment was determined to be 6 wells ( 1 plate) of keratinocytes and the optimal incubation time post UV exposure was found to be 24 hours. The same approach can also be used to determine the optimal transferring time by testing different transferring time intervals on gel strips containing 2 lanes. The primary and secondary antibodies concentrations can be optimized using the antibody titration on dot blot membrane. In order to obtain the best proteins signals with a minimal background noise on a PVDF membrane, the developing time is expected to be around 30 minutes when investigating other biomarkers as well. Chapter 2 provides very details of the approach to optimize different experiment parameters in Western blot assay and can be useful in the development of other Western blot protocols to study different cellular biomarkers.

The results from this thesis project suggest that milk phospholipids have protective effects against UV-induced DNA damage in keratinocytes. More research studies should be done to investigate the expression of other cellular biomarkers to elucidate the mechanism of how milk phospholipids protect human skin cells against UV radiation damage. 


\subsection{Conclusion}

Bovine milk phospholipids (1\%) solution showed that it can decrease $50.4 \%$ of p21 expression in human skin cells after exposing to UV radiation. A lower p21 expression suggested that less UV-induced DNA damage occurred in keratinocytes that were treated with milk phospholipids compared with the keratinocytes that were not treated. It is hypothesized that human skin cells may uptake the milk phospholipids and incorporate them into the cell membrane. This created a stronger and better physical barrier against UV damage. To gain a better understanding about the mechanism of how bovine milk phospholipids protect skin cells against UV radiation damage, future research studies should investigate on the expression of other biomarkers such as p53, tumor suppressor protein, p48 and Gadd45, proteins involved in DNA damage repair mechanisms. With more evidence about its protective effect against UV damage, bovine milk phospholipids can potentially be a chemopreventive agent. It can also possibly be incorporated into different sunscreen and nutritional products. 


\section{References}

(2012). "The Cell Cycle." Retrieved March 20th 2013, from http://users.rcn.com/jkimball.ma.ultranet/BiologyPages/C/CellCycle.html.

A., B. ( 2007). "Screening for skin cancer." US Preventive Services Task Force.

A. Ouhtit, A. G., H>K> Muller, L.L. Hill, L.B. OwenSchaub, H.N. Ananthaswamy (2000). "Loss of Fas-ligand expression in mouse keratinocytes during UV carcinogenesis." Am. J. Pathol. 157: 1975-1981.

A. V. Mudgil, N. S., F. Andriani, et al. (2003). "Ultraviolet B irradiation induces expansion of intraepithelial tumor cells in a tissue model of early cancer progression." J. Invest. Dermatol.(121): 191-197.

A. Ziegler, A. S. J., D>J. Leffell, et al. (1994). "Sunburn and p53 in the onset of skin cancer." Nature 372: 773-776.

A.J. Levine, J. M., C.A. Finlay (1991). "The p53 tumor supressor gene." Nature 351: 453-456.

A.V. Mudgil, N. S., F. Adriani, et al. (2003). "Ultraviolet B irradiation induces expansion of intraepithelial tumor cells in a tissue model of early cancer progression

" J. Invest. Dermatol. 121: 191-197.

Abcam "HELA, Human Epithelial Carcinoma Cell Line, Whole Cell Lysate."

Achay, Z. (2011). Protective Effects of Milk Phospholipids Against UV Photodamage in Human Skin Equivalents. Biomedical and General Engineering. DigitalCommon@CalPoly, Cal Poly, San Luis Obispo. MS in Biomedical Engineering.

Administration, F. U. F. a. D. (2014). "Ultraviolet (UV) Radiation." Retrieved July 14th, 2014, from http://www.fda.gov/Radiation-

EmittingProducts/RadiationEmittingProductsandProcedures/Tanning/ucm116425.htm.

Association, A. S. (2013). "Healthy Skin." Retrieved October 12th, 2013, from http://www.americanskin.org/resource/. 
B.J. Hwang, J. M. F., P.C. Hanawalt, et al. (1999). "Expression of the p48 xeroderma pigmentosum gene is p53-dependent and is involved in global genomic repair." Proc. Natl. Acad. Scie. 96: 424-428.

Beare-Rogers, J., et al. (2001). "Lexicon of Lipid Nutrition. (IUPAC Technical Report)." Pure Appl. Chem. 73: 685-744.

Bickers DR, L. H., Margolis D et al. (2006). "The burden of skin diseases: 2004 a joint project of the American Academy of Dermatology Association and the Society for Investigative Dermatology." Journal of the American Academy of Dermatology 55: 490-500.

Bio-Rad. "Precision Plus Protein Standards." Retrieved January 20th, 2013, from http://www.bio-rad.com/prd/en/US/LSR/PDP/a7b0f9ce-e080-4b51-ab994cded66497c1/Precision-Plus-Protein-Prestained-Standards.

BioRad (2014). Polyacrylamide Gel Electrophoresis (PAGE).

Block, B. "Biology Block - Radiation Mutation." Retrieved 09-22-2014, 2014, from http://biologyblock.com/.

Boiteux, S. (1993). "Properties and biological functions of the NIH and FPG proteins in Escherichia coli: two DNA glycolysases that repair oxidative damage in DNA." J. Photochem. Photobiol. 19: 87-96.

Brash, D. E. (1988). "UV Mutagenic Photoproducts in Escherichia coli and Human Cells: A Molecular Genetics Perspective on Human Skin Cancer." Photochem. Photobiol 49: 59-66.

Brash, D. E. (1988). "UV mutagenic photoproducts in Escherichia coli and human cells: a molecular genetics perspetive on human skin cancer." Photochem. Photobio 49: 59-66.

Brash ED, R. J., Simon JA et. al (1991). "A role for sunlight in skin cancer: UV-induced p53 mutations in squamous cell carcinoma." Proc. Natl Acad Sci(88): 10124-10128.

C, B. (1998). Human Structure and Function: Nursing Applications in Clinical Practise. Mosby Elsevier, London

C, T. and D. JS (2007). Skin Deep. New York, Checkmark Books. 
Cazzalini, O., et al. (2010). "Multiple roles of the cell cycle inhibitor p21CDKN1A in the DNA damage response." Mutation Research/Reviews in Mutation Research 704(1-3): 12-20.

Chatelain, E. and B. Gabard (2001). "Photostabilization of Butyl methoxydibenzoylmethane (Avobenzone) and Ethylhexyl methoxycinnamate by Bis-ethylhexyloxyphenol methoxyphenyl triazine (Tinosorb S), a New UV Broadband FilterII." Photochemistry and Photobiology 74(3): 401-406.

Christelle Lopez , M.-N. M., Rafael Jimenez-Flores (2010). "Lipid rafts in the bovine milk fat globule membrane revealed by the lateral segregation of phospholipids and heterogeneous distribution of glycoproteins " Cal Poly Digital Common.

Christie, W. W. (1995). Composition and structure of milk lipids. New York, Chapman \& Hall.

Contarini, G. and M. Povolo (2013). "Phospholipids in Milk Fat: Composition, Biological and Technological Significance, and Analytical Strategies." International Journal of Molecular Sciences 14: 2808-2831.

Coqueret, O. (2003). "New roles for p21 and p27 cell-cycle inhibitors: a function for each cell compartment?" Trends in cell biology 13(2): 65-70.

Dotto, G. P. (2000). "p21WAF1/Cip1: more than a break to the cell cycle?" Biochimica et Biophysica Acta (BBA) - Reviews on Cancer 1471(1): M43-M56.

Duan, R. D., Nilsson, A. (2009). "Metabolism of sphingolipids in the gut and its relation to imflammation and cancer development." Prog. Lipid Res. 48: 62-72.

E, M., et al. (2009). Prevention of hypothermia. Nursing Older People: 4, 34-38.

ehealthMD (2013). "Skin Cancer." Retrieved March 2nd, 2013, 2013, from http://ehealthmd.com/skin-cancer/what-skin-cancer\#axzz2NlybYCpb.

El-Deiry, W. S., et al. (1993). "WAF1, a potential mediator of p53 tumor suppression." Cell 75(4): 817-825. 
F, P. and P. R (2002). Normal skin its function and care. Nursing Care of the Skin. P. R. Oxford, Butterworth-Heinemann: 20-45.

Foundation, S. C. (2013). "Basal Cell Carcinoma." Retrieved February 3rd, 2013, 2013, from http://www.skincancer.org/skin-cancer-information/basal-cell-carcinoma.

Foundation, S. C. (2013). "Skin Cancer Facts." from http://www.skincancer.org/skin-cancerinformation/skin-cancer-facts.

Foundation, S. C. (2013). "Squamous Cell Carcinoma."

Foundation, S. C. (2014). "Melanoma."

Foundation, S. C. (2014 ). "Mosh Surgery." from http://www.skincancer.org/skin-cancerinformation/mohs-surgery.

Gallier, S., et al. (2010). "Using Confocal Laser Scanning Microscopy To Probe the Milk Fat Globule Membrane and Associated Proteins." Journal of Agricultural and Food Chemistry 58(7): 4250-4257.

Garner E, K. K. (2008). "Protective mechanisms of p53-p21-pRb proteins against DNA damageinduced cell death." Cell Cycle(7): 277-282.

Garner, E. and K. Raj (2008). "Protective mechanisms of p53-p21-pRb proteins against DNA damage-induced cell death." Cell Cycle 7(3): 277-282.

Gartel, A. L. and A. L. Tyner (1999). "Transcriptional Regulation of the p21(WAF1/CIP1)Gene." Experimental Cell Research 246(2): 280-289.

GeneTex. "p21 antibody." Retrieved March 8th, 2013, 2013, from http://www.genetex.com/p21antibody-GTX27960.html.

GJ, T. and D. BH (2009). Principles of Anatomy and Physiology: Organisation, Support and Movement and Control Systems of the Human Body. Hoboken, NJ, John Wiley and Sons. 
H. Nakazawa, D. E., P.L. Randell, K. Nakazawa, N. Martel, B.K. Armstrong, H. Yamasaki (1994). "UV and Skin Cancer: Specific p53 Gene Mutation in Normal Skin as a Biologically Relevant Exposure Measurement " Proc. Natl. Acad. Sci. 91: 360-364.

Haruta-Ono, Y., et al. (2012). "Orally administered sphingomyelin in bovine milk is incorporated into skin sphingolipids and is involved in the water-holding capacity of hairless mice." Journal of Dermatological Science 68(1): 56-62.

Haruto-Ono, S. S., Hiroshi Ueno, Satoshi Higurashi, Noriko Ueda, Ken Kato, Tadao Saito, Kazuhisa Matsunaga, Jiro Takata (2012). "Orally administered sphingomyelin in bovine milk is incorporated into skin sphingolipids and is involved in the water-holdeing capacity of hairless mice." Journal of Dermatological Science(68): 56-62.

Heid, H. W. and T. W. Keenan (2005). "Intracellular origin and secretion of milk fat globules." European Journal of Cell Biology 84(2-3): 245-258.

Invitrogen. "iBlot 7-minute Blotting System." Retrieved February 26th, 2013, 2013, from http://www.invitrogen.com/site/us/en/home/Products-and-Services/Applications/ProteinExpression-and-Analysis/Western-Blotting/Western-Blot-Transfer/iBlot-Dry-BlottingSystem.html.

Invitrogen. "XCell Surelock Mini-Cell Electrophoresis." 2013, from http://www.invitrogen.com/site/us/en/home/Products-and-Services/Applications/ProteinExpression-and-Analysis/Protein-Gel-Electrophoresis/Electrophoresis-Instruments-PowerSupplies-Accessories/Protein-Gel-Electrophoresis-Chamber-Systems/Xcell-Surelock-MiniVertical-Electrophoresis-Chamber.html.

J.D.Siliciano, C. E. C., Y. Taya, et al. (1997). "DNA damage induces phosphorylation of the amino terminus of p53." Genes Dev. 11: 3471-3481.

J.W. Harper, G. R. A., N. Wei, et al. (1993). "The p21 cdk-interacting protein Cip1 is a potent inhibitor of G1 cyclin-dependent kinases." Cell 75: 805-816.

Jana Cmielova, M. R. (2011). "Protein and its function based on a subcellular localization." Journal of Cellular Biochemistry 112(12): 3502-3506.

Ju Z, C. A., Rudolph KL (2006). "A dual role of p21 in stem cell aging." Ann NY Acad Sci(1100): 333-344. 
Keenan, T. (2001). "Historical Perspective: Milk Lipid Globules and Their Surrounding Membrane: A Brief History and Perspectives for Future Research." Journal of Mammary Gland Biology and Neoplasia 6(3): 365-371.

Keenan T.W , M. I. H. (2006). Intracellular origin of milk fat globules and the nature of the milk fat globule membrane. Advanced Dairy Chemistry, Lipids. I. P. F. F. P. L. H. McSweeney. New York, Springer. 2: 137-171.

Keenan T.W, P. S. (1995). "The milk fat globule membrane " Handbook of milk composition. Academic Press. San Diego, CA: 5-50.

Koh HK, G. A., Miller DR, Grossbart TA, Lew RA (1996). "Prevention and early detection strategies for melanoma and skin cancer: Current status." Archives of Dermatology 132: 436-442.

KOMABIOTECH (2014). "Western Blot Illustrated Assay." Retrieved June, 2014, from http://www.novusbio.com/support/support-by-application/western-blot/illustratedassay.html.

Kullenberg, D., Taylor LA, Schineider M, Massing U (2012). "Health Effects of dietary phospholipids." Lipids Health Dis.(11): 1-16.

Lee, J. Y., et al. (2009). "Nuclear translocation of p21WAF1/CIP1 protein prior to its cytosolic degradation by UV enhances DNA repair and survival." Biochemical and Biophysical Research Communications 390(4): 1361-1366.

Lemonnier L, D. D., Vespremi M, Abrams J, Brody E, Schmelz E (2002). "Sphingomyelin in the suppression of colon tumors: prevention versus intervention." Biochemistry and Biophysics(419): 129-138.

Li, H., et al. (2006). "Direct Interaction of p21 with p50, the Small Subunit of Human DNA Polymerase Delta." Cell Cycle 5(4): 428-436.

Lopez, C., et al. (2008). "Multiscale Characterization of the Organization of Triglycerides and Phospholipids in Emmental Cheese: From the Microscopic to the Molecular Level." Journal of Agricultural and Food Chemistry 56(7): 2406-2414. 
Lopez, C. M., M.N.; Jimenez-Flores, R. (2010). "Lipid rafts in the bovine milk fat globule membrane revealed by the lateral segregation of phospholipids and heterogeneous distribution of glycoproteins." Food Chem. 120: 22-33.

M.Kapoor, R. H., W.Yan, et al. (2000). "Cooperative phosphorylation at mutiple sites is required to activate p53 in response to UV radiation." Oncogene 19: 358-364.

Mather, I. and T. Keenan (1998). "Origin and Secretion of Milk Lipids." Journal of Mammary Gland Biology and Neoplasia 3(3): 259-273.

Melnikova, V. O. and H. N. Ananthaswamy (2005). "Cellular and molecular events leading to the development of skin cancer." Mutation Research/Fundamental and Molecular Mechanisms of Mutagenesis 571(1-2): 91-106.

Miller, L. (2010). "Analyze Gels and Western Blots with ImageJ." Retrieved May 4th, 2013, 2013, from http://lukemiller.org/index.php/2010/11/analyzing-gels-and-western-blots-withimage-jl.

Murphy, D. J. (2001). "The biogenesis and functions of lipid bodies in animals, plants and microorganisms." Progress in Lipid Research 40(5): 325-438.

N.H. Chehab, A. M., E.S. Stavridi, et. al (1999). "Phosphorylation of Ser-20 mediates stabilization of human p53 in response to DNA damage." Proc. Natl. Acad. Sci. 96: 1377713782.

NOVUSBIO (2014). "WESTERN BLOT ILLUSTRATED ASSAY." Retrieved June 8th, 2014, from http://www.novusbio.com/support/support-by-application/western-blot/illustratedassay.html.

Parkin DM, M. D., P Sasieni (2011). " Cancers attributable to solar (ultraviolet) radiation exposure in the UK in 2010." Br J Cancer 105: 566-569.

Patton, S. and T. W. Keenan (1975). "The Milk fat globule membrane." Biochimica et Biophysica Acta (BBA) - Reviews on Biomembranes 415(3): 273-309.

Patton, T. a. (2012). Structure and Function of the Body Structure and Function of the Body. Missouri MO, Mosby. 
Pereira Ma, J. J. D. R. V. H. L. S. M. L. K. A. I. L. D. S. (2002). "Dairy consumption, obesity, and the insulin resistance syndrome in young adults: The cardia study." JAMA 287(16): 2081-2089.

Perkins, N. D. (2002). "Not Just a CDK Inhibitor: Regulation of Transcription by p21<sup>WAF1/CIP1/SDI1</sup>." Cell Cycle 1(1): 35-37.

Pierce. "Pierce Microplate BCA Protein Assay Kit - Reducing Agent Compatible." from http://www.piercenet.com/instructions/2161997.pdf.

Prives, C. and V. Gottifredi (2008). "The p21 and PCNA partnership: A new twist for an old plot." Cell Cycle 7(24): 3840-3846.

R.J.W. Berg, H. J. v. K., H.G. Rebel, et al., (1996). "Early p53 alterations in mouse skin carcinogenesis by UVB radiation: Immunohistochemical detection of mutant p53 protein in clusters of preneoplastic epidermal cells." Proc. Natl. Acad. Sci. U.S.A.(93): 274-278.

Rass, K. and J. Reichrath (2008). UV Damage and DNA Repair in Malignant Melanoma and Nonmelanoma Skin Cancer. Sunlight, Vitamin D and Skin Cancer. J. Reichrath, Springer New York. 624: 162-178.

Rigel DS, R. J., Friedman R. (2010). "The evolution of melanoma diagnosis: 25 years beyond the ABCDs." CA Cancer J Clin. 60(5): 301-316.

Robenek, H., et al. (2006). "Butyrophilin controls milk fat globule secretion." Proceedings of the National Academy of Sciences 103(27): 10385-10390.

Rogers, H., Weinstock, MA, Harris, AR (2010). " Incidence estimate of nonmelanoma skin cancer in the United States." Arch Dermatol 146(3): 283-287.

RS., S. (2010). "Prevalence of a history of skin cancer in 2007: results of an incidence-based model." Arch Dermatol 146(3): 279-282.

Russell, A., et al. (2010). "Investigating the protective properties of milk phospholipids against ultraviolet light exposure in a skin equivalent model." 75692Z-75692Z. 
S., B. and P. R. (2005). Promoting Skin Health. Nursing Standard: 19, 36, 57-65.

S.A. Amundson, A. P., K.T. Do, et al. (2002). "A nucleotide excision repair master-switch: p53 regulated coordiate induction of global genomic repair genes." Cancer Biol. Ther. 1(145149).

Satyanarayana A, H. M., Kaldis P (2008). "p21 inhibits Cdk1 in the absence of Cdk2 to maintain the G1/s phase DNA damage checkpoint " Mol Biol Cell 19: 65-77.

Schubert, M., et al. (2011). "Milk-based phospholipids increase morning cortisol availability and improve memory in chronically stressed men." Nutrition research (New York, N.Y.) 31(6): 413-420.

Scicurious (2014). "Aging, Cancer and p53." from http://scicurious.wordpress.com/2010/07/14/aging-cancer-and-p53/.

Science, T. E. o. "Cell Cycle." Retrieved March 20th, 2013, from http://www.daviddarling.info/encyclopedia/C/cell_cycle.html.

Society, A. C. (2013). "Cancer Facts and Figures 2013." Retrieved February 20th, 2013, 2013, from http://www.cancer.org/research/cancerfactsfigures/cancerfactsfigures/cancer-factsfigures-2013.

Solozobova, V., et al. (2009). "Nuclear accumulation and activation of p53 in embryonic stem cells after DNA damage." BMC Cell Biology 10(1): 46.

Spitsberg, V. L. (2005). "Invited Review: Bovine Milk Fat Globule Membrane as a Potential Nutraceutical." Journal of Dairy Science 88(7): 2289-2294.

Sprong, C., et al. (2001). "Bactericidal activities of milk lipids " Antimicrob. Agents Ch. 45: 1298-1301.

Sprong, R. C., et al. (2002). "Bovine milk fat components inhibit food-borne pathogens." Int. Dairy 12: 209-215.

StudyBlue (2014). "Chapter 14: DNA Replication ". Retrieved 09-22-2014, 2014, from http://www.studyblue.com/notes/note/n/chapter-14-dna-replication-/deck/4757656. 
Surgery, A. C. o. M. (2013). "Overview of Mohs Micrographic Surgery." Retrieved February 3rd, 2013, 2013, from http://www.skincancermohssurgery.org/mohs-surgery/mohsprocedure.php.

T. Miyashita, J. C. R. (1995). "Tumor suppressor p53 is a direct transcriptional activator of the human bax gene." Cell 80: 293-299.

Tarras-Wahlberg, N., et al. (1999). "Changes in Ultraviolet Absorption of Sunscreens After Ultraviolet Irradiation." 113(4): 547-553.

V. L. Brown, C. A. H., T. Crook, J.G. Cronin, D.P. Kelsell, C.M. Proby (2004). "p16INK4a and p14ARF tumor suppressor genes are commonly inactivated in cutaneous squamous cell carcinoma." J. Invest. Dermatol. 122: 1284-1292.

V.A. Tron, M. J. t., L. Tang, et al. (1998). "p53-regulated apoptosis is differentiation dependent in ultraviolet B-irradiated mouse keratinocytes " Am. J. Pathol. 153: 579-585.

V.A. Tron, M. J. T., L. Tang, et al., (1998). "p53 regulated apoptosis is differentiation dependent in ultraviolet B-irradiated mouse keratinocytes." Am. J. Pathol. 153: 579-585.

Veereman-Wauters, G., et al. (2012). "Milk fat globule membrane (INPULSE) enriched formula milk decreases febrile episodes and may improve behavioral regulation in young children." Nutrition 28(7-8): 749-752.

Vesper H, S. E., Nikolova-Karakashian MN, Dillehay DL, Lunch DV, Merrill AH (1999). "Sphingolipids in food and the emerging importance of sphingolipids to nutrition." $\mathbf{J}$ Nutr(129): 1239-1250.

Vladislava O. Melnikova, H. N. A. (2004). "Cellular and Molecular Events Leading to the Development of Skin Cancer." Mutation Research 571: 91-106.

W.Zhang, E. R., d. Zelterman, et al. (2001). "Escaping the Stem Cell Compartment: Sustained UVB Exposure Allows 53 mutant keratinocytes to colonize adjacent epidermal proliferating units without incurrring additional mutations." Proc. Natl. Acad. Sci. U.S.A. 98: 191-197. 
Wade Harper, J., et al. (1993). "The p21 Cdk-interacting protein Cip1 is a potent inhibitor of G1 cyclin-dependent kinases." Cell 75(4): 805-816.

Y. Matsumura, H. N. A. (2002). "Molecular mechanisms of photocarcinogenesis." Front Biosci. 7: $765-783$. 


\section{Appendix}

2\% SDS Lysis Buffer $(\mathbf{5 0} \mathbf{~ m L})$, store at $\mathbf{- 2 0}^{\circ} \mathrm{C}$ (Adapted from Zyra 2011) (Achay 2011) $0.394 \mathrm{~g}$ Tris- $\mathrm{HCl}(0.05 \mathrm{M}), \mathrm{pH}=8.0$

$1 \mathrm{~g}(2 \% \mathrm{w} / \mathrm{v}) \mathrm{SDS}$

$0.077 \mathrm{~g}(10 \mathrm{mM})$ DTT (dithiothreitol)

$0.002 \mathrm{~g}(0.01 \mathrm{mM})$ EDTA (ethylenediaminetetraacetic acid) or $20 \mu \mathrm{L}$ from $500 \mathrm{mM}$ stock solution

$0.009 \mathrm{~g}(1 \mathrm{mM})$ PMSF (phenylmethylsulfonyl fluoride)* or $200 \mu \mathrm{L}$ from a $500 \mathrm{mM}$ stock solution

1 tablet Complete mini protease inhibitor cocktail* (Roche, Indianapolis, IN)

Dilute to $50 \mathrm{~mL}$ with $\mathrm{ddH}_{2} \mathrm{O}$

* add components immediately prior to use 